\title{
A STUDY OF THE CAUSES AND THE EXTENT OF VARIATIONS IN THE LARVAE OF ARBACIA PUNCTULATA
}

\author{
GRACE MEDES \\ Bryn Mawr College, Bryn Mawr, Pa. \\ ONE HUNDRED AND FTFTY-TWO FIGURES
}

\section{CONTENTS}

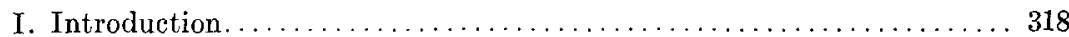

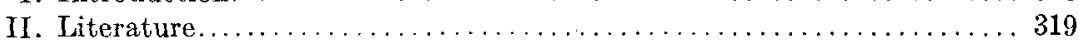

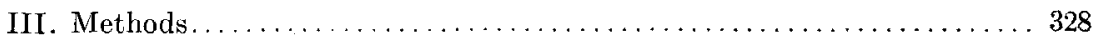

IV. Experimental ..................................... 331

A. The range of variation in the larvae of Arbacia punctulata at different seasons

B. The range of variation in Arbacia larvae subjected to changes in the surrounding medium

1. Changes in the concentration of normal sea-water

a. Concentration by evaporation

b. Dilution by addition of distilled water

2. Changes in the chemical composition of the sea-water

a. Changes in alkalinity

aa. Addition of acids

bb. Addition of alkalies

b. Addition of salts

aa. Isotonic solutions

bb. Hypertonic solutions

c. Addition of carbon dioxide

C. The range of variations in Arbacia larvac kept under standard conditions

1. Individual variations

a. Eggs from a single female fertilized with sperm from a single male

b. Eggs from a single female fertilized with sperm from different males

c. Eggs from different females fertilized with sperm from a single male

2. Variations due to staleness of sexual products

V. Discussion

A. Factors that could not be controlled 
1. Daily fluctuations in the sea-water in respect to

a. Density

b. Tempcrature

2. Variations in the germinal products at different seasons

B. Factors that could be controlled

1. Variations in the acidity and the alkalinity of the medium

2. Variations in the constitution of the medium

a. Accompanied by changes in density

b. Unaccompanied by changes in density

3. Presence of the products of metabolism

C. Combined effects of two or more of the factors in 1 and 2

D. Probable range of variation in Arbacia larvae in their natural environment

VI. Summary ..................................... 430

\section{INTRODUCTION}

The investigation presented in this paper was undertaken for the purpose of determining the normal development of the larvae of Arbacia punctulata under standard laboratory conditions, the extent and causes of variation which they exhibit, and the probable range of variation which they may undergo in their natural environment.

Much of the information available as to normal development during the period usually employed in experimental work must be gathered from control cultures accompanying the various lines of experimentation. These studies, however, most often deal with some limited phase of growth, such as fertilization or cleavage and hence offer but fragmentary accounts of normal development. It has seemed desirable, therefore, to obtain more detailed knowledge than is at present recorded as to development under laboratory conditions.

To accomplish this, two lines of experimentation were pursued: first, the observation of control cultures raised under conditions as nearly constant as possible; and second, the modification of the medium by varying the individual factors which constitute it. Through the first line of experimentation, it was hoped, not only to obtain a standard type that might serve as a basis for future experimental work, but also to determine the extent and causes of such variations as occur under constant conditions of the surrounding medium. Through the second line 
of experimentation, it was hoped to obtain some data on the specific effects of the various factors in the environment and on the laws governing the reactions of the embryos to these fluctuating conditions. And finally, by determining the limits to which variations could be pushed in the developing embryos, it was hoped to ascertain the probable extent of variations in the larvae of Arbacia punctulata in their natural environment.

\section{LITERATURE}

Studies of limited phases of this problem have been made by previous investigators on Arbacia and on other American and European species, mainly Toxopneustes, Strongylocentrotus, Echinus and Spaerechinus.

Tennent ('10) made a study of the eggs and embryos of Toxopneustes variegatus with a view to obtaining more detailed knowledge than had been previously recorded, of the development under laboratory conditions. The variations observed by him "fall into three classes,--fluctuating variations, defects, multiplicities. The fluctuating variations were those of length and correlation," and were determined by the statistical method. The defects consisted in the absence of a skeletal rod or of an arm, or of a malformation of a part of the body; the multiplicities in the presence of more than the normal number of skeletal rods or more than the usual number of arms. The frequent appearance of some characteristic defect or multiplicity among the embryos of a series of cultures in which the eggs or the sperm were all derived from a single individual, offered an opportunity for the study of inheritable variations.

Vernon ('95 and '00) also applied statistical methods as being preeminently suited to a study of variations. In these two papers he attempted to determine not only the range of variations but also their causes: the effect, if any, that changes in environment may produce, and the period in the life of the embryo at which it is most susceptible to modifications in environmental conditions. He established "that Echinoderm larvae vary from the average in respect of size of their various 
parts according to the law of frequency error, in the same manner as Galton found to be the case for man . . . ." $\mathrm{He}$ arrived at the conclusion "that the larvae show a considerable variation in size apart from any influence caused by conditions of environment. These variations Weismann considers to be due to actual differences of the germ plasm."

Moreover, he demonstrated that changes in the surrounding medium increase considerably the extent of variability, and so, he argued, offer a wider opportunity for the operation of natural selection. Having determined as accurately as possible the normal size and variability, he investigated the modifications consequent upon seasonal changes and such alterations of the medium as might occur in nature; as, for instance, changes of concentration of the sea-water, changes of temperature, changes of amount of oxygen and of carbon dioxide, and changes produced by addition of uric acid and of urea. As Vernon's object was primarily to determine the extent of ultimate variation produced by the different experimental conditions to which he subjected the ova and embryos, his measurements were taken at the eighth day of development, the time when the larva of Strongylocentrotus lividus normally attains its maximum size. This offered no opportunity for the observation of any gradual adjustment of the organism to its changed environment or any progressive lessening of its power of resistance, as could be detected by measurements at frequent intervals.

One of the earliest investigations of the effects of changes of the constitution of sea-water upon normal development of the sea-urchin was made by Pouchet and Cambry ('89). Since calcium is the element most concerned in formation of the skeleton, they concluded that decrease in the relative amount of this constituent of sea-water must produce some characteristic effect upon growth; that this effect would not be incurred by the skeleton alone, because it is an integral part of the tissues of the animal; and hence that modifications of those tissues from which it is built must also be involved. They failed in an attempt to raise larvae in an artificial Ca-free medium, but succeeded in doing so in sea-water in which as much as nine-tenths of the 
calcium was replaced by sodium. They found that the latter medium not only produced lack of skeleton, but also diminished rate of growth, decreased size, and lowered vitality, so that a much smaller percentage reached the gastrula stage than when normal sea-water was employed.

Herbst ('93), investigating the effects of changed composition of the sea-water upon development, concluded that the modifications produced in this manner are brought about as the result, not of chemical but of physical changes, especially of osmotic pressure. He states that the effect of like amounts of different salts decreases with increasing molecular weights of the latter; but this law holds only for the equi-basic salts of one and the same metal. To the salts of different metals, tissues are permeable in varying degrees; that is, the epithelium of the Echinoid larva is almost negligibly permeable to lithium, but somewhat readily to potassium and sodium. He believed "dass die Seeigel larven den Salzen des umgebenden Mediums gegenüber ein gewisses Auswahlvermögen geltend machen and nur solche Stoffe aus dem Mecrwasser aufnehmen, welche für ihre Entwicklung notwendig sind."

In a later paper ('95), however, he altered his views in regard to the cause of modifications produced by lithium salts and concluded that the effects could be of a chemical as well as of a physical nature;--"dass die Zellen der Echinidenlarven die Salze des betreffenden Metallen aufnehmen . . . . und zurückhalten."

Still later ('95), he carries further his studies of the effects of changes of the medium, employing various salts of lithium and sodium. The results of these experiments show, he says, "dass man mit sämmtlichen Lithiumsalzen den normalen Entwickelungsgang in derselben Weise würde abändern können, wenn die Säure, an welche das Metall gebunden ist, nicht schädlich auf die Eier resp. Jarven wirken würde. An dem Zustand der Zellen jener Blastulae, welche in einer Mischung von Lithium aceticum gestorben sind, sieht man, dass dieselben durch Essigsäure abgetödtet worden sind. Es scheint hiernacht, als würde das organische Lithium-salze innerhalb der Larvenzellen 
in freie Säure und Metall gespalten und letzteres vielleicht an das lebende Protoplasma gebunden, während die Säure selbst frei bleibe." The action of the salt will then be specifically that of the metal in those instances where the acid itself is not harmful or where some other substance is present which neutralizes the effect of its anions.

In his succeeding series of articles he deals with three main problems: ('97) what inorganic substances are indispensible in the medium for the normal development of the Sea-urchin; ('01) what rôle does each of these substances perform; and finally ('03), are the chemical processes which accompany embryonic development immovably fixed, or does the developing organism possess the power to regulate its chemical composition, even in a varying medium so that the normal end product will be obtained.

In these investigations he confirms the conclusions arrived at previously, that each substance in the medium produces its specific effect and that the various elements normally present in the sea-water may, in only a few instances and to a limited degree, be replaced by closely allied substances. Throughout his discussions he emphasizes repeatedly the fact that the effects vary in intensity on the individuals derived from the eggs and sperms of different parentage and even on those of the same parentage. Moreover, he shows that eggs obtained in different years and seasons in some instances respond differently to the same treatment. Temperature also plays an important rôle in producing modifications.

Fischel ('09), on account of the important rôle played by the chlorides of potassium, magnesium and calcium in regulating the oxidation processes in artificial parthenogenesis of sea-urchin eggs, investigated the action of these salts upon normally fertilized eggs in order to determine their specific effect in parthenogenesis, and to obtain more detailed knowledge of fertilization itself. He replaced part of the sea-water with isoor hyper-tonic solutions of the above mentioned salts and concluded that the injuries produced resulted from chemical modifications of the protoplasm. Longer exposure to these altered conditions or briefer subjection to stronger solutions, involved 
also fundamental alteration in physical characters,-mainly increased osmotic pressure in the blastocoele, resulting in inflation and death. Fischel believed that these substances, which played so important a part in regulating oxidations in artificial parthenogenesis, were intrinsically harmful, but were controlled by the processes set into action by membrane-formation. $\mathrm{He}$ observed, as had the previous investigators, that, while the limits of endurance for the different Echinoids employed were narrow and about the same for all, yet the response to environment was not absolutely identical for all the species nor for all the individuals of the same species.

Hyper- and hypo-tonic solutions were employed by Vernon ('95), who diluted and concentrated the natural sea-water to the limits of endurance, ranging from about $850 \mathrm{cc}$. diluted to a liter on the one hand, to $1150 \mathrm{cc}$. concentrated to a liter on the other. He found that the maximum growth was attained in a solution containing $50 \mathrm{cc}$. of distilled water per liter and resulted in a 15.6 per cent increase in size.

The variations in early development produced by changes of temperature have been the subject of numerous investigations. One of the earliest observations recorded on this subject was that of Herbst ('95). While he did not report any direct effect of temperature on the developing embryos, he believed that the markedly different response to experimental conditions shown by the eggs of two successive years, was due to the difference in temperature of the sea-water of the regions from which the eggs and sperms were obtained.

The effects of temperature and season on development were made the subject of a detailed investigation by Vernon ('95). He concluded that the larvae of Strongylocentrotus lividus "reach their maximum body length when impregnation is performed at about $17^{\circ} .5$ to $21^{\circ} .5$, whilst at temperatures above or below these limits, the larvae become smaller, and that too in greater proportion the more the temperature varies from the favorable limits." Subjection to the altered temperature for one minute during fertilization proved quite as effective as 
longer treatment in producing reduction in size, while briefer periods gave proportionally less marked results.

In his later paper ('00) his earlier observations were confirmed, and additional ones on later stages showed that "this degree of reaction diminished in more or less regular proportion from the time of impregnation onwards." So marked were his results that he believed future research would reveal the justification for assuming this to be "a general law of variation" not only for temperature but also for other experimental conditions.

He found that season affected growth in Strongylocentrotus, a result which he ascribed to differences in maturity of the eggs and sperms. During the period in which his experimental work was done, namely, from the beginning of April until the first of October, two maxima were obtained, one early in May and one in September, with a minimum about the middle of August. Impregnations made at this time resulted in 24.9 per cent decrease in size below those made on the ninth day of May. Observations on Spaerechinus supported, in the main, those upon Strongylocentrotus, although in general the former were less modified by changes in the environment.

Driesch ('93), in his Entwicklungsmechanische Studien, gives a brief table showing the more rapid development of the Spaerechinus embryos at increased temperature $31^{\circ}$, as compared with a control culture at $19^{\circ}$. A difference, already apparent at the two-cell stage, gradually increased during the succeeding period until, at the time when the control had begun to show a 'prismform' structure, the others were typical plutei with long arms.

Peter ('05) showed that the cells of Echinus and Spaerechinus, under an increase of $10^{\circ}$ in temperature, divided two and onehalf times as often,-an acceleration comparable to that of chemical reactions at greater temperature.

Marcus ('06) experimented with Strongylocentrotus lividus and found a decided increase in rate of development in his 'Warmekultur' $\left(22^{\circ}\right)$ over that of the 'Zimmerkultur' $\left(17^{\circ}\right.$ to $\left.19^{\circ}\right)$, and a still greater increase above the 'kaltekultur' $\left(9^{\circ}\right)$. In the first the primary mesenchyme cells were approximately 
seventy-two in number while in the second they were about forty-five and in the last, twenty-five. But the less numerous underwent a compensating increase in diameter, so that cell size was in inverse ratio to cell number.

Godlewski ('08) confirmed the conclusions of Marcus for Echinus, that "die erhöhte Temperature, die grössere Konzentration der Salze im Seewasser, der höhere Alkalinitätsgrad des Umgebenden Mediums begünstigen die Häufigkeit der Zellteilungen während der Furchung," so that the embryos which have developed under these conditions contain a greater number of cells than those which have developed in lower temperature or in more dilute sea-water or in a lower degree of alkalinity. But, since during the following period no considerable increase of absolute mass of the nuclear substance of the embryo occurs, and since through the divisions of this cleavage period the nuclear substance is distributed to a greater number of cells, it results that the nuclei of those blastulae which have developed in lower temperature or in lower salt- or hydroxylconcentration, are smaller than those which have been raised under the reverse condition. Consequently the absolute amount of nuclear substance seems to be independent of external factors.

Loeb ('08) determined the temperature-coefficient of the eggs of Strongylocentrotus purpuratus for the time between fertilization and the first cleavage division, and found that it varied from 3.91 for the interval between $3^{\circ}$ and $13^{\circ}$, to 1.74 for the interval between $12^{\circ}$ and $22^{\circ}$, with an average of 2.86 for each ten degrees of temperature. Peter's average ('05) was 2.15. Loeb's coefficient for the time from the beginning of the first to the beginning of the second division, ranged from 3.33 for the interval between $5^{\circ}$ and $15^{\circ}$, to 1.91 for $10^{\circ}$ to $20^{\circ}$, with an average of 2.56. He argued that since the temperature-coefficient for the 'Lebensdauer' of the fertilized and unfertilized egg was two for each degree of temperature, "die chemischen Vorgänge welche die Lebensdauer dieser Organismen bedingen, nicht identisch sein können mit den Vorgängen, welche der Entwickelung zugrunde liegen." 
Herbst ('06), in his Vererbungsstudien II, as a preliminary to a study of the effects of changes of temperature in hybridized forms, gives a brief summary of the effects of similar changes on the larvae from straight fertilized eggs of Strongylocentrotus, Echinus and Spaerechinus. In Strongylocentrotus, a tendency toward increase in body-length, with arm-length approximately unchanged, gave a slight increase in total size. With Echinus, body-length became less whereas arm-length showed only a slight increase, so that the resulting individuals were relatively smaller. In Spaerechinus, the body-length was also less, but owing to a much greater increase in length of arm-rods the developed plutei were of considerably greater size. In all, he found with increased temperature a tendency toward increased complexity of skeleton, as shown by the number of rods and accessory processes, accompanied in Strongylocentrotus by the beginnings of lattice-formation.

Peter (08) also subjected the eggs of Spaerechinus granularis and Echinus microtuberculatus to such modifications of the medium as were conducive to more rapid growth, such as increased temperature and heightened alkalinity, and found a greater variability, as measured by number of primary mesenchyme cells, correlated with accelerated development. He employed three grades of temperature, a 'Kaltekultur' at about $13^{\circ}$ to $16^{\circ}$, a 'Warmekultur' about $23^{\circ}$ to $26^{\circ}$, and a 'Zimmerkultur' between the two. In the warmer cultures variability was increased and was accompanied generally but not always by an increase in the mean number of skeleton-producing cells. A similar effect was produced by increasing the alkalinity, whereas acidity resulted in changes similar to those occasioned by lower temperatures. In none of these experiments, however, was rate of growth, he argued, decreased below that probably occurring under natural conditions since even in his 'Kaltekultur' the temperature was somewhat above that of the open sea in the region from which his specimens were taken; and in the acid solutions, although rate of development was decreased, it was not less than that of his 'Kaltekultur.' 
Hence he argued that, since variability was decreased with decreased rate of development, the extreme variants occurring in the cultures subjected to this lowered temperature would not lie beyond that of those found in the open sea. But in his more rapidly developing cultures the variability would be increased beyond these limits; consequently the extreme variants in these solutions would lie in either direction beyond the limits of his normal growth-curve,--a fact which he believes of significance in the establishment of species. He discusses the relative variability of individuals of the same parentage as compared with that of the offspring of different parentage, and finds that of the latter wider and more intense.

Loeb ('98) reported the accelerating effect of alkalies and the retarding effect of acids upon the early embryonic and larval development of Arbacia. He ascribed the beneficial action of alkalies to an acceleration and the harmful effect of acids to an inhibition of oxidation processes. This effect was scarcely discernible during the first few hours of development, but by the second and sometimes the third day the larvae subjected to the alkaline solution were noticeably in advance of the controls, while the development of those in the acid sea-water was retarded or completely inhibited.

Herbst ('03), working with a medium of artificial sea-water containing magnesium sulphate and the chlorides of sodium, potassium and calcium, found that a slight degree of alkalinity, which might not pass above or below a certain point, was essential to development. The optimum concentration varied in the different genera, and, upon approaching the limits of endurance, the individual differences in the offspring of the same parents were made more pronounced. In contrast to the results of Loeb with Arbacia, Herbst found that for Spaerechinus and Echinus the sea-water possessed the optimum concentration of hydroxyl and that addition of alkali caused a retarding of development similar to that which occurred when too little was present.

Moore, Roaf and Whitely ('05) emphasized the 'steadying action' of the sea-water upon variations in the concentration 
of the hydroxyl and the hydrogen ions on account of the mixed phosphates and carbonates which it contains, whereby addition of acid or alkali brings about a readjustment of the equilibrium instead of a corresponding wide swing in the concentration of the hydrogen and hydroxyl ions. They found that a disturbance of the equilibrium toward the acid side was much more harmful than toward the alkaline, since addition of alkali or of alkaline salts such as di-sodic phosphate in small amounts produced a beneficial effect upon growth, whereas acids or acid-salts were from the start inhibitory in their action. The concentration of the hydrogen and the hydroxyl ions seemed to be the determining factor in development, while the action of the cation entered as a specific factor only in case the hydrogen and hydroxyl concentrations were low, as with the phosphates of the alkalies.

Loeb ('06) placed newly fertilized eggs of Strongylocentrotus lividus in neutral van't Hoff solution and found that none developed beyond the four- to eight-cell stage. Addition of 0.1 ce. $\mathrm{N} / 100 \mathrm{KOH}$ to $50 \mathrm{cc}$. of the solution allowed a few eggs to reach the blastula stage; addition of 0.2 cc. allowed 60 per cent to reach the gastrula stage and 0.4 and $0.8 \mathrm{cc} . \mathrm{N} / 100 \mathrm{KOH}$ to 50 cc. permitted all to develop into larvae. With greater concentrations of the hydroxyl, the eggs were more or less injured, until in 0.8 cc. $\mathrm{N} / 100 \mathrm{KOH}$ none could segment. He did not, however ('13), believe the rate of development affected, as it was not noticeably raised by the addition of $0.5 \mathrm{cc}$. or $0.7 \mathrm{cc}$. $\mathrm{N} / 10 \mathrm{NaOH}$ to a neutral solution of $\mathrm{M} / 2(\mathrm{NaCl}+\mathrm{KCl}+$ $\mathrm{CaCl}_{2}$ ). The increased rate of oxidations in the presence of excessive amounts (more than 0.8 cc. $\mathrm{N} / 10 \mathrm{NaOH}$ to 50 cc. of the neutral solution) "suffices to suppress the development of the egg" and hence "cannot be utilized for any conclusions upon the normal oxidations in the sea-urchin egg."

\section{METHODS}

The experimental work for this paper was done at Woods Hole, Massachusetts, during the summers of 1914 and 1915. In the first year, the experiments were carried on during the latter part of July, all of August and early September, and in the 
second summer extended from the twelfth of June until the first of Aingust.

Upon being brought into the laboratory, the sea-urchins were placed in clean glass aquaria with running water, and used as soon as possible, generally within twenty-four hours after being received. Usually the experiments were begun at once. Each sea-urchin was washed, first in fresh water, then in sterilized sea-water, cut horizontally through the test, and inverted over a Syracuse watch-glass. If the eggs were ripe, they were extruded at once through the genital pores, and only those individuals which responded immediately were used. Eggs and sperms were examined under the microscope, and the spermatozoa employed only when they were very active, and the eggs only when nearly one hundred per cent were mature.

The solutions to be used in the experiment were previously prepared and placed in separate beakers, while a similar series of solutions were kept in readiness in a set of watch-glasses. Into each of the former a portion of the eggs was dropped, and into the latter sufficient of the sperm to give a slightly milky suspension. About two drops of each sperm-suspension was then added to its corresponding portion of eggs, and the mixture quickly stirred and allowed to settle. By having everything in readiness and by using a fresh pipette for each solution, the entire operation could be concluded within about five minutes; consequently the eggs and sperm were subjected to the action of the changed medium only a few seconds before being brought together. This was highly desirable, in order to eliminate as far as possible any specific effect of the altered medium upon the unfertilized sex-products.

As soon as the eggs had settled, the supernatant liquid was siphoned off, fresh solution added and the process repeated once every fifteen minutes during the first hour. The eggs, which by this time had usually reached the two-cell stage, were poured into finger-bowls and allowed to stand until they swam at the surface of the water, when they were transferred with as little of the liquid as possible to finger-bowls containing fresh solutions. In the cultures in which the blastulae did 
not swim but remained on or near the bottom of the dish the liquid was siphoned off from above as thoroughly as possible, and the blastulae poured into the fresh solutions. Transfers were made at the close of each twenty-four hours of development, so that during the five days of the experiment nine changes were made: four during the first hoưr, one after about six hours, and after twenty-four, forty-eight, seventy-two and ninety-six hours respectively.

All the sea-water employed was obtained from the harbor at a sufficient distance from shore to insure freedom from shorecontamination, conveyed in glass vessels and filtered before using. During the experiments the finger-bowls were kept covered with glass plates to prevent evaporation and kept standing in the aquarium surrounded by running sea-water. From time to time the temperature of this water was compared with that of the open sea at high tide and about three feet below the surface, and at no time did it show a greater difference than one-half of one degree. The greatest possible cleanliness was observed throughout, every dish and instrument being sterilized each time it was used.

Rate of growth was determined by measurement of the skeleton, as this seemed to afford the most nearly constant character and the one most capable of accurate determination. A micrometer eye-piece, Zeiss no. 4 ocular and objective D were employed. The measurements in this paper are in these micrometer units, each one of which is equivalent to $0.036 \mathrm{~mm}$. Four measurements were made upon each pluteus; the first, from the posterior end of the right body-rod to the end of the right anal arm (fig. a, A. R.); the second, from the end of the left body-rod to the end of the left anal arm; the third, from the posterior end of the right body-rod to the end of the right oral arm (text fig. a, O. R.); and the fourth, from the end of the left body-rod to the end of the corresponding oral arm. Each measurement thus included an arm and a body length, excepting in the young forms where the skeletons were still represented by the tri-radiate spicules. In this case the lina $a-a^{\prime}$ (fig. b) would correspond to the first two measurements given 
above, and $a-a^{\prime \prime}$ to the last two. In whatever position the pluteus lies some foreshortening must necessarily occur. Vernon ('95) selected measurements taken from the side as most nearly accurate; but on account of a divergence laterally of the arms at the oral end of the pluteus, some error must necessarily occur under this mode of treatment. Moreover, by this method, measurements could be taken only on one side of the animal. Since one of the purposes of the present investigation was to determine any irregularities in the skeleton of each individual, measurements from both sides of the body were desirable. By selecting only those specimens which lay in one definite position, - - that is, flat against the slide with anal surface directed upwards, the slight error due to foreshortening was reduced to a minimum.

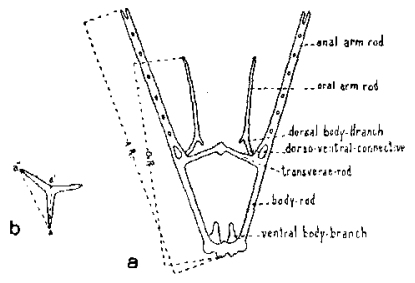

Figs. $a$ and $b$

\section{EXPERIMENTAL}

The summer egg-production of Arbacia at Woods Hole during 1915 was divided into two periods. The periods of sexual maturity were of longer duration for the males than for the females, as the former developed somewhat in advance of the latter and remained active later. In 1914, an early period began in the latter part of May while the following summer the first mature females were not obtained until about the sixth of June. In 1915, about a week after the first ripe specimens were obtained, practically all were mature. During the next two weeks nearly every female opened possessed ovaries filled with ripe eggs and the males extruded exceedingly active sperm. A gradual decline in the percentage of mature individuals then occurred until the middle of July when scarcely one could be obtained. 
A week of almost complete rest followed, succeeded by a period of sexual maturity, which also showed an early maximum and a gradual decline in the proportion of ripe individuals. By the middle of September all the females possessed pale and exhausted ovaries, while the males were to a large extent active. The spermatozoa, however, were less vigorous than those obtained early and became inactive in a much shorter time after extrusion.

Plot 1 gives the general growth curves of the control cultures taken during the entire period of experimentation. Hours after fertilization are plotted as absissa, size as ordinate. A represents the average of four control cultures run during August and the two weeks of September 1914; B, 24 during the early part of the following summer; and $\mathrm{C}$, nine during the latter half of July, 1915. A and C were taken during corresponding periods of egg-production and were arranged thus for the purpose of comparing the general growth curves of the two years. D represents the measurements of all the control cultures for the entire period. $\mathrm{E}$ and $\mathrm{F}$ are lines drawn through the extreme variants in the control averages.

Averages of the control cultures of the various periods

\begin{tabular}{|c|c|c|c|c|c|}
\hline & 24 HOURS & 48 HOURS . & 72 HOURS & 96 ноบнs & 120 HOURS \\
\hline A. & 4.64 & 45.34 & 59.62 & 68.66 & 74.21 \\
\hline B. & 19.31 & 60.77 & 76.23 & 80.90 & 81.54 \\
\hline C. . & 8.79 & 58.81 & 74.68 & 78.19 & 80.60 \\
\hline D. . & 15.31 & 58.25 & 73.62 & 78.68 & 80.34 \\
\hline
\end{tabular}

Before taking up a more detailed consideration of the separate cultures, some general observations may be drawn from these figures. $\mathrm{D}$, the average of 3600 individuals raised during widely varying seasons of two successive summers, may be taken as our standard growth-curve. When the embryo was 24 hours old, the skeleton measured 15.31 and extended nearly through the body. Figure 1 represents a normal skeleton of approximately this size. When the normal individual was 48 hours old, the four arms were well developed and the skeleton 
had elongated to 58.25, an increase of 42.94. This represents the period of most rapid growth.

During the next 24 hours a retarding in rate of skeletal development took place, and at the end of 72 hours the embryo measured 73.62 , an increase. of 15.37 or about one-third of that obtained the previous day. During the next 24 hours rate of growth diminished still more, and, at the close of this period, the larva had reached 78.68, an increase of only 5.06, or 6.8 per cent.

At the age of 120 hours the larva had attained its maximum average length, 80.34 , which is only 2.1 per cent in excess of

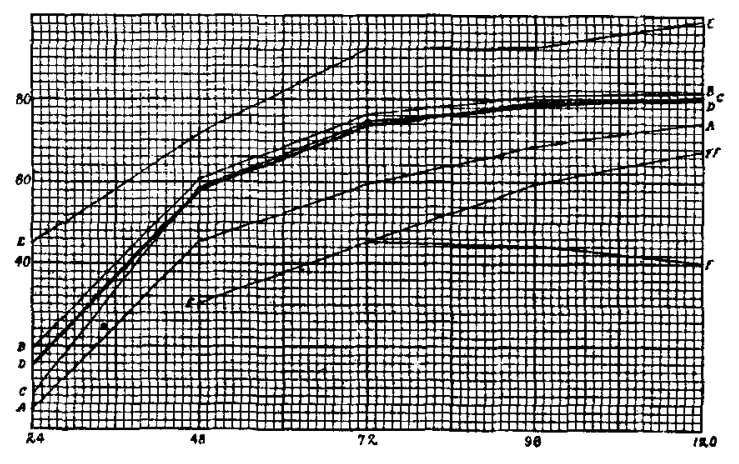

Plot 1

that 24 hours previous. At this time, however, a wide variation prevailed among the larvae of different cultures. Some were just attaining their greatest length while others had already passed this point and had begun to undergo reduction. As resorption of the skeleton took place very rapidly, individuals of this age were found with anal arms almost completely lacking and oral arms scarcely more prominent (fig. 24).

It was evident, not only from observation of the activity of the sperms and of the percentage of mature females, but also from a comparison of the growth-curves of these periods, that the individuals raised from eggs of the early period were much more vigorous. Their development during the first 24 hours was more rapid, and they attained a much greater size. Those obtained during the second period of 1914 were much less 
vigorous than those of the early period of 1915. They were smaller, developed more slowly, and, in the experimental solutions, showed a greater divergence from the normal type. The same may be said, though to a less degree, of those raised during the corresponding period of the following summer. The first few hours of slow development were followed by an interval of more rapid growth, and at the age of 48 hours they were of about normal size. Ultimately, however, in all the cultures there occurred a nearly complete readjustment, and at the age of 120 hours, the averages of the several periods, in contrast to their variabilities, showed the least deviation from type.

The first series of experiments was undertaken for the purpose of determining the effects of dilution and concentration of normal sea-water on the developing embryo.

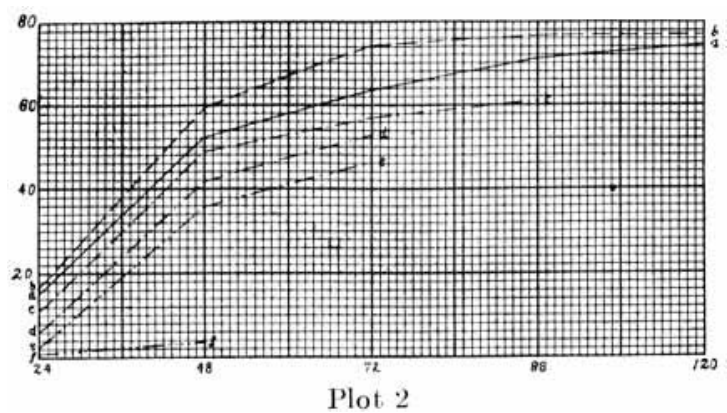

In Experiment 1, the following solutions were employed:

Experiment 1. Plot 2. August 10,1914

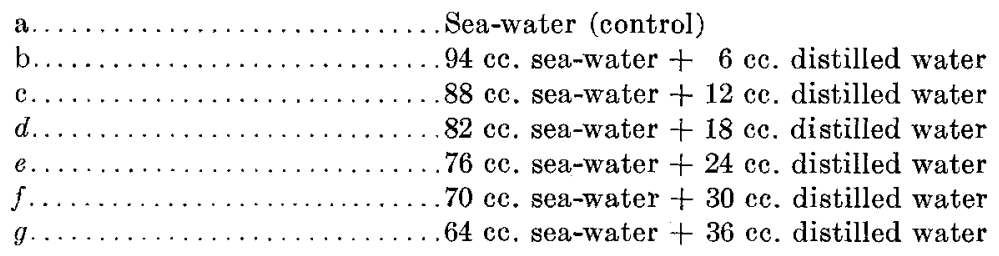

Tables 1 to 6 give the standard deviation, mean length, and coefficient of variation for one hundred individuals, four measurements each, and Plot 2, the growth-curves for the anal arms. Figures 1 to 22 illustrate one typical individual from each of the solutions on the various days of the experiment. 
TABLE 1

Constants, Experiment 1. Solution a (control)

\begin{tabular}{|c|c|c|c|c|}
\hline & & MEAN & $\begin{array}{l}\text { STANDARD } \\
\text { DEVIATION }\end{array}$ & $\begin{array}{l}\text { COEFFICIENT OF } \\
\text { VARIATION }\end{array}$ \\
\hline \multirow{4}{*}{24 hours } & (Right anal. & $15.50 \pm 0.32$ & $4.76 \pm 0.22$ & $30.77 \pm 1.60$ \\
\hline & Left anal. . & $15.50 \pm 0.32$ & $4.78 \pm 0.22$ & $30.89 \pm 1.60$ \\
\hline & Right oral. & $15.50 \pm 0.32$ & $4.76 \pm 0.22$ & $30.77 \pm 1.60$ \\
\hline & Left oral.. & $15.50 \pm 0.32$ & $4.78 \pm 0.22$ & $30.89 \pm 1.60$ \\
\hline \multirow{4}{*}{48 hours } & Right onal. & $52.28 \pm 0.33$ & $4.93 \pm 0.23$ & $9.44 \pm 0.45$ \\
\hline & Left anal. & $52.00 \pm 0.34$ & $5.08 \pm 0.24$ & $9.78 \pm 0.47$ \\
\hline & Right oral. & $40.49 \pm 0.28$ & $4.17 \pm 0.19$ & $10.32 \pm 0.49$ \\
\hline & Left oral. . & $40.58 \pm 0.27$ & $4.12 \pm 0.19$ & $10.17 \neq 0.49$ \\
\hline \multirow{4}{*}{72 hours } & Right anal. & $63.78=0.28$ & $4.21 \pm 0.20$ & $6.60 \neq 0.31$ \\
\hline & Left anal... & $63.66 \neq 0.28$ & $4.17 \pm 0.19$ & $6.56=0.31$ \\
\hline & Right oral.. & $45.54 \pm 0.28$ & $4.27 \pm 0.20$ & $9.39=0.45$ \\
\hline & Left oral.......... & $45.58 \pm 0.28$ & $4.21 \pm 0.20$ & $9.24=0.44$ \\
\hline \multirow{4}{*}{96 hours } & (Right anal. & $71.25 \pm 0.28$ & $4.27 \pm 0.20$ & $5.99 \pm 0.28$ \\
\hline & Left anal... & $71.07 \pm 0.29$ & $4.38 \pm 0.20$ & $6.16 \pm 0.29$ \\
\hline & Right oral & $56.36 \pm 0.23$ & $3.43 \pm 0.16$ & $6.09 \pm 0.29$ \\
\hline & Left oral. .......... & $56.47 \pm 0.22$ & $3.34 \pm 0.15$ & $5.91 \pm 0.28$ \\
\hline \multirow{4}{*}{120 hours } & Right anal. & $74.72 \pm 0.30$ & $4.46 \pm 0.21$ & $5.97 \pm 0.28$ \\
\hline & Left anal... & $74.78 \pm 0.29$ & $4.42 \pm 0.21$ & $5.92 \pm 0.28$ \\
\hline & Right oral.......... & $66.03 \pm 0.18$ & $2.71 \pm 0.12$ & $4.10 \pm 0.19$ \\
\hline & Left oral.. ........ & $66.04 \pm 0.18$ & $2.76 \pm 0.13$ & $4.18 \pm 0.19$ \\
\hline
\end{tabular}

A comparison of the growth-curve of the control individuals of this experiment with that of A, Plot 1, shows a much more rapid development in this culture during the early stages than was that of the general average for that period. Compared with the total average of the controls (D), they were of about the same length at the close of the first 24 hours; they then developed more slowly, and, through a proportionately greater growth the fourth day, attained a size 71.25 , only slightly less than that of the general average, 78.68 .

It may be noted that the specimens in culture $b$ were larger throughout the entire period than were those of culture $a$; those of $c, d$ and $e$ were smaller. In $f$, the skeletons were present at 24 hours only as minute centers which at the close of the next day had not differentiated beyond the tri-radiate 
TABLE 2

Constants, Experiment 1. Solution b

\begin{tabular}{|c|c|c|c|c|}
\hline & & MEAN & $\begin{array}{l}\text { STANDARD } \\
\text { DEVIATION }\end{array}$ & $\begin{array}{l}\text { COFFFICIENT OF } \\
\text { VARIATION }\end{array}$ \\
\hline \multirow{4}{*}{24 hours } & Right anal. & $16.51 \pm 0.35$ & $5.19 \pm 0.24$ & $31.47 \pm 1.64$ \\
\hline & Left anal. & $16.59 \pm 0.34$ & $5.17 \pm 0.24$ & $31.21 \pm 1.62$ \\
\hline & Right oral. & $16.51 \pm 0.35$ & $5.19 \pm 0.24$ & $31.47 \neq 1.64$ \\
\hline & Left oral. . & $16.59 \pm 0.34$ & $5.17 \pm 0.24$ & $31.21 \pm 1.62$ \\
\hline \multirow{4}{*}{48 hours } & Right anal. & $59.76 \pm 0.33$ & $5.00 \pm 0.23$ & $8.37 \pm 0.40$ \\
\hline & Left anal... & $59.81 \pm 0.34$ & $5.06 \pm 0.24$ & $8.46 \pm 0.40$ \\
\hline & Right oral. & $44.56 \pm 0.26$ & $3.86 \pm 0.18$ & $8.67 \pm 0.41$ \\
\hline & Left oral... & $44.60 \pm 0.26$ & $3.90 \pm 0.18$ & $8.74 \pm 0.42$ \\
\hline \multirow{4}{*}{72 hours } & Right anal. & $74.21 \pm 0.29$ & $4.40 \pm 0.20$ & $5.93 \pm 0.28$ \\
\hline & Left anal. & $74.04 \pm 0.29$ & $4.39 \pm 0.20$ & $5.93 \pm 0.28$ \\
\hline & Right oral. & $52.60 \pm 0.26$ & $3.89 \pm 0.18$ & $7.41 \pm 0.35$ \\
\hline & Left oral.. & $52.65 \pm 0.26$ & $3.97 \pm 0.18$ & $7.54 \pm 0.36$ \\
\hline \multirow{4}{*}{96 hours } & Right anal. & $76.85=0.28$ & $4.29 \pm 0.20$ & $5.58 \pm 0.26$ \\
\hline & Left anal. & $76.85 \pm 0.29$ & $4.37 \pm 0.20$ & $5.59 \pm 0.27$ \\
\hline & Right oral. & $61.81 \pm 0.23$ & $3.44 \pm 0.16$ & $5.57 \pm 0.26$ \\
\hline & Left oral... & $61.73 \pm 0.22$ & $3.39 \pm 0.16$ & $5.50 \pm 0.26$ \\
\hline \multirow{4}{*}{120 hours } & (Right anal. & $77.00 \pm 0.27$ & $4.13 \neq 0.19$ & $5.36 \neq 0.25$ \\
\hline & Left anal. . & $76.89 \pm 0.27$ & $4.09 \pm 0.19$ & $5.32 \pm 0.25$ \\
\hline & Right oral. & $67.69 \pm 0.20$ & $3.08=0.14$ & $4.55 \pm 0.21$ \\
\hline & Left oral... & $67.65 \pm 0.20$ & $3.08 \pm 0.14$ & $4.56 \pm 0.21$ \\
\hline
\end{tabular}

stage. In solution $g$, cleavage occurred, though slowly and irregularly, and resulted in somewhat abnormal looking blastulae; but at an age of 24 hours almost all of them had died, while none of those remaining showed evidences of forming skeletons.

The most characteristic modification produced in the skeleton was reduction of the typical structures. This may be seen especially well in figures 18,19 and 20 , representing $a, b$ and $c$ at the age of 96 hours. In $b$, the spines were less prominent, the dorsal body-branches were smaller and the ventral bodybranches less complex. In figure 20 , all these modifications are more pronounced. In the more dilute solutions a retarded fusion of the transverse rods and of the posterior ends of the body-rods generally occurred, as may be observed in $c$ at the age of 96 hours (fig. 20). 
TABLE 3

Constants, Experiment 1. Solution c

\begin{tabular}{|c|c|c|c|c|}
\hline & & MEAN & $\begin{array}{l}\text { STANDARD } \\
\text { DEVIATION }\end{array}$ & $\begin{array}{l}\text { COEFFICIENT OF } \\
\text { VARIATION }\end{array}$ \\
\hline \multirow{4}{*}{24 hours } & Right anal. & $11.05 \pm 0.21$ & $3.25 \pm 0.15$ & $29.47 \pm 1.52$ \\
\hline & Left anal. . & $11.06 \pm 0.22$ & $3.27 \pm 0.15$ & $29.62 \pm 1.53$ \\
\hline & Right oral. & $11.05 \pm 0.21$ & $3.25 \pm 0.15$ & $29.47 \pm 1.52$ \\
\hline & Left oral... & $11.06 \pm 0.22$ & $3.27 \pm 0.15$ & $29.62 \pm 1.53$ \\
\hline \multirow{4}{*}{48 hours } & Right anal. & $48.86 \pm 0.33$ & $4.91 \pm 0.23$ & $10.05 \pm 0.48$ \\
\hline & Left anal. . & $48.77 \pm 0.32$ & $4.87 \pm 0.23$ & $9.99 \pm 0.48$ \\
\hline & Right oral. & $38.08 \pm 0.24$ & $3.65 \pm 0.17$ & $9.60 \pm 0.46$ \\
\hline & Left oral... & $38.08 \pm 0.24$ & $3.67 \pm 0.17$ & $9.64 \pm 0.46$ \\
\hline \multirow{4}{*}{72 hours } & Right anal. & $57.18 \pm 0.26$ & $3.98 \pm 0.19$ & $6.97 \pm 0.33$ \\
\hline & Left anal... & $57.18 \pm 0.27$ & $4.07 \pm 0.19$ & $7.13^{\circ} \pm 0.34$ \\
\hline & Right oral... & $43.74 \pm 0.24$ & $3.61 \pm 0.17$ & $8.25 \pm 0.39$ \\
\hline & Left oral.... & $43.62 \pm 0.24$ & $3.64 \pm 0.17$ & $8.36 \pm 0.40$ \\
\hline \multirow{4}{*}{96 hours } & Right anal. & $60.93 \pm 0.25$ & $3.76 \pm 0.17$ & $6.17 \pm 0.29$ \\
\hline & Left anal... & $60.86 \pm 0.25$ & $3.83 \pm 0.18$ & $6.30 \pm 0.30$ \\
\hline & Right oral. & $49.09 \pm 0.24$ & $3.57 \pm 0.17$ & $7.28 \pm 0.34$ \\
\hline & Left oral... & $49.86 \pm 0.23$ & $3.50 \pm 0.16$ & $7.02 \pm 0.33$ \\
\hline
\end{tabular}
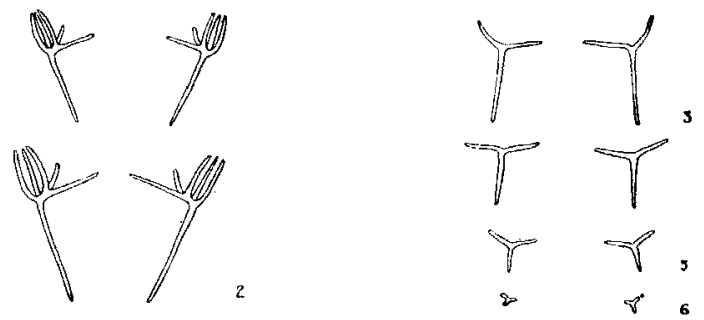

Figs. 1 to 22 Experiment 1. Sea-water diluted with distilled water.

Fig. 1 1a, 24 hrs. Control.

Fig. $21 b, 24$ hrs. Size increased above the control.

Fig. $31 c$, figure $41 d$, figure $5 \mathrm{le}$, figure $61 f, 24 \mathrm{hrs}$. Gradual inhibition in size, otherwise normal.

The next experiment in this series was made the following summer to determine more closely the limits within which increase of size could be obtained by dilution of the sea-water, and also the effects which increased concentration would produce upon the developing embryo. Moreover, previous ex- 
periments performed this second season had shown that the larvae were more viable and it was hoped to maintain those in the dilute solutions alive longer in order to determine the results at the period of their maximum size.
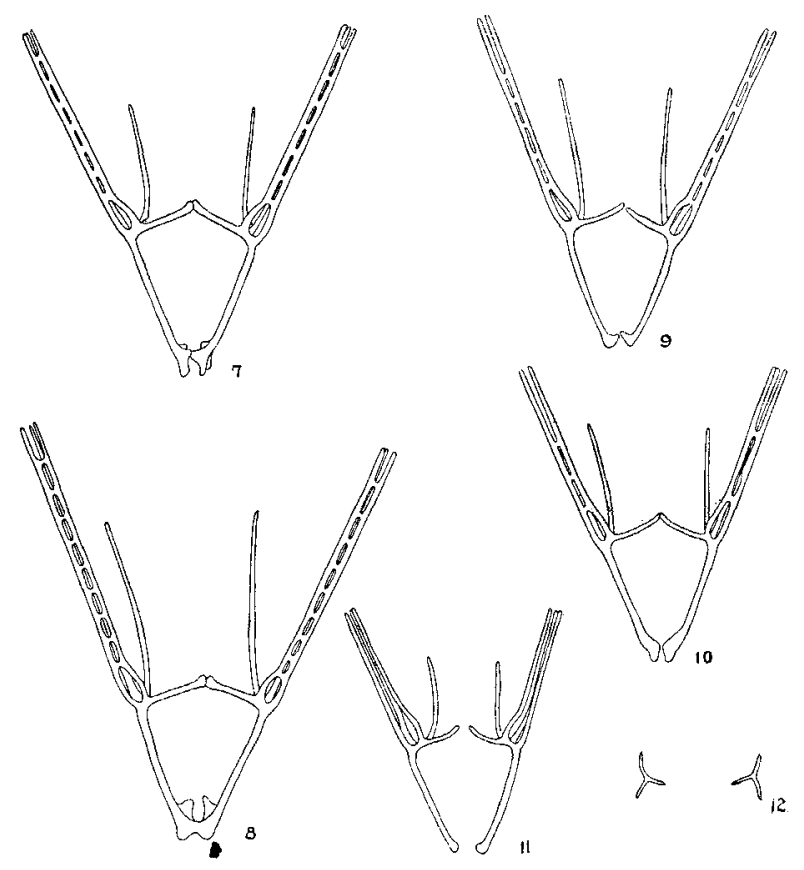

Fig. $71 a, 48 \mathrm{hrs}$. Control.

Fig. $81 b, 49$ hrs. Larger than control.

Fig. $91 c, 48 \mathrm{hrs}$. Of about the same size as control.

Fig. $101 d, 48 \mathrm{hrs}$. Somewhat smaller than control and less highly developed.

Fig. $111 e, 48 \mathrm{hrs}$. Smaller and in less advanced stage of development.

Fig. $121 f, 48 \mathrm{hrs}$. Has not passed beyond tri-radiate stage.

The following solutions were employed: (S. W. is used in the following tables to designate normal sea-water. C. S. W. indicates normal sea-water concentrated to one-half its volume by continuous heating at $70^{\circ} \mathrm{C}$.). 

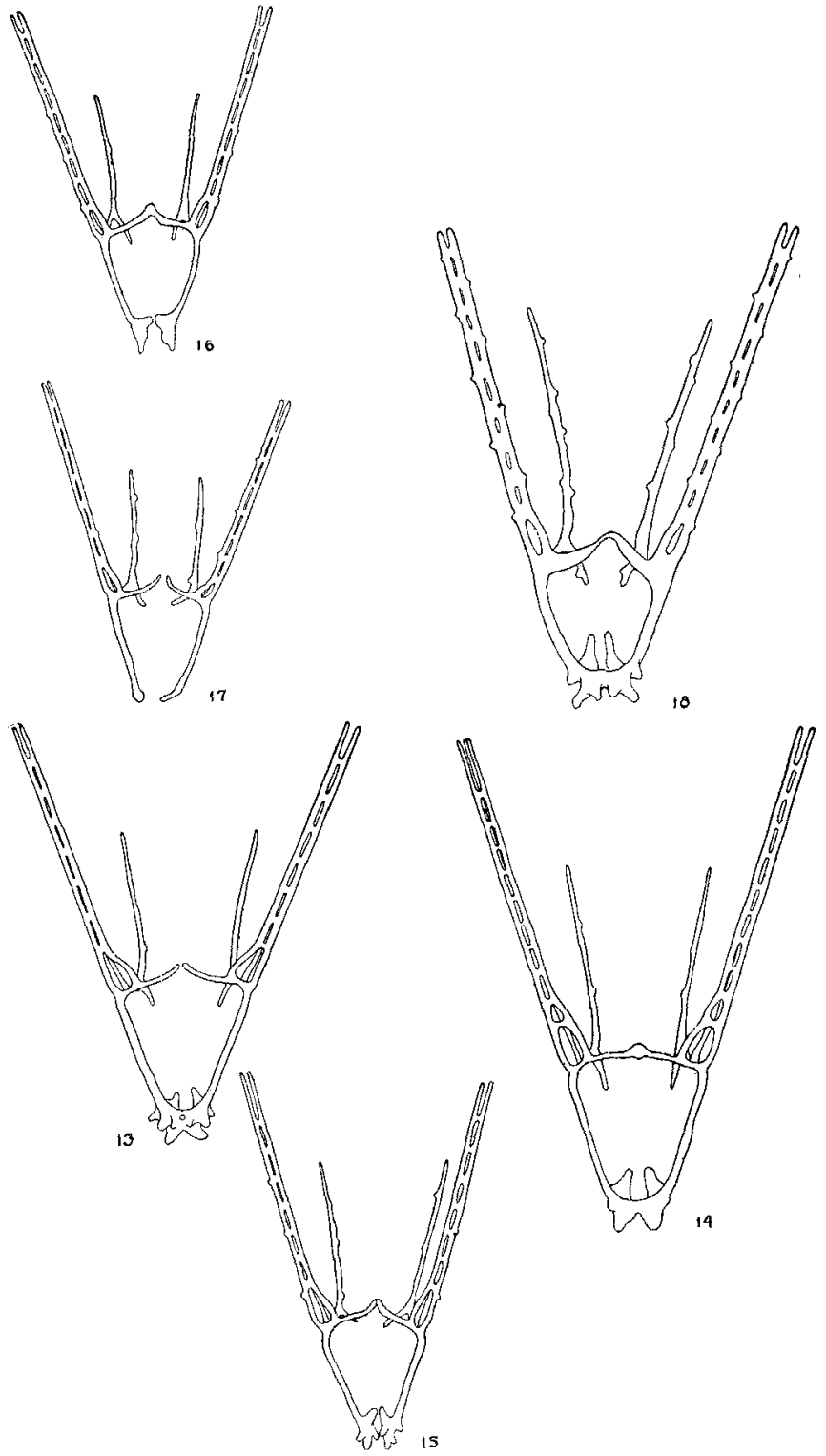

Fig. $131 a, 72$ hrs. Control.

Fig. $141 b, 72$ hrs. Larger than control, otherwise normal.

Fig. $151 c$, figure $161 d$, figure $171 e, 72 \mathrm{hrs}$. Gradual inhibition as to size. Fusion retarded.

Fig. $181 a, 96$ hrs. Control. 
TABLE 4

Constants, Experiment 1. Solution d

\begin{tabular}{|c|c|c|c|c|}
\hline & & MEAN & $\begin{array}{l}\text { STANDARD } \\
\text { DEV1ATION }\end{array}$ & $\begin{array}{l}\text { COEFFICIENT OF } \\
\text { VARIATION }\end{array}$ \\
\hline \multirow{4}{*}{24 hours } & Right anal. & $5.99 \pm 0.16$ & $2.43 \pm 0.11$ & $40.58 \pm 2.23$ \\
\hline & Left anal... & $5.90 \pm 0.16$ & $2.40 \pm 0.11$ & $40.76 \pm 2.19$ \\
\hline & Right oral. & $5.99 \pm 0.16$ & $2.43 \pm 0.11$ & $40.58 \pm 2.23$ \\
\hline & Left oral... & $5.90 \pm 0.16$ & $2.40=0.11$ & $40.58=2.19$ \\
\hline \multirow{4}{*}{48 hours } & Right anal. & $41.67 \pm 0.32$ & $4.79 \pm 0.22$ & $11.50 \pm 0.55$ \\
\hline & Left anal. & $42.04 \pm 0.31$ & $4.68 \pm 0.22$ & $11.14 \pm 0.53$ \\
\hline & Right oral. & $33.59 \neq 0.22$ & $3.26 \pm 0.15$ & $9.73 \pm 0.46$ \\
\hline & Left oral. & $33.55 \pm 0.22$ & $3.36 \pm 0.16$ & $10.03 \pm 0.48$ \\
\hline \multirow{4}{*}{72 hours } & Right anal. & $52.87 \pm 0.27$ & $4.04 \pm 0.19$ & $7.64 \pm 0.36$ \\
\hline & Left anal..... & $53.05 \pm 0.27$ & $4.14 \pm 0.19$ & $7.81 \pm 0.37$ \\
\hline & Right oral.... & $40.91 \pm 0.21$ & $3.17 \pm 0.15$ & $7.76 \pm 0.37$ \\
\hline & Left oral. . & $40.84 \pm 0.21$ & $3.23=0.15$ & $7.90 \pm 0.37$ \\
\hline
\end{tabular}

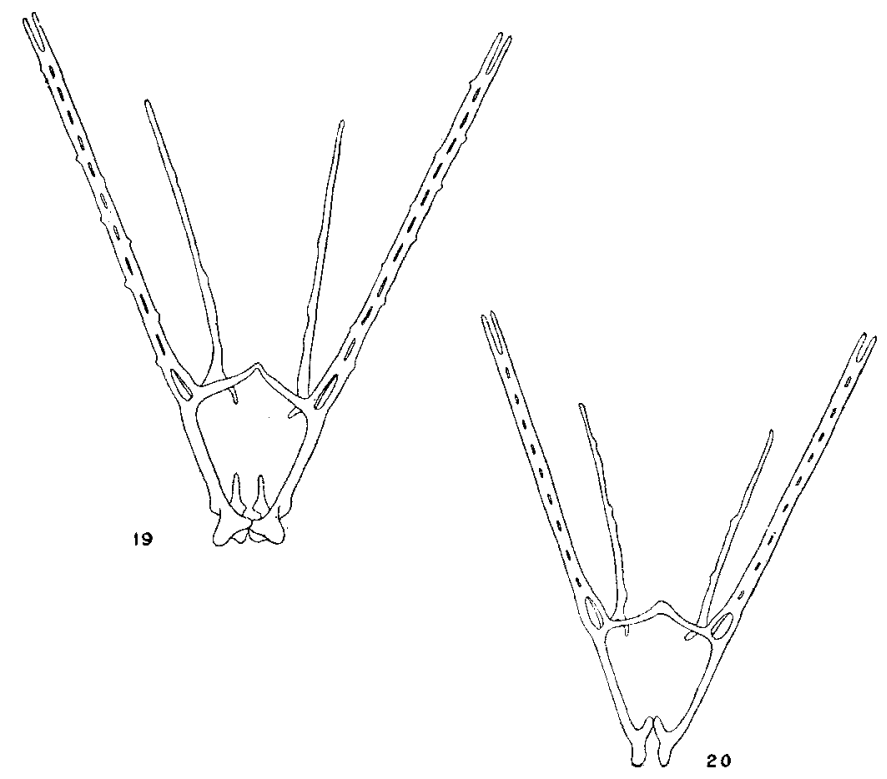

Fig. $191 b, 96$ hrs. Larger than control.

Fig. $201 c, 96$ hrs. Smaller than control. Body-rods still unfused at the posterior ends. 
TABLE 5

Constants, Experiment 1. Solution e

\begin{tabular}{|c|c|c|c|c|}
\hline & & MEAN & $\begin{array}{l}\text { STANDARD } \\
\text { DEVIATKON }\end{array}$ & $\begin{array}{c}\text { COEFPICIENT OF } \\
\text { VARIATION }\end{array}$ \\
\hline \multirow{4}{*}{24 hours } & Right anal. & $2.35 \pm 0.13$ & $1.98 \pm 0.09$ & $84.54 \pm 6.28$ \\
\hline & Left anal. . & $2.35 \neq 0.13$ & $1.98 \pm 0.09$ & $84.54 \pm 6.28$ \\
\hline & Right oral & $2.51 \pm 0.13$ & $2.04 \pm 0.09$ & $81.35 \pm 5.91$ \\
\hline & Left oral. & $2.51=0.13$ & $2.04 \pm 0.09$ & $81.35 \pm 5.91$ \\
\hline \multirow{4}{*}{48 hours } & Right anal. & $35.98 \pm 0.30$ & $4.55 \pm 0.21$ & $12.65 \pm 0.61$ \\
\hline & Left anal. & $36.03 \pm 0.31$ & $4.60 \pm 0.21$ & $12.79 \pm 0.61$ \\
\hline & Right oral. & $29.29 \pm 0.25$ & $3.71 \pm 0.17$ & $12.69 \pm 0.61$ \\
\hline & Left oral. & $26.36 \pm 0.24$ & $3.65 \pm 0.17$ & $12.43 \pm 0.60$ \\
\hline \multirow{4}{*}{72 hours } & Right ar & $46.37 \pm 0.21$ & $3.23=0.15$ & $6.98 \pm 0.33$ \\
\hline & Left anal. & $46.38 \pm 0.21$ & $3.19 \neq 0.15$ & $6.89 \pm 0.33$ \\
\hline & Right oral. & $35.91 \pm 0.18$ & $2.77 \pm 0.13$ & $7.71 \pm 0.37$ \\
\hline & Left oral. & $33.95 \pm 0.18$ & $2.77 \pm 0.13$ & $7.73 \pm 0.37$ \\
\hline
\end{tabular}

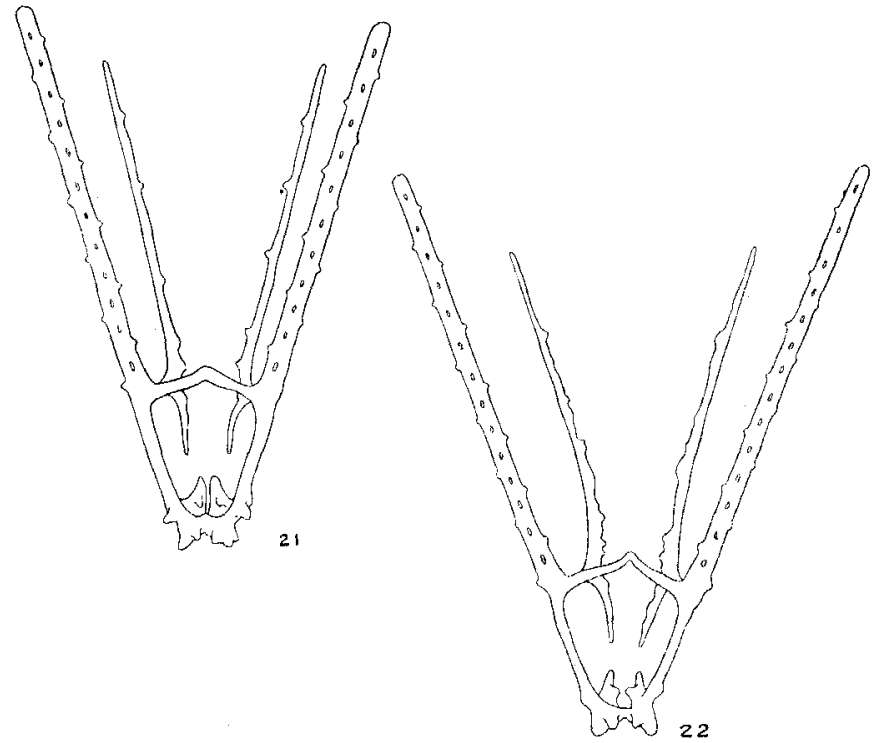

Fig. 21 la, $120 \mathrm{hrs}$. Control.

Fig. $221 b, 120 \mathrm{hrs}$. Specimen normal in all respects except size, which is increased above that of control. 
TABLE 6

Constants, Experiment 1. Solution $f$

\begin{tabular}{|c|c|c|c|c|}
\hline & & MEAN & $\begin{array}{l}\text { STANDARD } \\
\text { DEVIATION }\end{array}$ & $\begin{array}{l}\text { COFHFICIENT OF } \\
\text { VARIATION }\end{array}$ \\
\hline \multirow{4}{*}{24 hours } & Right anal. & $0.82 \pm 0.07$ & $1.14 \pm 0.05$ & $139.45=14.70$ \\
\hline & Left anal. & $0.83 \pm 0.07$ & $1.12 \pm 0.05$ & $135.35=13.94$ \\
\hline & Right oral. & $0.82 \pm 0.07$ & $1.14 \pm 0.05$ & $139.45 \pm 14.70$ \\
\hline & Left oral... & $0.83 \pm 0.07$ & $1.12 \pm 0.05$ & $135.35 \pm 13.94$ \\
\hline \multirow{4}{*}{48 hours } & fRight anal. & $3.86 \pm 0.23$ & $3.51 \pm 0.16$ & $91.09= \pm$ \\
\hline & Left anal... & $3.86 \pm 0.23$ & $3.51 \pm 0.16$ & $91.09 \pm$ \\
\hline & Right oral. & $4.24 \pm 0.24$ & $3.61 \pm 0.17$ & $85.37 \pm$ \\
\hline & Left oral... & $4.24 \pm 0.24$ & $3.61 \pm 0.17$ & $85.37 \pm$ \\
\hline
\end{tabular}

Experiment 2. Plots 3 and 4. June 20, 1915

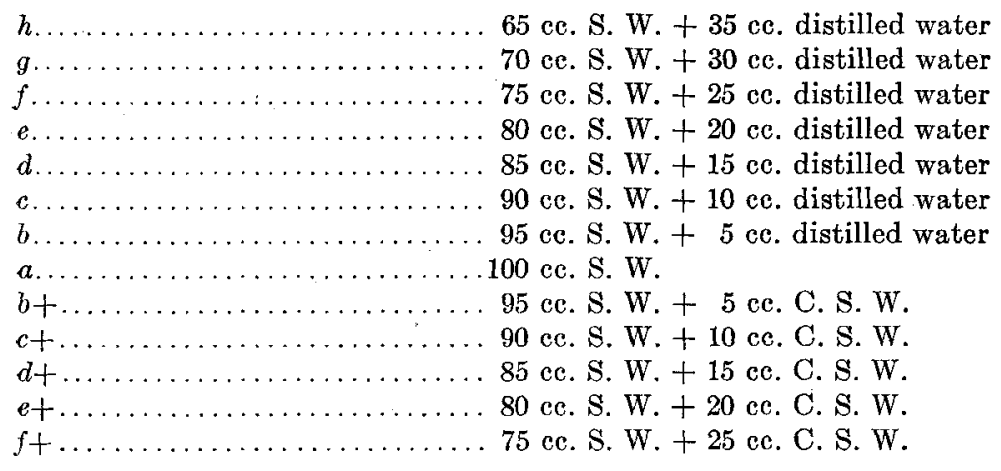

The following measurements were obtained:

\begin{tabular}{|c|c|c|c|c|c|c|c|}
\hline & 24 HOURS & 48 HOURS & 72 HoURs & 96 HOURS & 120 youns & 144 HoUns & 168 ноURs \\
\hline$h$. & & & & & & & \\
\hline$g \ldots \ldots \ldots$ & 16.62 & 32.10 & 44.78 & 47.85 & & & \\
\hline$f \ldots \ldots \ldots$ & 27.43 & 63.14 & 76.13 & 81.47 & 82.14 & & \\
\hline$e \ldots \ldots$ & 32.21 & 68.82 & 79.89 & 83.83 & 85.81 & 86.13 & 84.46 \\
\hline$d \ldots \ldots$ & 33.92 & 71.88 & 83.03 & 86.42 & 88.71 & 83.21 & 72.47 \\
\hline c. . & 34.87 & 74.91 & 87.20 & 90.03 & 85.93 & 75.34 & 58.31 \\
\hline$b \ldots \ldots$ & 35.90 & 73.15 & 85.09 & $88 . \dot{7} 4$ & 79.11 & 62.11 & 44.39 \\
\hline$a \ldots \ldots$ & 36.82 & 70.14 & 81.95 & 85.66 & 71.77 & 44.63 & 37.91 \\
\hline$b+\ldots$ & 32.07 & 66.78 & 78.10 & 80.73 & 68.34 & 49.27 & 42.84 \\
\hline$c+\ldots$ & 25.13 & 62.15 & 73.91 & 73.81 & 85.11 & 53.48 & 48.13 \\
\hline$d+\ldots \ldots \ldots$ & 14.51 & 53.97 & 65.95 & 66.87 & 61.73 & 57.36 & 54.26 \\
\hline$e+\ldots \ldots \ldots$ & 3.20 & 43.96 & 56.09 & 56.29 & & & \\
\hline
\end{tabular}


The control specimens, $a$, underwent a rapid early growth which resulted in a size at the age of 24 hours more than twice that of the average. The maximum point on their growthcurve occurred at an age of 96 hours, followed by a steady diminution in size. At the close of 144 hours the arms were shortened to a small fraction of their previous length (fig. 23), and on the following day practically nothing remained of the

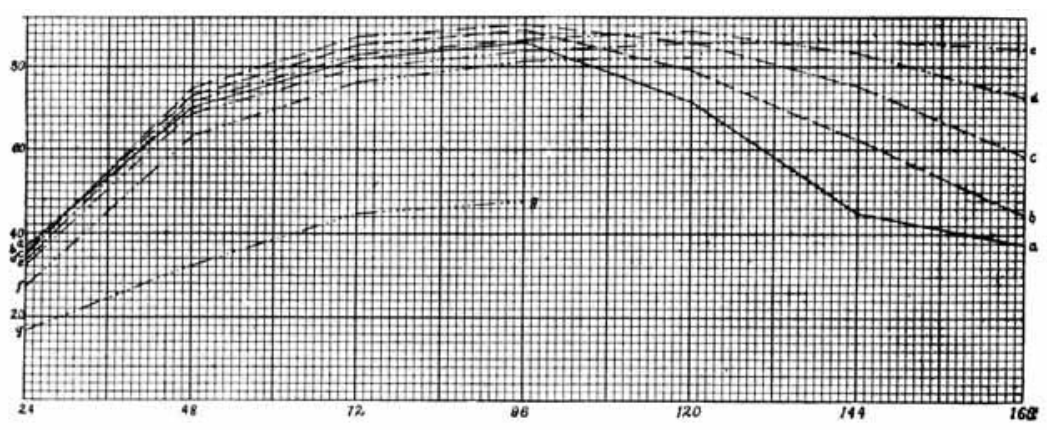

Plot 3

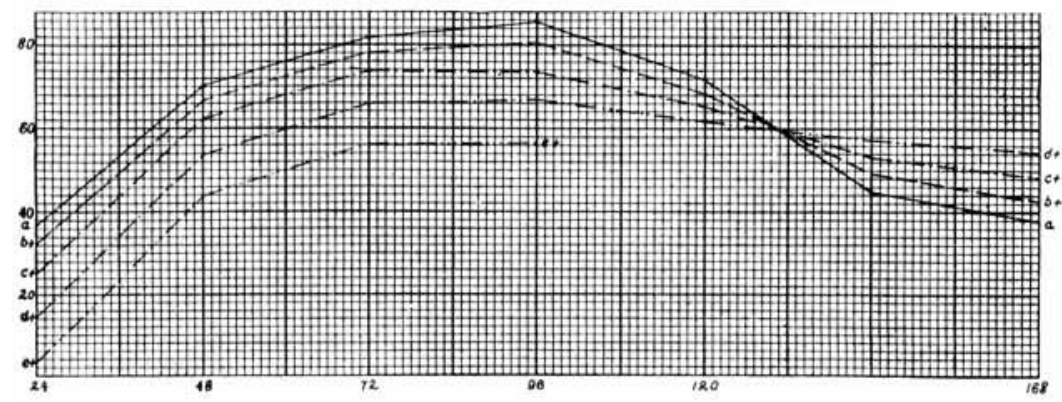

Plot 4

skeleton except the body-rods with greatly reduced ventral branches and dorso-ventral connectives (fig. 25).

In comparing the growth-curves of the specimens in the various solutions, we find that a primary inhibition of growth occurs in the diluted sea-water, increasing in intensity in proportion to the dilution of the medium. A secondary readjustment occurs, however; consequently the specimens in $b$, 
$c, d$ and $e$ attain a greater size than those in $a$, with $c$ largest, $b$ and $d$ somewhat smaller and $e$ about equal to $a$. The highest points in the growth-curves of the larvae in $b$ and $c$ are reached at 96 hours, coincident in time with that of $a$. Those in $d$ do not reach their maximum until 120 hours and in $e$ until 144

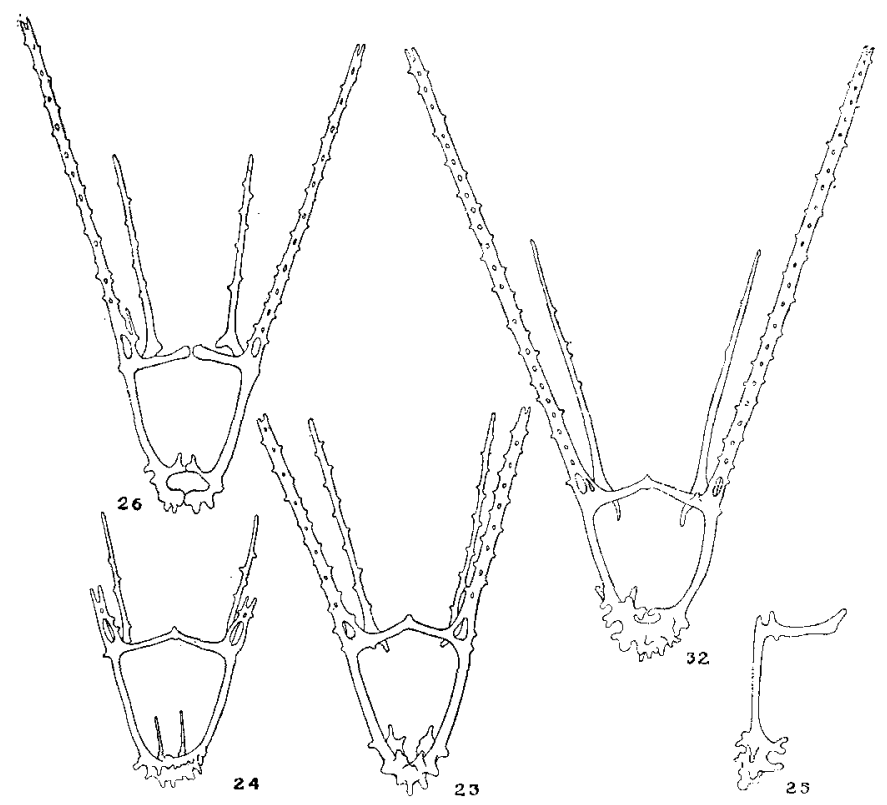

Figs. 23 to 26 Experiment 2. Sea-water diluted with distilled water.

Fig. $232 a, 120$ hrs. Resorption of the skeleton has commenced. Anal arms are affected more noticeably than oral.

Fig. $242 a, 168$ hrs. Resorption more advanced. Anal arms almost disappeared. Oral arms reduced.

Fig. $252 a, 168$ hrs. Drawn from left side. Resorption still more advanced. Anal and oral arms almost entirely disappeared.

Fig. $262 d, 96$ hrs. Slight irregularities in the skeleton, and retarded fusing of the lateral connective and body-rods.

hours, indicating ultimate retarding of development. Moreover, in these more dilute solutions, the secondary readjustment fails to occur and the specimens in $g$ attain an ultimate size only about one-half as great as those in $a$. Those in $h$ underwent cleavage but failed to form skeletons. 
In the solutions of greater concentration than that of the normal sea-water (Plot 4), there occurred a proportionately greater reduction in size,-an effect which must be looked upon in the light of an inhibiting of growth rather than of a

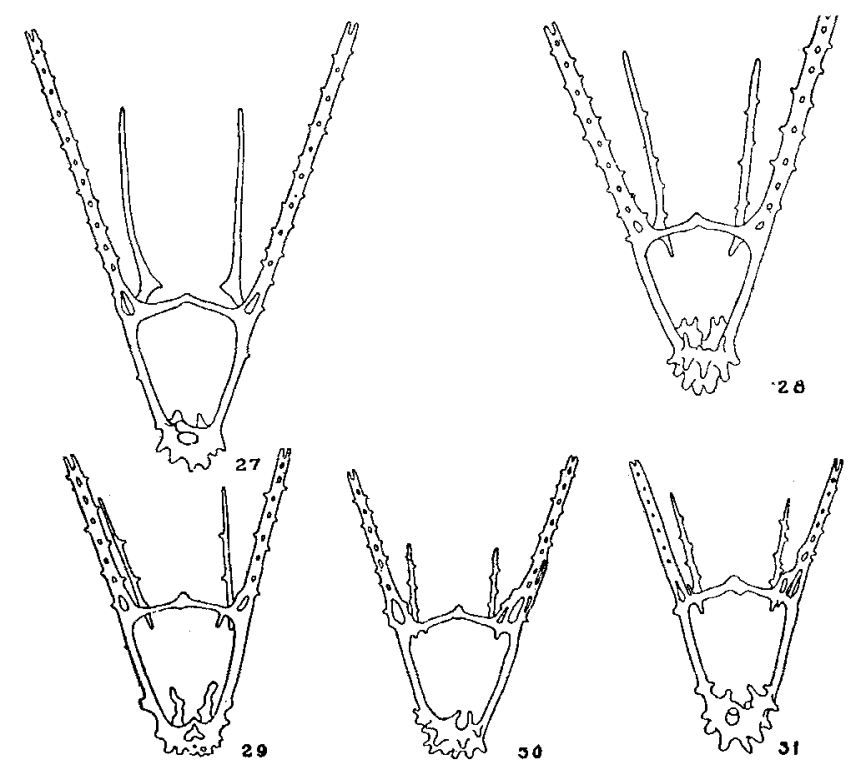

Figs. 27 to 31 Experiment 2. Normal sea-water concentrated.

Fig. $272 a$, figure $282 b+$, figure $292 c+$, figure $302 d+$, figure $312 e+, 96$ hrs. Prominent processes on the posterior parts of the body-rods and the ventral body-branches. Fusing of the lateral connectives with heavy deposit of calcareous material. Irregularity of structure of skeleton.

Fig. 32 Experiment 3. Sea-water gradually concentrated by evaporation.

Fig. $323 d, 96$ hrs. Slender rods as in dilute solutions, but processes more prominent; irregularity of form as in concentrated sea water.

retarding of development, since all reach their maxima at an age of 96 hours. An exception must be made in the case of $c+$, but its diminution is exceedingly slight and the maximum may lie close to the 96 hour point. The decrease in size in $a$ as indicated by its growth-curve is shared to a less extent by $b+$, and still less by $c+$ and $d+; e+$ reached its maximum at the 
age of 96 hours, but for the last 24 hours growth had practically ceased. During the entire period, however, this culture was well within the range of the control culture, $\mathrm{F}$, plot 1 . In $f+$, the eggs underwent cleavage, but did not develop further..

The modifications in the skeleton in these diluted solutions were of the same type as in the preceding experiment, $-\mathrm{a}$ reduction in the size and number of processes and a delayed fusion of the lateral connectives and of the body-rods (fig. 26). This tendency toward reduction in skeletal structures seemed to have no correlation with increase or decrease of size, since it was displayed by those larger as well as by those smaller than the control.

Conversely, in the solutions of greater concentrations a tendency toward increased complexity of structure appears, accompanied by the reduction in size deseribed above. Figures 27 to 31 illustrate one individual from the control and one from each of the more concentrated solutions after 96 hours. Figure 26 is taken from $d, 15$ per cent dilution, on the same day. This increased complexity of structure is shown by the greater prominence of the spines as well as by the greater size and number of the processes on the posterior part of the body-rods. In contrast to the delayed fusion of the individual elements in the diluted solutions, those in the concentrated ones show a tendency, not only toward early fusion, but also toward excessive depositing of calcareous material at the points of contact of the transverse rods.

As the limits of endurance are approached in the more diluted and concentrated solutions, ' a tendency toward irregularity of structure appears. This is illustrated somewhat in figure 26, where an accessory spine on the right side of the larva near the base of the arm-rods, interrupts the otherwise highly symmetrical condition. It is shown more clearly in the following drawings (figs. 27 to 31), where each increased concentration produces a higher degree of irregularity.

The third experiment in this first series was undertaken for the purpose of observing whether the organism would undergo 
less modification if subjected gradually to the changed conditions, and of determining what regulations, if any, would occur in the process of adjustment.

Solutions similar to those used in the preceding experiment were prepared and were let stand in the open air with a control kept closely covered to prevent evaporation. A second control was allowed to evaporate along with the other experimental solutions. The temperature of the sea-water at the beginning of the experiment was $17.25^{\circ} \mathrm{C}$. The volume and specific gravity of each solution were taken every day, and at the close of the experiment the estimated specific gravity was checked against the determined.

Five dishes of each of the various solutions were set out together at the beginning of the experiment, and all allowed to evaporate. Each day one of these was utilized to supply the corresponding culture with fresh medium.

Volume of the solutions

\begin{tabular}{|c|c|c|c|c|c|c|}
\hline conc. & 0 HOURS & 24 HOU RS & 48 HOU RS & 72 ноURs & 96 ноU RS & 120 ноч Rs \\
\hline \multicolumn{7}{|l|}{ per cent } \\
\hline 70 & 200 & 191.5 & 184.5 & 179.0 & 169.0 & 160.0 \\
\hline 75 & 200 & 191.7 & 184.6 & 179.1 & 169.1 & 160.2 \\
\hline 80 & 200 & 191.75 & 184.75 & 179.1 & 169.2 & 160.3 \\
\hline 85 & 200 & 191.0 & 184.0 & 178.7 & 168.6 & 159.5 \\
\hline 90 & 200 & 191.0 & 184.1 & 178.75 & 168.7 & 159.6 \\
\hline 95 & 200 & 191.4 & 184.0 & 178.6 & 168.7 & 159.6 \\
\hline 100 & 200 & 191.0 & 184.2 & 178.9 & 168.9 & 159.6 \\
\hline 105 & 200 & 191.3 & 184.4 & 179.1 & 169.0 & 160.0 \\
\hline 110 & 200 & 191.0 & 184.0 & 178.5 & 168.6 & 159.5 \\
\hline 115 & 200 & 191.7 & 184.6 & 179.1 & 169.1 & 160.1 \\
\hline 120 & 200 & 191.5 & 184.5 & 179.0 & 169.0 & 160.0 \\
\hline Average.... & 200 & 191.35 & 184.33 & 178.89 & 168.9 & 159.85 \\
\hline
\end{tabular}


Specific gravity (estimated) of the solutions

\begin{tabular}{|c|c|c|c|c|c|c|}
\hline & 0 HOURs & 24 HOURS & 48 HOURS & 72 ноО Rs & 96 HOURS & 120 ноU Rs \\
\hline$g$ & 1.01561 & 1.01631 & 1.01694 & 1.01736 & 1.01848 & 1.01953 \\
\hline f. & 1.01673 & 1.01748 & 1.01846 & 1.01860 & 1.01980 & 1.02092 \\
\hline e.. & 1.01784 & 1.01864 & 1.01936 & 1.01984 & 1.02112 & 1.02232 \\
\hline$d$. & 1.01896 & 1.01981 & 1.02058 & 1.02108 & 1.02244 & 1.02371 \\
\hline c.. & 1.02007 & 1.02097 & 1.02178 & 1.08232 & 1.02376 & 1.02510 \\
\hline b.. & 1.02119 & 1.02214 & 1.02299 & 1.02356 & 1.02508 & 1.02650 \\
\hline$a a$. & 1.02230 & 1.02330 & 1.02420 & 1.02480 & 1.02640 & 1.02790 \\
\hline$b+$. & 1.02341 & 1.02447 & 1.02541 & 1.02604 & 1.02772 & 1.02929 \\
\hline$c+$. & 1.02453 & 1.02563 & 1.02662 & 1.02728 & 1.02904 & 1.03069 \\
\hline$d+$. & 1.02565 & 1.02680 & 1.02782 & 1.02817 & 1.03036 & 1.03208 \\
\hline$e+$. & 1.02676 & 1.02797 & 1.02883 & 1.02976 & 1.03168 & 1.03348 \\
\hline
\end{tabular}

Measurements of larvae. Experiment 9. Plot 5 (diluted sea-water). Plot 6 (concentrated sea-water). June 17, 1915

\begin{tabular}{|c|c|c|c|c|c|}
\hline & 24 но URs & 48 ноบrs & 72 ноURя & 96 ноURs & 120 ноО Нв \\
\hline$g \ldots$. & 17.34 & 39.91 & 60.10 & 77.91 & 91.47 \\
\hline$f \ldots$. & 23.25 & 48.92 & 69.97 & 84.24 & 94.32 \\
\hline$e \ldots$ & 28.21 & 56.18 & 79.81 & 88.17 & 95.19 \\
\hline$d \ldots$ & 32.74 & 68.30 & 86.10 & 92.28 & 95.86 \\
\hline$c \ldots \ldots$ & 34.26 & 69.41 & 84.77 & 90.13 & 92.71 \\
\hline$b \ldots$ & 36.07 & 66.21 & 79.69 & 84.05 & 84.17 \\
\hline$a a$. & 37.14 & 62.39 & 72.11 & 74.17 & 74.75 \\
\hline$a \ldots$ & 38.10 & 67.83 & 82.13 & 88.78 & 93.25 \\
\hline$b+$. & 32.12 & 54.79 & 64.15 & 66.76 & 66.82 \\
\hline$c+\ldots$ & 25.44 & 46.68 & 55.32 & 57.90 & 58.15 \\
\hline$d+\ldots \ldots \ldots \ldots$ & 13.21 & 38.84 & 46.06 & 47.87 & 48.09 \\
\hline$e+\ldots \ldots \ldots \ldots$ & 1.03 & 27.26 & 33.24 & 34.02 & 34.21 \\
\hline
\end{tabular}

In comparing the growth-curve of the control for this experiment with that of our normal, we find a much more rapid early development resulting in a size more than twice that of the average. Constant and gradual growth was maintained during the four following days, so that each point on the growthcurve was considerably in excess of the normal (D, plot 1), and at the close of the experiment the specimens from this control culture measured 93.25 , or 12.91 more than the general average 80.34 . 
The primary inhibiting effect of the various degrees of dilution may be seen by a comparison of the points of their growthcurves (Plot 5) at the 24 hour period. These points fall from 38.10 , the size of the control, through 37.14 , the average of culture $a a$, started in normal sea-water and allowed to evaporate for 24 hours, and terminate with $17.34(g)$, started in 30

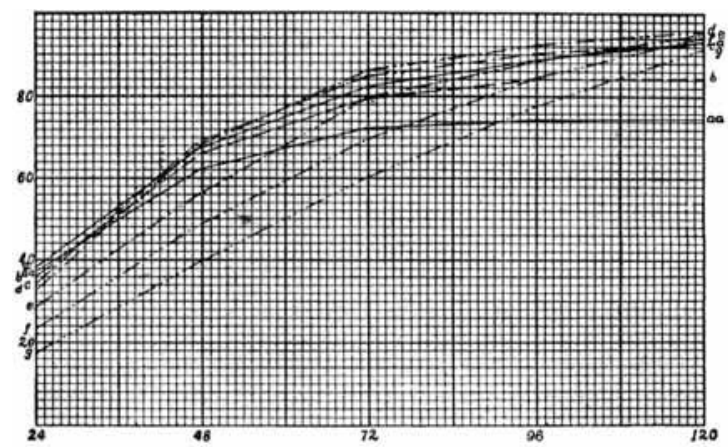

Plot 5

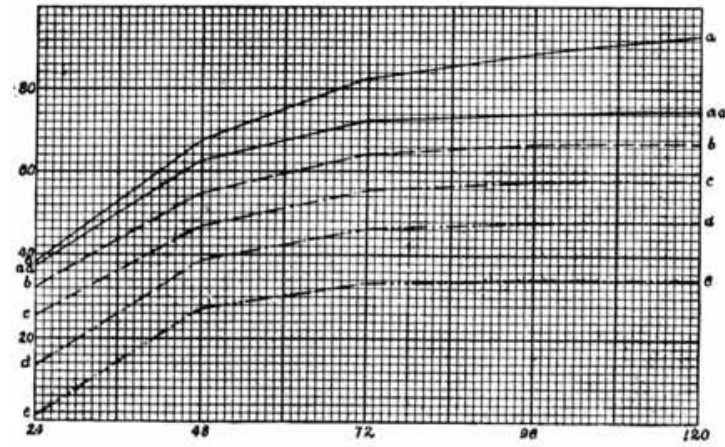

Plot 6

per cent dilution but now evaporated to 95.7 per cent of its original volume.

In the solutions of greater concentration than that of normal sea-water each culture showed a corresponding decrease in size, until in $e+$ the skeletons were represented merely by minute tri-radiate spicules of very nearly the same size as 
those in the corresponding culture of Experiment 2. Meanwhile, however, the solution had become concentrated by evaporation to a specific gravity of 1.02797 , a concentration slightly greater than that of solution $f+$, Experiment 2, specific gravity 1.02788 , in which development had not passed beyond the blastula stage.

At the end of 24 hours, all the cultures in the experiment were in the same order, as regards size, as those in Experiment 2 had been at the same age, and showed about the same inhibition of growth, although they were now in sea-water of approximately 4.3 per cent greater concentration.

The specimens in $a a$ averaged slightly less than those in $a$, and, since these two cultures were started in normal sea-water, this decreased rate of growth cannot be ascribed to any primary inhibition due to sudden changes of osmotic pressure, but must have been due to the gradually increasing concentration. This effect was still more evident on the following days. Inhibition became more pronounced as the solution became more concentrated, until, at the end of 72 hours, a specific gravity of 1.02790 was attained. This was slightly in excess of that of solution $h$, Experiment 2, in which the eggs failed to develop beyond late cleavage.

In the cultures with diluted sea-water the early effects were similar to those in the corresponding solution of Experiment 2 ; but, as concentration gradually took place, secondary effects were produced. On the one hand, as those solutions of moderate dilution became evaporated to a density greater than that which Experiment 2 showed to be the optimum for growth, the effects specific to concentration replaced those peculiar to dilution; and the secondary characteristics were more evident the earlier the time of their appearance. On the other hand, in those cultures which were initially diluted more highly than was advantageous for growth, such as $e, f$ and $g$, there was produced an early inhibition of growth. But as the medium became less injurious, secondary readjustment occurred and growth became more rapid as the concentration approached the ideal range. 
In 72 hours, solution $c$ had become concentrated to about the same specific gravity as that of $a$. We have then, at this stage two solutions of almost identical concentration, one of which has been maintained constantly in this condition and the other of which has reached it through a process of gradual evaporation; yet in the latter, the size, notwithstanding an early inhibition, has increased materially above the normal. As the concentration increases beyond that of sea-water, rate of growth decreases, and at the age of 120 hours the plutei are 0.5 per cent smaller than the control. We have therefore, at this point, two solutions of different concentration,- - the one, that of normal sea-water with a specific gravity of 1.0223 , and the other, that of a concentrated solution of a specific gravity of 1.0251, an increase of 12 per cent, in which the larvae, by widely different courses of treatment, have reached the same end. The ultimate effect could, of course, only be speculated upon, but at this point two facts are evident; - -first, that we have in two similar solutions individuals of the same parentage, reaching entirely different conditions through unlike treatment; and second, we have the same individuals, through further dissimilar treatment, converging to the same point.

In all these cultures of Experiment 3 the specimens were the offspring of the same parents, but were subjected to such widely different conditions that there was produced an increasingly great primary inhibition of growth in the solutions from $a$ to.g. Those in which this early inhibition was least marked, i.e., those of the least dilution, are exposed at the close of the experiment to the most unfavorable conditions. To what, then, is this early inhibition due? To what extent may early inhibition be overcome by later favorable conditions? In how far may favorable conditions during the first hours of cleavage so benefit the organism that later adverse circumstances fail to produce modification of normal growth? And is an increased size at any one period necessarily indicative of or coincident with acceleration of development?

The primary inhibition could be ascribed to either of two causes,--first, shock attendant upon sudden change of medium 
from normal sea-water to one of changed concentration; or second; an influence directly injurious to growth during the earliest stages of development in those solutions which later act most favorably, such as a 10 or 15 per cent dilution. Solution $a a$ is one from which any element of shock must have been eliminated. At the close of 24 hours it has a specific gravity of 1.0233 , or 4.4 per cent greater than the control. If early inhibition during the first 24 hours were the results of unfavorable conditions alone, we should expect the inhibition in growth in each solution to increase gradually as the concentration becomes greater, but instead we obtain the following results:

Percentages of decrease in size compared with the control

\begin{tabular}{c|c|c|c|c|c} 
ночrs & \multicolumn{1}{|c|}{ a } & b+ & $c+$ & $d+$ & e+ \\
\hline 24 & 2.5 & 15.7 & 33.2 & 65.3 & 97.2 \\
48 & 8.0 & 19.2 & 31.1 & 42.7 & 59.8 \\
72 & 12.2 & 21.8 & 32.6 & 43.9 & 59.5 \\
96 & 16.4 & 24.7 & 34.7 & 46.0 & 61.6 \\
120 & 19.8 & 28.3 & 37.6 & 48.4 & 64.3 \\
\hline
\end{tabular}

In the $a a$ solution, the inhibition is slight the first day, and increases in intensity as the concentration gradually becomes greater. In solution $b+$, the inhibition at the end of 24 hours is only slightly less than that at the end of 48 hours. In $c+$, the inhibition is greater at the close of 24 hours than at the close of 48 , after which it increases in intensity. The same is true of solutions $d+$ and $e+$ to an even more marked degree, and in the latter the recovery is not complete until the third day.

From these facts we may conclude that there is an early and separate inhibition factor due solely to sudden changes of medium and that subsequent inhibition or acceleration of growth is a secondary factor which may operate independently. In view of this, we may be justified in interpreting the early inhibition produced in the solutions of high dilution, which later cause acceleration in growth rate, as one due to the sudden change of physical conditions and not to a retarding effect 
produced directly upon the developing embryo during the periods of blastula and gastrula formation.

Vernon ('95), working upon Strongylocentrotus, concluded that subjection for one minute to a temperature above or below that of the control was quite as effective in producing an ultimate reduction in size as exposure for 1 hour. In his experiments with sea-water of increased and decreased densities $(' 00)$, he found that a brief subjection to diluted sea-water (for example, from the time of fertilization until 6 or 12 hours after) produced a decrease in growth rate, whereas continued exposure ( 1 to 144 hours) brought about an increase, and he suggested that primary reduction in size was due to shock attendant upon transfer from dilute to normal sea-water. No such effects, he believed, resulted from transfer from normal sea-water to dilute; for ova used in the same experiment, which were kept for 5 and for 24 hours respectively in normal seawater and then transferred to dilute sea-water for the remainder of the period, resulted in a 2.6 and 2.8 per cent increase of size. But it seems probable that there may have been a 'shock' quite as great in the latter instance as in the former. In the first experiment, however, when he subjected the larvae for the briefer periods to the dilute sea-water, they were removed from the more favorable medium before the effects of the primary inhibition could be completely overcome. But when they were left for a longer time (such as, 144 or 192 hours) in this medium, the effects of the more dilute solution had sufficient time in which to compensate for both transfers and an ultimate increase in size was induced. The same explanation could be offered for the second experiment, when the larvae were kept for the first few hours in normal sea-water and then transferred to a more dilute medium. The ultimate effect of this later long subjection to more favorable conditions was, as we should expect, a growth more than sufficient to compensate for the shock produced by short exposure to the more concentrated medium. Had this subjection been of longer duration and treatment with dilute medium briefer, he might have obtained larvae of normal or even of reduced size. 
Herbst ('06), investigating the effect- of increased temperature, found an increase in the number of roots of the multiple arm-rods and in the number with latticed structure. If they were removed from the warmer medium before the time of mesenchyme formation, the simple rods characteristic of Strongylocentrotus prevailed. If they were removed at the gastrula stage, multiple-formation was inhibited to a greater degree than when they were transferred at the pluteus stage.

This leads directly to the consideration of our second question: "To what extent may early inhibition be overcome by later favorable conditions?" In Experiment 3, cultures $f$ and $g$, we have examples of early treatment with a medium so adverse that, under continuous subjection, life could scarcely be maintained (compare with $f$ and $g$, Experiment 2), followed by a later more favorable medium within the range of optimum concentration. At the close of the experiment the larvae approximate so closely the control that they may scarcely be termed subnormal. As far as size is concerned, we have a complete compensation for early inhibition; but the ultimate growth attained is not equal to that which would have occurred had the larvae been subjected during the entire period to a concentration equal to that of these solutions at the close of the experiment, nor so slight as that which would have been produced by continued subjection to solutions of the original concentrations. This tends to confirm Vernon's conclusion that "the range of the harmful effect of an adverse condition is always greater than the succeeding influence of a favorable one. The larvae never attain the maximum size to which they can develop, nor the minimum at which they can maintain life."

Our third question, "In how far may favorable conditions during the first few hours of cleavage so benefit the organism that the later adverse circumstances fail to produce ultimate modification of growth," is more difficult to answer, since, as the data given above show, any sudden change at the time of impregnation has a deleterious effect upon the organism. If the transfer be to a medium intrinsically beneficial, and the subjection be of sufficiently long duration, the injury may be only temporary. 
In solution $c$, Experiment 3, we have a medium that, if used continuously, would produce maximum growth; but in this experiment it has become, at the close of the fifth day, concentrated to a strength which if employed for the entire period, would have caused a decided decrease in size. At the close of the experiment the larvae are slightly smaller than the control. Although this decrease is almost negligible, it is evident that early exposure has not been so beneficial to the organism as to produce an ultimate increase in size. This becomes the more significant when we consider that the latter period is of shorter duration,--two days as compared with three days of more favorable conditions. In solution $d$, also, at first the dilution is greater than is most advantageous for development; at the close of 24 hours, evaporation has brought the solution to within the range of the optimum, yet the one day of unfavorable medium reduces the percentage of excess of size to a figure considerably closer to the normal. It seems conclusive, then, that later conditions of an adverse nature, although briefly employed, may undo the effects of an early beneficial medium; but this later force has not been able to injure the organism to such an extent that it approaches on either side the limits of growth.

One further question raised by Experiment 2 remains to be considered. Is a size greater than the normal indicative of more advanced development, or is it really beneficial to the organism? Resorption of the skeleton at this period of the life history of Arbacia is an abnormal process due to inanition of the larvae raised under these experimental conditions, and hence would probably be incurred first by those which have been most vigorous and have developed most rapidly. If rate of resorption of the skeleton be taken then, as an index of development, it follows from the facts shown in Plot 3 that the individuals of those cultures which have produced increase of size above the control, are not really in a more advanced stage of development. Thus, although the specimens of $d$ and $e$ attain a greater maximum than those of $a$, they reach it later, indicating an inhibition of development rather than an acceleration. In other words, we cannot conclude that any condition which 
may be productive of a size greater than the normal is necessarily the optimum for development.

Just as increased growth is not necessarily correlated with accelerated development, so decreased size need not be associated with abnormality of structure. In the solutions of Experiment 3 in which a size above the normal is attained, there are discernible some effects of previous adverse conditions. An example of this is given in figure 32 , which represents a specimen from solution d, Experiment 3, 96 hours. Although this individual,- - one of the extreme variants in the solution, attained a size of 103, and its measurements taken on the two sides would indicate a perfect symmetry, slight irregularities, such as the presence of an accessory rod at the base of the right arm and a bowing of the left body-rod suggest some abnormalities of development. This skeleton, moreover, lacks the distinctive marks of those associated with growth in dilute solutions, that is, general simplicity of structure. The spines are about as numerous as under normal conditions, the ventral body-branches are possibly even more highly developed and the point of fusion of the transverse rods is somewhat prominent. All these suggest some influence of the concentrated condition of the solution and suggest that a change of medium, even when the larva is approaching its maximum size, may produce some effect upon the skeleton.

Vernon ('95) gives a graph (fig. 5, loc. cit.) of the effect of salinity on growth of Strongylocentrotus. He found "that the larvae reached their maximum growth in a solution containing 50 cub. centims. of distilled water per liter, where they are 15.6 per cent larger than those developed in water of normal condition. With greater dilution than this they steadily decrease in size again, till in a solution containing 150 cub. centims. of distilled water per liter, they are on an average 4.3 per cent smaller than the normal. . . . . When the sol. contains only 25 cub. centims. of distilled water per liter, the larvae are 9.5 per cent larger than the normal, and when only 12.5 cub. centims., 5 per cent larger." 
Vernon's measurements correspond to body-length alone,.but since he also determined the arm-lengths and found them practically unaffected by alterations of medium, the general shape of his growth-curve, if not his actual percentages, may be used for comparisons.

Vernon found in Strongylocentrotus that maximum growth occurred at 950 cc. sea-water diluted to one liter; with Arbacia it lies at about 900 . In concentrations of less density than this, the general growth-curve falls off somewhat more rapidly in Strongylocentrotus than in Arbacia. In the former at about 875 cc. sea-water to the liter the growth rate is approximately equal to that in normal, while the same is true with Arbacia at about 825 . Vernon was unable to secure development in water of greater dilution than $150 \mathrm{cc}$. distilled water to the liter, whereas Arbacia under similar treatment reaches a size above the normal. Upon further dilution of the sea-water, Arbacia larvae show a steady decrease in size until $750 \mathrm{cc}$. per liter is reached, when, as the limit of endurance is approached, a sudden drop occurs. A somewhat similar curve is produced in seawater of greater concentration, though with a less abrupt fall. Vernon, however, figures a very slight decline, so that as a concentration of $1150 \mathrm{cc}$. to the liter is approached, a point beyond which growth is impossible, the decrease in size is exceedingly slight.

In view of the great variation in growth produced by slight modifications in the concentration, Vernon suggests that the variation known to exist in the concentration of sea-water must have some influence upon ths size of the larvae. Garrey ('15) gives a table of the freezing point depressions of ocean water in various localities, ranging from $\Delta=1.093$ (Dakin) at Kiel harbor, to $\Delta=2.29$ (Bottazi) at Naples. At Woods Hole the concentration varies considerably in different localities and under different conditions such as tides and rain-falls, as shown by Garrey in an earlier paper ('04). Here he also gives a table of freezing point depressions of water from various localities in that vicinity which shows variations in $\Delta$ ranging form $\Delta=1.78$ in the laboratory tap water after one extremely heavy rain, to 
$\Delta=1.84$, his maximum value, obtained from water of the Basin of the United States Fisheries Laboratory. 'Garrey gives his average freezing point depression at Woods Hole at $\Delta=1.81$, which he says is equivalent to a specific gravity of 1.02426. His variation in concentration, then from $\Delta=1.78$ to $\Delta=1.85$ would range from 1.02385 to 1.02479 at $31.5^{\circ} \mathrm{C}$. Taking 1.02426 therefore as the normal concentration of the sea-water in that region, we would obtain a range of variation of about 5 per cent in Arbacia larvae between these two extremes.

The second series of experiments dealt with the effects of acidity and alkalinity, and for this purpose the following solutions were employed:

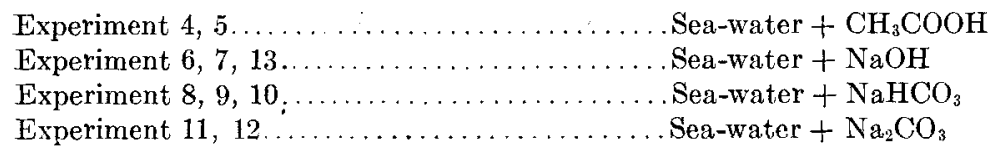

The $\mathrm{Na}_{2} \mathrm{CO}_{3}$, being technically a salt, grades over into the next series of experiments, but its alkaline reaction, due to the fact that it is the salt of a strong base with a weak acid, relates it more closely in its physiological effects to the other experiments of this series.

Two experiments were performed with the acid solutions. The first was begun September 8, 1914. This was the last experiment of that season, and mature females were exceedingly difficult to obtain. Moreover, the death-rate, even in the control cultures, was so high that the eggs did not lend themselves well to experimental conditions. The data obtained are given, however, as a basis for comparison with similar experiments under more favorable circumstances.

The solutions employed were:

Experiment 4. Plot \%. September 8, 1914

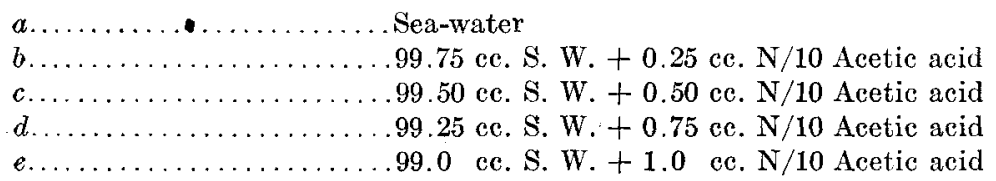


The corresponding measurements were:

\begin{tabular}{|c|c|c|c|c|c|}
\hline & 24 HOURS & 48 HOURS & 72 HovRs & 96 moURS & 120 मо ठRs \\
\hline $\begin{array}{l}a \ldots \ldots \ldots \ldots \ldots \ldots \\
b \ldots \ldots \ldots \ldots \ldots \ldots \\
c \ldots \ldots \ldots \ldots \ldots \ldots \\
d \ldots \ldots \ldots \ldots\end{array}$ & 7.73 & $\begin{array}{r}56.88 \\
12.83 \\
2.36 \\
0.61\end{array}$ & $\begin{array}{r}66.33 \\
32.09 \\
18.71 \\
8.85\end{array}$ & $\begin{array}{l}71.57 \\
43.85 \\
34.86 \\
29.34\end{array}$ & $\begin{array}{l}76.77 \\
50.61\end{array}$ \\
\hline
\end{tabular}

On June 15 of the succeeding year the second experiment was begun and solutions of the following composition employed:

Experiment 5. Plot 8. June 15, 1915

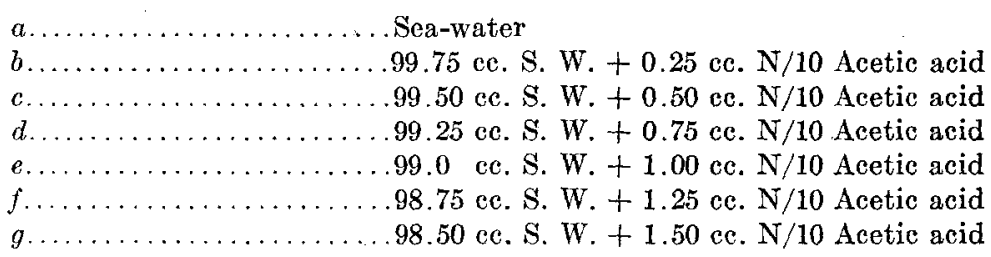

The corresponding measurements were:

\begin{tabular}{|c|c|c|c|c|c|}
\hline & 24 HOURS & 48 HOURS & 72 HоURs & 96 Hovns & 120 ночня \\
\hline$a \ldots \ldots \ldots$ & 5.92 & 56.27 & 74.13 & 88.73 & 98.95 \\
\hline$b \ldots \ldots \ldots$ & 5.74 & 53.29 & 71.88 & 83.93 & 93.20 \\
\hline$c \ldots \ldots \ldots \ldots$ & 5.34 & 49.86 & 68.84 & 80.12 & 86.14 \\
\hline$d \ldots \ldots \ldots \ldots \ldots$ & 4.67 & 44.71 & 63.79 & 70.30 & 73.32 \\
\hline$e \ldots \ldots \ldots \ldots \ldots$ & 3.62 & 37.28 & 55.21 & 59.17 & \\
\hline$f \ldots \ldots \ldots \ldots$ & 2.20 & 23.92 & 43.02 & & \\
\hline
\end{tabular}

The growth curve for the control in Experiment 4 indicates a size somewhat larger than that of the general average of the controls for that season. Compared with the control of Experiment 5, it measures somewhat more at the ages of 24 and 48 hours; then undergoes an inhibition of growth, resulting in a size at the age of 120 hours but little larger than the average of $5 a$ at the age of 72 .

Only three of the cultures that were treated with acids in Experiment 5 formed skeletons; in $5 e$ the eggs segmented and finally reached an early gastrula stage, but were abnormal and did not swim at the surface. In $b, c$ and $d$ there was an extremely rapid development following a slow growth during the first few 
hours. The unusually great increase of average size must have been due to the large death-rate which gradually eliminated all but the most nearly normal by the 72 hour period. By this time all were less active and, in solutions $c$ and $d$, were disintegrating.

In the corresponding experiments of the following year the controls were far below the general average at the age of 24

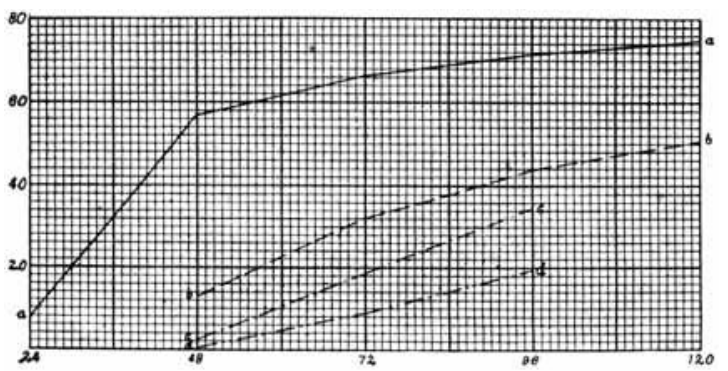

Plot 7

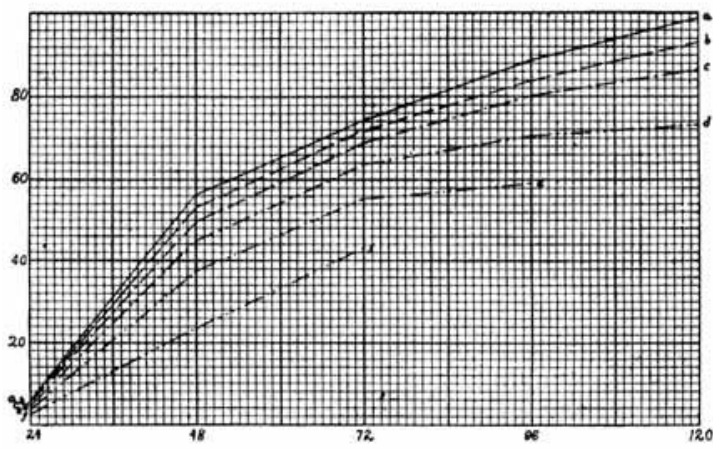

Plot 8

hours, but they then grew so rapidly that on the last two days they were the extreme high variants on the growth-curve, Plot 1 E.

The skeletons undergo characteristic modifications. All the parts are more slender than in the normal, as, shown in figure 41 , drawn from an individual of solution $b$ at the 72 hour stage. A comparison with figure 40 , representing one of the control at the same age, demonstrates the lighter structure of all the parts. 
In very weak solutions, however, this does not involve a reduction in the number or size of the spine-like processes of the arms; but in higher concentration of acid the latter effect also is produced (fig. 42, 5c). Correlated with the disappearance of these spines, there is a retarded fusion of the separate rods in

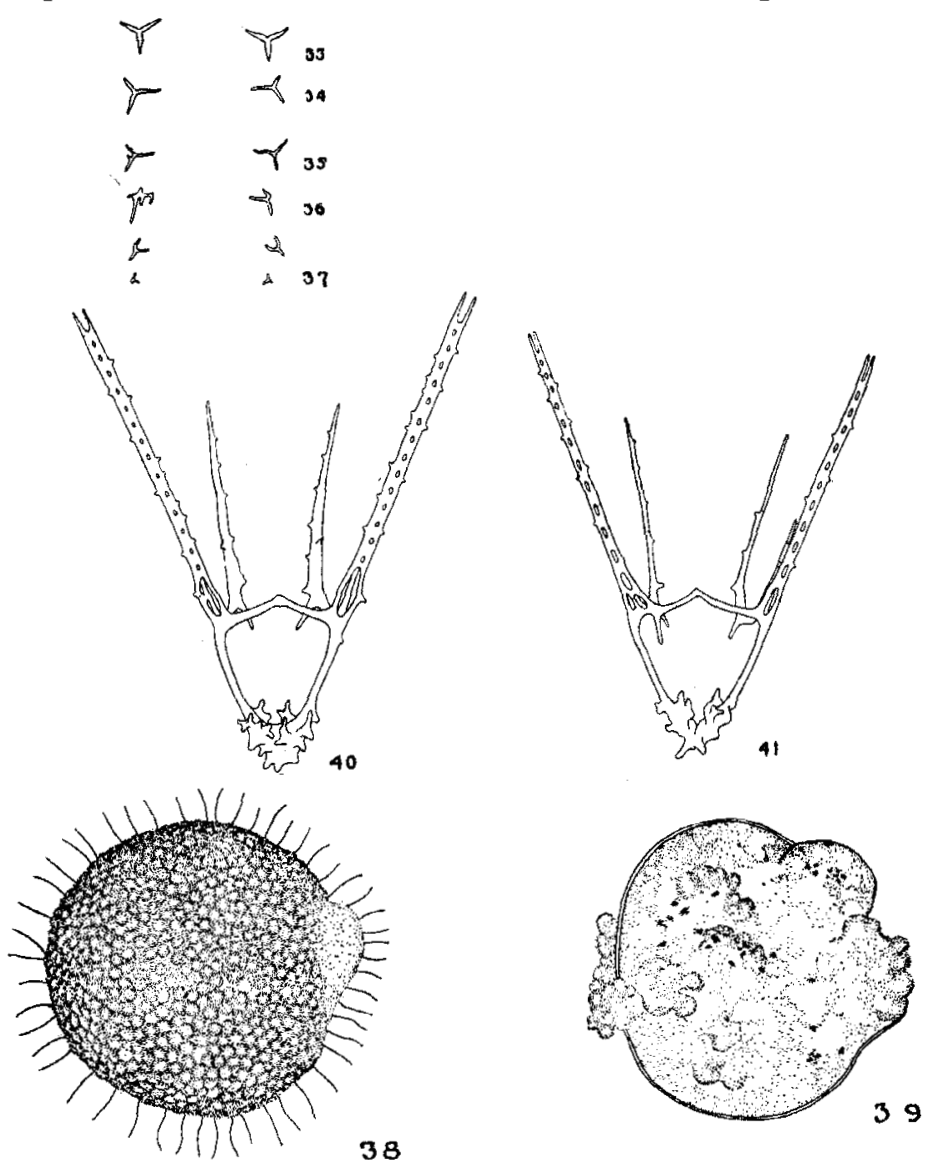

Figs. 33 to 48 . Experiment 5. $\mathrm{HCl}$.

Fig. $335 a, 24$ hrs. Control.

Fig. $345 b$, figure $355 c$, figure $365 d$, figure $375 e, 24$ hrs. Diminution of size and irregularity of structure.

Fig. $385 f, 24$ hrs. Blastula stage, somewhat irregular.

Fig. $395 g, 24$ hrs. Egg cytolyzed. Pigment collected in irregular clumps.

Fig. $405 a, 72$ hrs. Control.

Fig. $415 b, 72 \mathrm{hrs}$. All the parts more slender. 
the anal arms (figs. 43 to 46 , solutions $d, e$ and $f$ ). Figure 45 from $5 e, 72$ hours, represents a typical specimen, nearly symmetrical, with arm- and body-rods forming a widely spread $V$. There is no evidence of spines and the number of cross-bars in the arms is greatly reduced. The ventral branches are lacking.

In contrast with the gradual disappearance of spines and cross-bars, there is a tendency toward formation of accessory

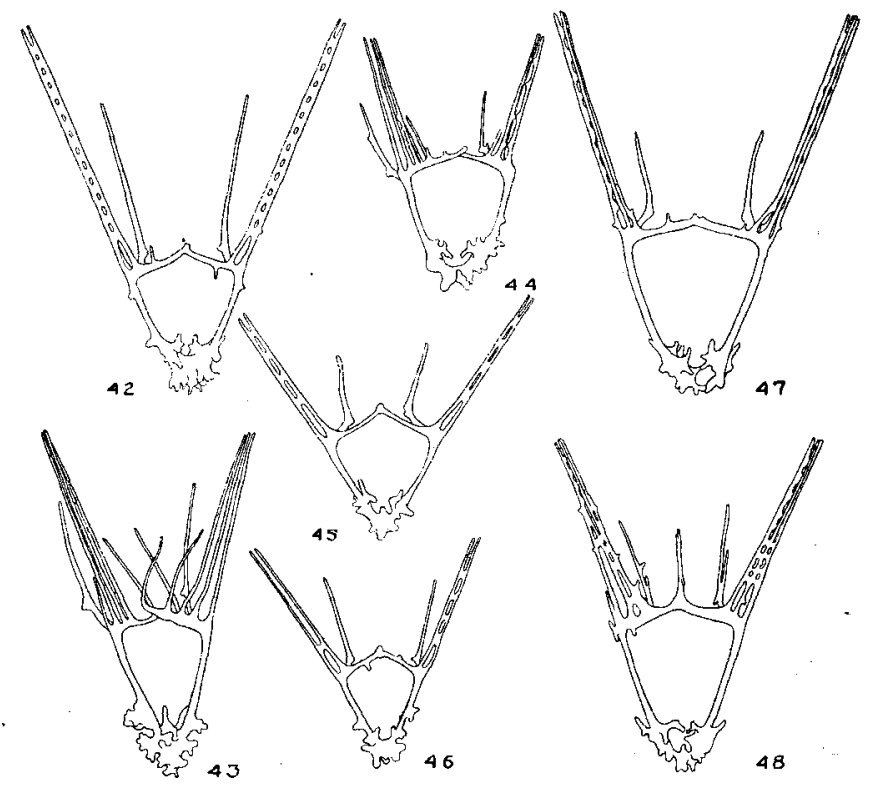

Fig. $425 c, 72 \mathrm{hrs}$. Reduction in size. All the parts more slender. Spines lacking from the arm-rods.

Fig. $435 d, 72 \mathrm{hrs}$. Slender and more reduced in size. Arm-rods unfused, with accessory rods across the lateral connectives. Posterior body-rods prominent.

Fig. $445 e, 72$ hrs. Same characters, more pronounced.

Fig. $455 e, 72 \mathrm{hrs}$. Body symmetrical, slender. Arm-rods slightly fused, spreading.

Fig. $465 f, 72 \mathrm{hrs}$. Same characters, still more marked. Greater reduction in size.

Fig. $475 d, 96 \mathrm{hrs}$. Same characters, not so pronounced as in the stronger solutions. Four rods in each arm.

Fig. $485 e, 96$ hrs. Irregularity of structure. Accessory rods on oral arms and at point of fusion of lateral connectives. 
rods in the arms. Figure $43, \mathrm{~V} d$, is a typical specimen. Four unfused rods are present on each side, arising at intervals along the transverse rods and the ends of the latter have bent anteriorly and elongated into additional ones. In figure 47, $\mathrm{V} d, 96$ hours, four rods are present in each anal arm, and the prominent openings in the lattice-work indicate incomplete fusion.

TABLE 7

Constants, Experiment 6. Solution a (Control)

\begin{tabular}{|c|c|c|c|c|}
\hline & & MEAN & $\begin{array}{l}\text { STANDARD } \\
\text { DEVIATION }\end{array}$ & $\begin{array}{c}\text { COEFFICIENT OF } \\
\text { VARIATION }\end{array}$ \\
\hline \multirow{4}{*}{36 hours } & Right anal & $34.65 \pm 0.19$ & $2.89 \pm 0.13$ & $8.36 \pm 0.40$ \\
\hline & Left anal. & $34.60=0.19$ & $2.91 \pm 0.13$ & $8.43 \pm 0.40$ \\
\hline & Right oral. & $22.11 \pm 0.10$ & $1.56=0.07$ & $7.06 \pm 0.33$ \\
\hline & Left oral. & $22.15 \pm 0.10$ & $1.55 \pm 0.07$ & $7.03 \pm 0.33$ \\
\hline \multirow{4}{*}{48 hours } & Right anal & $46.48 \pm 0.19$ & $2.84 \pm 0.13$ & $6.11 \pm 0.29$ \\
\hline & Left anal & $46.48 \neq 0.19$ & $2.84 \pm 0.13$ & $6.11=0.29$ \\
\hline & Right oral. & $26.65 \pm 0.14$ & $2.21 \pm 0.10$ & $8.31=0.39$ \\
\hline & Left oral. & $26.60 \pm 0.15$ & $2.24 \pm 0.10$ & $8.42 \pm 0.40$ \\
\hline \multirow{4}{*}{72 hours } & Right anal & $63.67=0.19$ & $2.82 \pm 0.13$ & $4.43 \pm 0.21$ \\
\hline & Left anal. & $63.67 \pm 0.18$ & $2.74 \pm 0.13$ & $4.31 \pm 0.20$ \\
\hline & Right oral. & $37.29=0.15$ & $2.29 \pm 0.10$ & $6.16 \pm 0.29$ \\
\hline & Left oral. & $37.32=0.16$ & $2.41 \neq 0.11$ & $6.47 \pm 0.31$ \\
\hline \multirow{4}{*}{96 hours } & Right anal. & $69.47 \neq 0.19$ & $2.87 \pm 0.13$ & $4.13 \pm 0.19$ \\
\hline & Left anal. & $69.58 \pm 0.19$ & $2.96 \pm 0.14$ & $4.25 \pm 0.20$ \\
\hline & Right & $44.79 \pm 0.19$ & $2.90 \pm 0.13$ & $6.48 \pm 0.31$ \\
\hline & Left oral. & $44.64 \pm 0.19$ & $2.87 \neq 0.13$ & $6.45 \pm 0.30$ \\
\hline \multirow{4}{*}{120 hours } & Right & $74.59 \pm 0.23$ & $3.54 \pm 0.16$ & $4.75 \pm 0.22$ \\
\hline & Left ar & $73.71 \pm 0.23$ & $3.41 \pm 0.16$ & $4.63 \pm 0.22$ \\
\hline & Right oral. & $48.71 \pm 0.23$ & $3.49 \pm 0.16$ & $7.18 \pm 0.34$ \\
\hline & Left oral & $48.70=0.23$ & $3.45=0.16$ & $7.09 \pm 0.34$ \\
\hline
\end{tabular}

Although all the typical parts of the skeleton are present, the specimen is marked by a slight lack of symmetry. In many individuals, this irregularity is much more evident, especially in regard to the cross-bars in the anal arms (fig. $485 e, 96$ hours). Here even the oral arms have shared in multiple rod-formation and, at the point of fusion of the transverse rods, an additional rod is formed. 
TABLE 8

Constants, Experiment 6. Solution $b$

\begin{tabular}{|c|c|c|c|c|}
\hline & & MRAN & $\begin{array}{l}\text { STANDARD } \\
\text { DEVIATION }\end{array}$ & $\begin{array}{l}\text { COEFEICIENT OF } \\
\text { VARIATION }\end{array}$ \\
\hline \multirow{4}{*}{24 hours } & Right anal. & $1.48 \pm 0.08$ & $1.32 \pm 0.06$ & $89.19 \pm 6.84$ \\
\hline & Left anal.. & $1.48 \pm 0.08$ & $1.32 \pm 0.06$ & $89.19 \pm 6.84$ \\
\hline & Right oral. & $1.26 \pm 0.07$ & $1.18 \pm 0.05$ & $93.65 \pm 7.41$ \\
\hline & Left oral. . & $1.26 \pm 0.07$ & $1.18 \pm 0.05$ & $93.65 \pm 7.41$ \\
\hline \multirow{4}{*}{36 hours } & Right anal. & $35.01 \pm 0.23$ & $3.42 \pm 0.16$ & $9.79 \pm 0.47$ \\
\hline & Left anal. . & $34.98 \pm 0.22$ & $3.36 \pm 0.16$ & $9.61 \pm 0.46$ \\
\hline & Right oral. . & $21.32 \pm 0.17$ & $2.56 \pm 0.12$ & $12.04 \pm 0.57$ \\
\hline & Left oral... & $21.35 \pm 0.17$ & $2.55 \pm 0.12$ & $11.94 \pm 0.57$ \\
\hline \multirow{4}{*}{48 hours } & Right anal. & $41.97 \pm 0.22$ & $3.26 \pm 0.15$ & $7.78 \pm 0.37$ \\
\hline & Left anal. & $41.95 \pm 0.21$ & $3.23 \pm 0.15$ & $7.71 \pm 0.37$ \\
\hline & Right oral. . & $28.51 \pm 0.17$ & $2.54 \pm 0.12$ & $8.92 \pm 0.42$ \\
\hline & Left oral............ & $28.47 \pm 0.16$ & $2.45 \pm 0.11$ & $8.62 \pm 0.41$ \\
\hline \multirow{4}{*}{72 hours } & Right anal. & $45.55 \pm 0.27$ & $4.15 \pm 0.19$ & $9.11 \neq 0.43$ \\
\hline & Left anal... & $45.56 \pm 0.27$ & $4.09 \pm 0.19$ & $8.99 \pm 0.43$ \\
\hline & Right oral.... & $34.94 \neq 0.19$ & $2.93 \pm 0.14$ & $8.41 \pm 0.40$ \\
\hline & Left oral........... & $34.98 \pm 0.18$ & $2.78 \pm 0.13$ & $7.97 \pm 0.38$ \\
\hline \multirow{4}{*}{96 hours } & Right anal. & $49.78 \pm 0.27$ & $4.10=0.19$ & $8.23 \pm 0.39$ \\
\hline & Left anal... & $49.76 \pm 0.27$ & $4.13 \pm 0.19$ & $8.31 \neq 0.39$ \\
\hline & Right oral. & $38.59 \pm 0.24$ & $3.61 \pm 0.17$ & $9.35 \pm 0.45$ \\
\hline & Left oral... & $38.59 \pm 0.22$ & $3.40 \pm 0.16$ & $8.83 \pm 0.42$ \\
\hline \multirow{4}{*}{120 hours } & Right anal. & $51.33 \pm 0.30$ & $4.51 \pm 0.21$ & $8.79 \pm 0.42$ \\
\hline & Left anal... & $51.32 \pm 0.30$ & $4.58 \pm 0.21$ & $8.93 \pm 0.42$ \\
\hline & Right oral. & $42.18 \pm 0.20$ & $3.08 \pm 0.14$ & $7.30 \pm 0.34$ \\
\hline & Left oral... & $42.16 \pm 0.20$ & $3.09 \pm 0.14$ & $7.33 \pm 0.35$ \\
\hline
\end{tabular}

In Experiment 6 alkali was added to the sea-water in the following concentrations:

Experiment 6. Plot 9. September 5, 1914

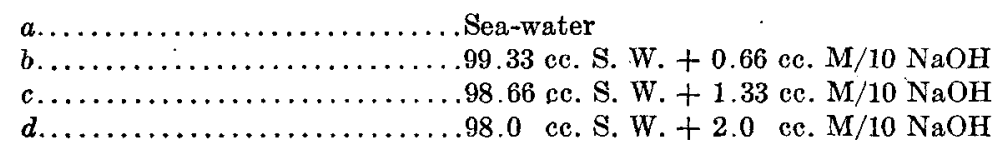

The growth-curve for the control culture resembles rather closely that of the general average for this period, except that 
TABLE 9

Constants, Experiment 6. Solution c

\begin{tabular}{|c|c|c|c|c|}
\hline & & MEAN & $\begin{array}{l}\text { STANDARD } \\
\text { DEVIATION }\end{array}$ & $\begin{array}{l}\text { COEFFICIENT OF } \\
\text { VARIATION }\end{array}$ \\
\hline \multirow{4}{*}{24 hours } & Right anal. & $3.21 \pm 0.12$ & $1.87 \pm 0.08$ & $58.49 \pm 3.62$ \\
\hline & Left anal. & $3.21 \pm 0.12$ & $1.87 \pm 0.08$ & $58.49 \pm 3.62$ \\
\hline & Right oral. & $3.37 \pm 0.12$ & $1.87 \pm 0.08$ & $56.09 \pm 3.41$ \\
\hline & Left oral. & $3.37 \pm 0.12$ & $1.87 \pm 0.08$ & $56.09 \pm 3.41$ \\
\hline \multirow{4}{*}{36 hours } & Right anal. & $35.15 \pm 0.27$ & $4.06 \pm 0.19$ & $11.57 \pm 0.55$ \\
\hline & Left anal... & $35.10 \pm 0.26$ & $3.97 \pm 0.18$ & $11.33 \pm 0.54$ \\
\hline & Right oral. & $23.98 \pm 0.22$ & $3.36 \pm 0.16$ & $14.03 \pm 0.68$ \\
\hline & Left oral... & $23.85 \pm 0.22$ & $3.34 \pm 0.15$ & $14.01 \pm 0.68$ \\
\hline \multirow{4}{*}{48 hours } & Right anal. & $40.63 \pm 0.28$ & $4.16 \pm 0.19$ & $10.25 \pm 0.49$ \\
\hline & Left anal. & $40.63 \pm 0.28$ & $4.16 \pm 0.19$ & $10.25 \pm 0.49$ \\
\hline & Right oral. & $29.15 \pm 0.25$ & $3.85 \pm 0.18$ & $13.20 \pm 0.64$ \\
\hline & Left oral... & $29.06 \pm 0.25$ & $3.79 \pm 0.18$ & $13.08 \pm 0.63$ \\
\hline \multirow{4}{*}{72 hours } & Right anal. & $43.21 \pm .0 .29$ & $4.32 \pm 0.20$ & $9.99 \pm 0.48$ \\
\hline & Left anal... & $43.11 \pm 0.25$ & $4.22 \pm 0.20$ & $9.79 \pm 0.47$ \\
\hline & Right oral. . & $33.32 \pm 0.23$ & $3.55 \pm 0.16$ & $10.67 \pm 0.51$ \\
\hline & Left oral... & $33.13 \pm 0.22$ & $3.33 \pm 0.15$ & $10.06 \pm 0.48$ \\
\hline \multirow{4}{*}{96 hours } & Right anal. & $45.13 \pm 0.30$ & $4.53 \pm 0.21$ & $10.05 \pm 0.48$ \\
\hline & Left anal..... & $45.01 \pm 0.30$ & $4.56 \pm 0.21$ & $10.14^{\prime} \pm 0.48$ \\
\hline & Right oral.... & $32.78 \pm 0.25$ & $3.78 \pm 0.18$ & $11.55 \pm 0.54$ \\
\hline & Left oral... & $32.96 \pm 0.25$ & $3.80 \pm 0.18$ & $11.53 \pm 0.55$ \\
\hline
\end{tabular}

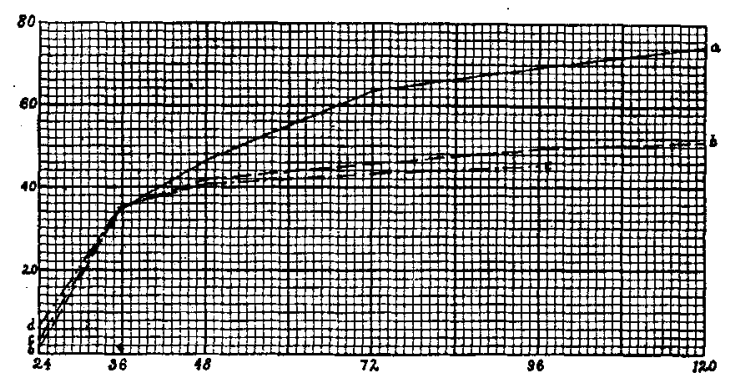

Plot 9

at 24 hours the measurements of the general average indicate the presence of small tri-radiate spicules, whereas in this solution no skeletal structures have appeared. In solution $b$ (fig. 
TABLE 10

Constants, Experiment 6 . Solution d

\begin{tabular}{|c|c|c|c|c|}
\hline & & MEAN & $\begin{array}{l}\text { STANDARD } \\
\text { DEVIATION }\end{array}$ & $\begin{array}{l}\text { COEFFICIENT OF } \\
\text { VARIATION }\end{array}$ \\
\hline \multirow{4}{*}{24 hours } & Right anal. & $6.20 \pm 0.27$ & $4.00=0.19$ & $64.67 \pm 4.18$ \\
\hline & Left anal. . & $6.20 \pm 0.27$ & $4.00 \pm 0.19$ & $64.67 \pm 4.18$ \\
\hline & Right oral. & $6.04 \pm 0.27$ & $4.07 \pm 0.19$ & $67.41 \pm 4.41$ \\
\hline & Left oral. & $6.04 \pm 0.27$ & $4.07 \pm 0.19$ & $67.41 \pm 4.41$ \\
\hline \multirow{4}{*}{36 hours } & (Right anal. & $35.23 \pm 0.28$ & $4.29 \pm 0.20$ & $12.20 \pm 0.56$ \\
\hline & Left anal. & $35.42 \pm 0.28$ & $4.26 \pm 0.20$ & $12.05 \pm 0.58$ \\
\hline & Right oral. & $28.05 \pm 0.23$ & $3.41 \pm 0.16$ & $12.17 \pm 0.58$ \\
\hline & Left oral .. & $28.03 \pm 0.22$ & $3.41 \pm 0.16$ & $12.14 \pm 0.58$ \\
\hline
\end{tabular}

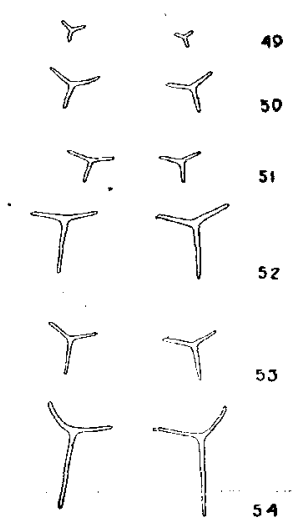

Figs. 49 to 70 . Experiment 6 . NaOH.

Fig. $49 \quad 6 a, 24$ hrs. Control.

Fig. $506 b$, figures 51 and $526 c$, figures 53 and $546 d, 24 \mathrm{hrs}$. Increased size in the solutions of greater alkalinity.

50), however, most of the specimens are more advanced and possess skeletons ranging from minute rounded centers which can be detected only by their bright shiny appearance, to distinct tri-radiate spicules. In solution $c$ (figs. "51 and 52) and $d$ (figs. 53 and 54), the tri-radiate character of the spicules is evident in nearly all, while in many of $d$ the posterior rays have begun to differentiate into body-rods.

At the age of 36 hours, the individuals of culture $a$ possessed skeletons of approximately the same size as those of the other 
cultures; all the averages were now so nearly equal that no conclusive evidence could be drawn as to the relative heights of the various growth-curves at this particular period (figs. 55 to 60 ). At the age of 48 hours, however, $a$ was decidedly larger than $b$ and $c$ (figs. 61 to 63 ) and an increased difference was evident
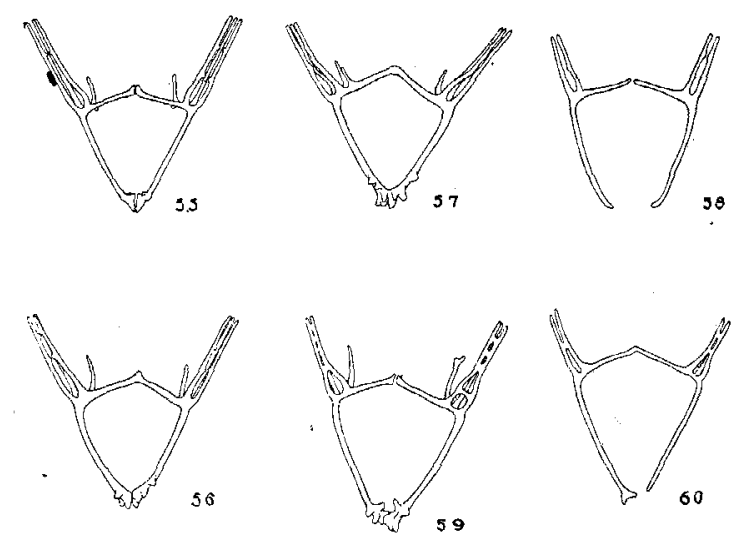

Ifig. $556 a, 36$ hrs. Control. Figure $566 b$, figures 57 and $586 c$, figures 59 and $606 d, 36 \mathrm{hrs}$. All of approximately the size. Variation increased and asymmetry gradually acquired in the stronger solutions.

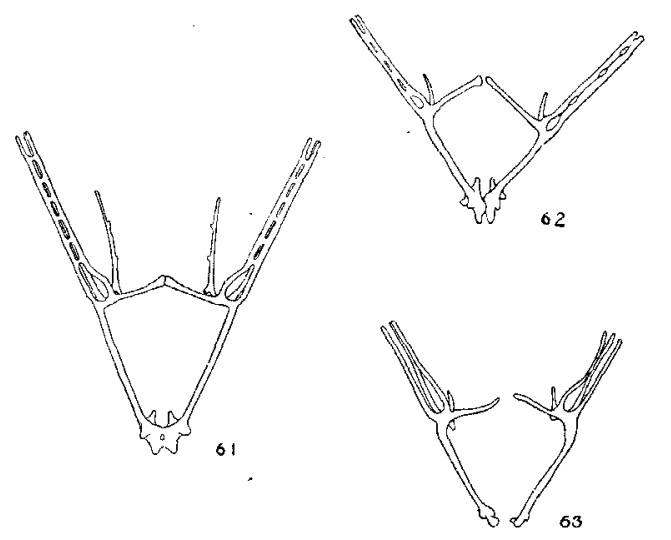

Fig. $616 a, 48 \mathrm{hrs}$. Control.

Fig. $626 b$, figure $636 c, 48 \mathrm{hrs}$. Greater inhibition of growth in the alkaline solutions. Retarded fusion of the various elements. Irregularity. 
at 72 (figs. 64 to 66 ) and 96 (figs. 67 to 69 ); $c$ did not develop past the 96 hour stage.

Although all the specimens were of approximately the same size at the age of 36 hours, an inhibition of development was
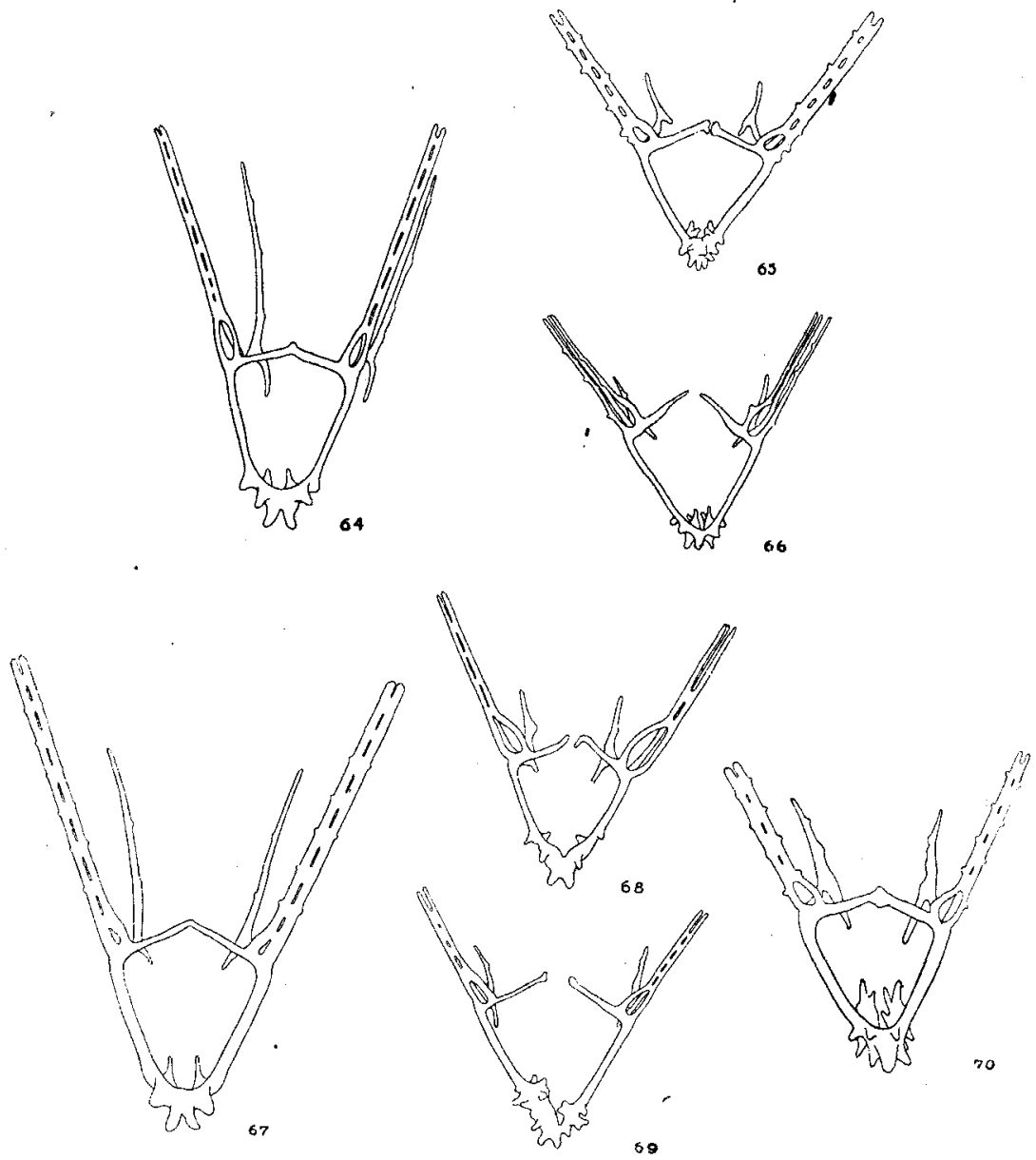

Fig. $646 a, 72$ hrs. Control.

Fig. $656 b$, figure $666 c, 72$ hrs.; figure $676 a$, Control; figure $686 b$, figure 69 $6 c, 96 \mathrm{hrs}$; f figure $706 b, 120 \mathrm{hrs}$. Same characters, becoming more pronounced at the later periods and in the stronger solutions. 
evident in the stronger solutions. Figure 55 represents a typical individual of the control cultures, and practically all the specimens were in a similar stage of development. The same may be said of solution $b$ (fig. 56). But in solution $c$, figures 57 and 58 represent two of the extreme variants and it may be seen that, although of approximately the same size, both larvae are in a less advanced stage than either of the above. This is true also of those in $d$ (figs. 59 and 60).

In the stronger solutions, moreover, there enters the element of irregularity of structure, apparent only in the minuter details. In the specimen represented by figure $62(b, 48$ hours), for instance, fusion of the transverse rods would probably not have occurred in the mid-line. In figure $63(c, 48$ hours), one body-rod is longer and heavier than the other, and the individual elements in the left anal arm are very slightly distorted. In figure 68 ( $b, 96$ hours), the transverse rods are unequally developed and that on the right side seems to have undergone a secondary elongation in order to meet the other.

This experiment was repeated a number of times and a slight variation was found in the exact time at which the control culture outgrew those in the alkaline solution. In one instance the specimens in solutions $b$ were still of larger size at 48 hours, but by 72 hours, the only apparent difference was the greater degree of symmetry of those of the control. In this set of solutions, too, there was less difference in size between the specimens of the control and those of the alkaline solutions at the late stages, - a condition which seemed to prevail in all the experiments of the early part of the following year, when the specimens in general were more viable, and those in the experimental solutions seemed able to live under more extreme conditions. On the other hand, in experiments when the controls themselves were less vigorous, the difference in size between them and the specimens in the treated solutions appeared more exaggerated in later stages, following an earlier appearance of the typical irregularities. For instance, figures 71, 72, 73 and 74 (Experiment 7) are drawn from the 24 hour stage of specimens from solutions corresponding to $a, b, c$ and $d$ of Experiment 6 . 
At this time, $a$ possessed small tri-radiate spicules and later formed skeletons which were normal in all but size, measuring only $3.7,41.56,53.22,62.37$ and 64.24 on the various days. The alkaline solutions showed at 24 hours a much greater excess of size over the controls than did the corresponding culture of Experiment 6, but the skeletons were irregular and in later stages became far more abnormal.

At this time the specimens in culture $a$ were apparently in a healthy condition, swimming about and their mouths and alimentary tracts undergoing periodic contractions. This also was true of those in solutions $b$ and $c$, and slightly less marked in $d$ and $e$. In $f$ the specimens were still swimming at the surface, but were less active, and in $g$ there was a much higher death-rate and many of the specimens were swimming lower in the dish.

The third experiment in Series II was made with $\mathrm{NaHCO}_{3}$.

Experiment 8. Plot 10. July 10, 1914

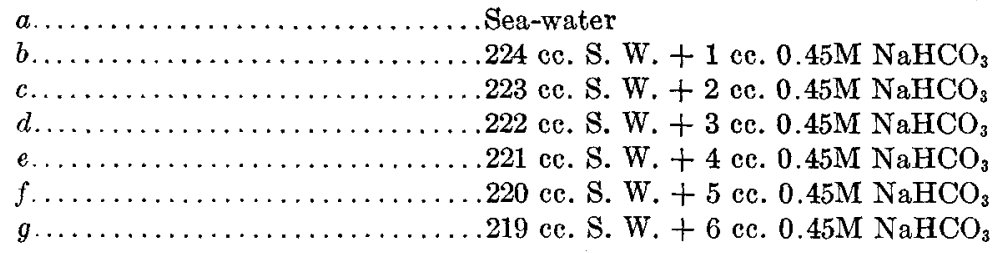

The corresponding growth measurements were:

\begin{tabular}{|c|c|c|c|c|c|c|c|}
\hline & 18 Ho URs & 24 HOURA & 48 Hours & 72 но URs & 84 Ho URs & 96 нouns & 120 HобRS \\
\hline$a$. & 14.10 & 44.83 & 70.07 & 92,01 & 49.73 & 44.37 & 40.31 \\
\hline$b$ & 20.23 & 46.81 & 70.84 & 90.92 & 68.13 & 61.91 & 56.24 \\
\hline$c$. & 25.19 & 48.20 & 72.13 & 89.95 & 75.24 & 69.10 & 62.11 \\
\hline$d$ & 29.92 & 50.92 & 71.46 & 88.88 & 79.14 & 73.92 & 66.45 \\
\hline$e$. & 34.87 & 49.85 & 69.72 & 87.10 & 81.97 & 76.65 & 71.04 \\
\hline$f \ldots$ & 32.01 & 47.20 & 68.21 & 84.89 & 85.83 & 79.85 & 74.92 \\
\hline$g \ldots \ldots$ & 28.14 & 44.13 & 66.10 & 81.17 & 84.01 & 81.97 & 78.15 \\
\hline
\end{tabular}

The control growth-curve resembles that of Experiment 2 in that it reaches an early maximum which is followed by resorption of the skeleton. Here, the period of greatest growth occurs still earlier, before the 72 hour stage, after which a 
rapid decrease in size takes place. As concerns rate of growth, the specimens in the experimental solutions behave similarly to those in the sea-water to which $\mathrm{NaOH}$ had been added. Solutions $b, c, d$ and $e$ produced during the first 18 hours an increasingly beneficial effect and $g$ surpassed $a$ by a smaller per-
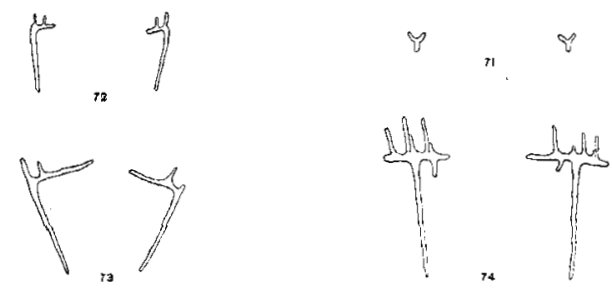

Figs. 71 to 74 . Experiment 7 .

Fig. $717 a, 24 \mathrm{hrs}$. Control.

Fig. $727 b$, figure $737 c$, figure $747 d, 24 \mathrm{hrs}$. Solutions same as in the previous experiments. In this series the characters were more pronounced and the irregularities very prominent at $24 \mathrm{hrs}$.

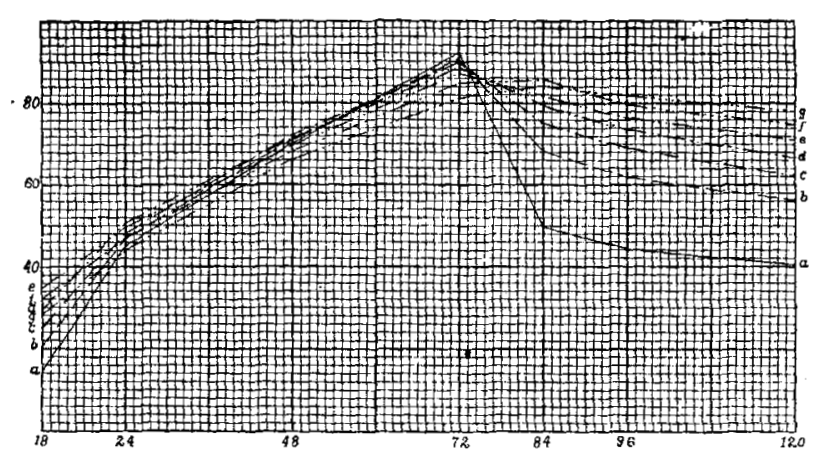

Plot 10

centage, indicating that the degree of alkalinity most conducive to growth at this period has been exceeded.

At 18 hours, then, the concentration of solution $e$ was optimum for growth; at 24 hours, that of $d$; at 48 hours, that of $c$; and at 72 , that of $a$, as is indicated by their positions on the growth-curves on the various days. Hence, although an increased alkalinity produced an accelerated initial development, 
there was a gradual shifting toward the bottom, of the growthcurves of those in higher concentrations of the hydroxyl, with the specimens of the control ultimately the largest.

The growth-curves of $f$ and $g$ reach their maxima 24 hours later than the others. In solutions of less alkalinity, skeletal resorption was more rapid and at the close of 120 hours the positions of all the cultures were the reverse of that indicated at the age of 72 hours.

Another experiment was made with $\mathrm{NaHCO}_{3}$ added in greater proportions in order to determine the effects of still higher concentrations of the acid salt. For this purpose the following solutions were employed:

Experiment 9. Plot 11. July 15, 1915

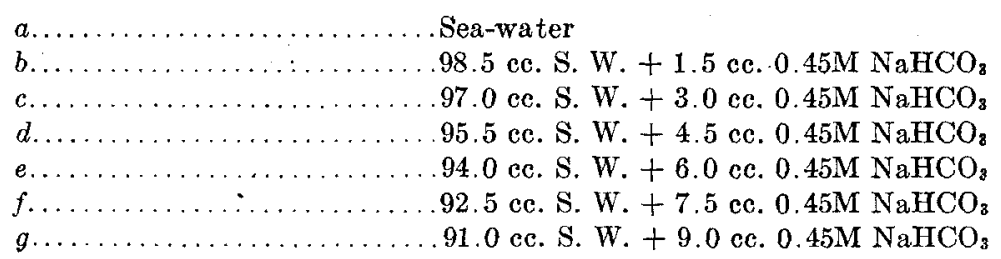

The corresponding measurements were:

\begin{tabular}{|c|c|c|c|c|c|}
\hline & 24 HOU RS & 48 ноบ Rs & 72 HOURS & 96 พOURS & 120 HоURS \\
\hline$a \ldots$ & $28: 84$ & 74.05 & 85.91 & 92.13 & 95.08 \\
\hline b... & 34.15 & 76.09 & 86.12 & 90.81 & 92.74 \\
\hline$c \ldots \ldots \ldots$ & 30.21 & 68.91 & 78.18 & 82.14 & 83.69 \\
\hline$d \ldots$ & 25.94 & 62.87 & 70.25 & 72.94 & 73.98 \\
\hline$e \ldots$. & 21.30 & 57.89 & 64.19 & 65.97 & 66.15 \\
\hline$f \ldots \ldots \ldots \ldots \ldots$ & 12.11 & 50.24 & 56.13 & 57.89 & 58.02 \\
\hline$g \ldots \ldots \ldots \ldots \ldots$ & 2.07 & 41.32 & 45.77 & 47.15 & \\
\hline
\end{tabular}

In this experiment also, there was shown the specific effect of alkalinity upon length of skeleton. Solution $b$, which was approximately equivalent to $8 e$, produced a similar modification of the rate of growth. In all the others, the concentrations of the hydroxyl were greater than in any of Experiment 8 ; $c$, however, caused an acceleration during the first day; in 
all the rest the specimens were smaller throughout the entire fericd.

In Experiment 10 still greater percentages of $\mathrm{NaHCO}_{3}$ were employed in order to obtain the limit of endurance at early stages. In Experiment 9 an inhibition of growth was plainly discernible in the stronger solutions, even during the early periods, but judging from the active movements of the specimens during the first 48 hours, it was evident that much stronger solutions could be employed.

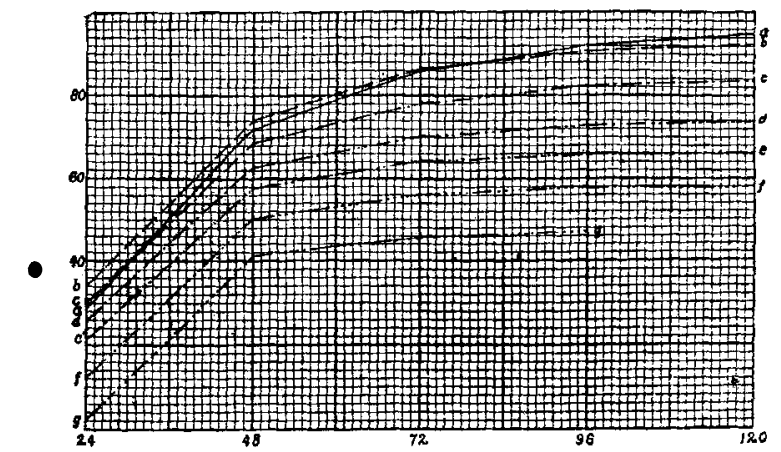

Plot 11

Experiment 10. July 15, 1915

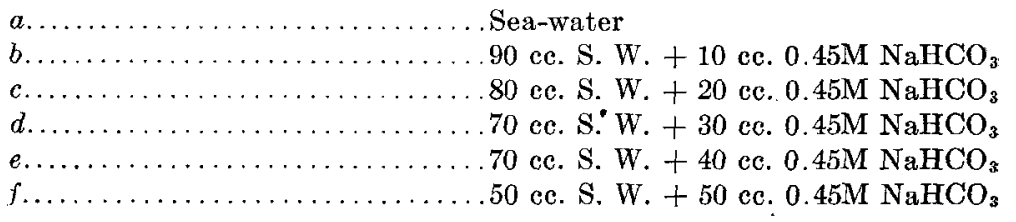

Figures 75 to 80 show specimens from the various solutions at the age of 24 hours. In $a$ (fig. 75) the three branches of the tri-radiate spicule have elongated into body-rod, transverse rod and dorso-ventral connective, and the rods of the anal arms are beginning to form. In $b$ (fig. 76) gastrulation has just taken place, producing individuals which appear abnormal only in lack of skeletons. This culture, however, contained on 
the following day a small percentage of individuals with skeletons represented by small heavy tri-radiate spicules The specimens in solution $c$ (fig. 77) were irregular and abnormal looking and were moving about slowly on the bottom of the dish. Gastrulation had begun, but had proceeded only a little
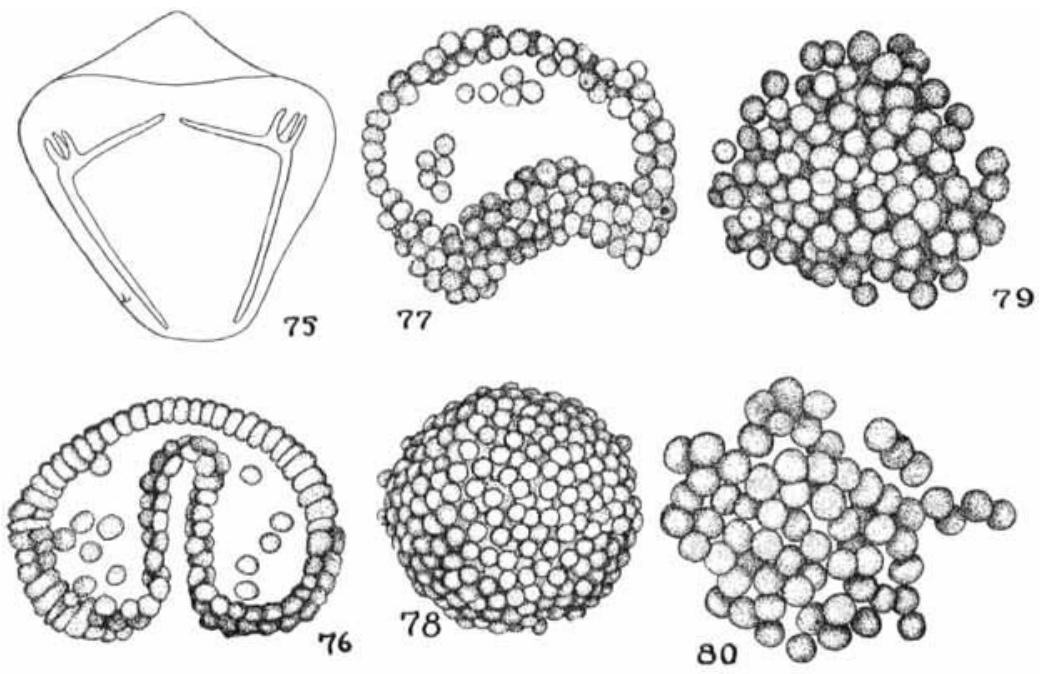

Figs. 75 to 80 . Experiment $10 . \mathrm{NaHCO}_{3}$.

Fig. $75 \quad 10 a, 24$ hrs. Control.

Fig. 76 10b, 24 hrs. Gastrulation. No skeletons. (Optical section.)

Fig. 77 10c, 24 hrs. Gastrulation just commenced. No further development. (Optical section.)

Fig. $7810 d, 24$ hrs. Blastula.

Fig. $7910 e, 24$ hrs. Morula-like mass of cells.

Fig. $8010 f, 24 \mathrm{hrs}$. Morula-like mass of cells in less advaneed stage of development.

way and the walls presented a rough and uneven appearance. In the other three solutions (figs. 78 to 80 ) all were dead, $d$ (fig. 78) after reaching the blastula stage, and $e$ and $f$, a late cleavage. In $e$ (fig. 79), the smaller cells indicate a slightly more advanced stage than in $f$ (fig. 80), but both have become irregular, morula-like masses. 
The effects upon the skeletons caused by subjection to the carbonate solutions were very different, in all respects except size, from those produced by the increased hydroxyl concentration. In the latter there was no appreciable tendency toward a thickening of the skeletal structures nor toward a reduction of parts, but in the carbonate solutions these were the most prominent and characteristic changes. Figure 81 represents one of the control specimens (Experiment 9), 48 hours old and figure 82, one from $c$ at the same age. All the structures are heavier, especially the rods of the oral arms and the body-
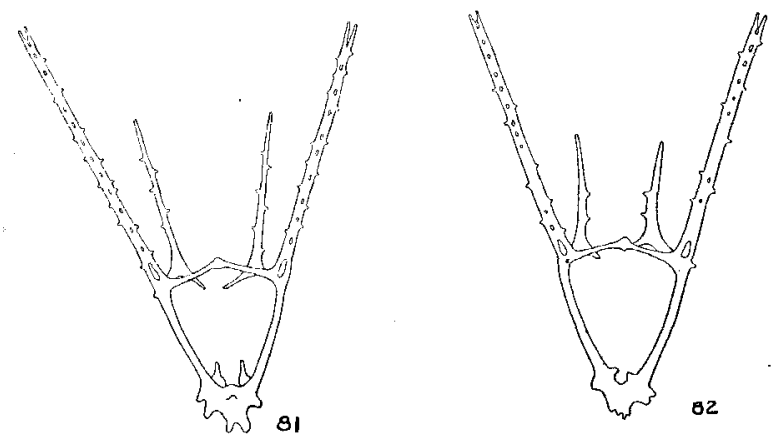

Figs. 81 to 87 Experiment $9 \mathrm{NaHCO}_{3}$.

Fig, $819 a, 48$ hrs. Control.

Fig. $829 c, 48 \mathrm{hrs}$. Structures heavier, especially oral arms and body-rods.

rods. There has been a precocious closing of the interspaces in the anal arms and the spines are reduced in number. A fusion of the skeletal elements often occurs early, accompanied by decided thickenings at the points of contact. In other instances, even at a late period, the individual elements remain distinct. The ventral body-branches are frequently present as thick, fused, club-shaped masses giving little or no indication of separate processes (fig. 83, $f, 72$ hours). At other times, especially in the stronger solutions, no ventral body-branches are present (fig. 84, $g, 48$ hours). Figures 85,86 , and 87 are taken from solution $f$ at the age of 72 hours, and depict the typical modifications. Figure 85 represents one nearly resembling the normal 
and is the most usual type. It is very much simplified in outline, thickened in every portion of the skeleton, with only slight traces remaining of the lattice-formation in the anal arms, and with a reduction in the number of spines and processes of the

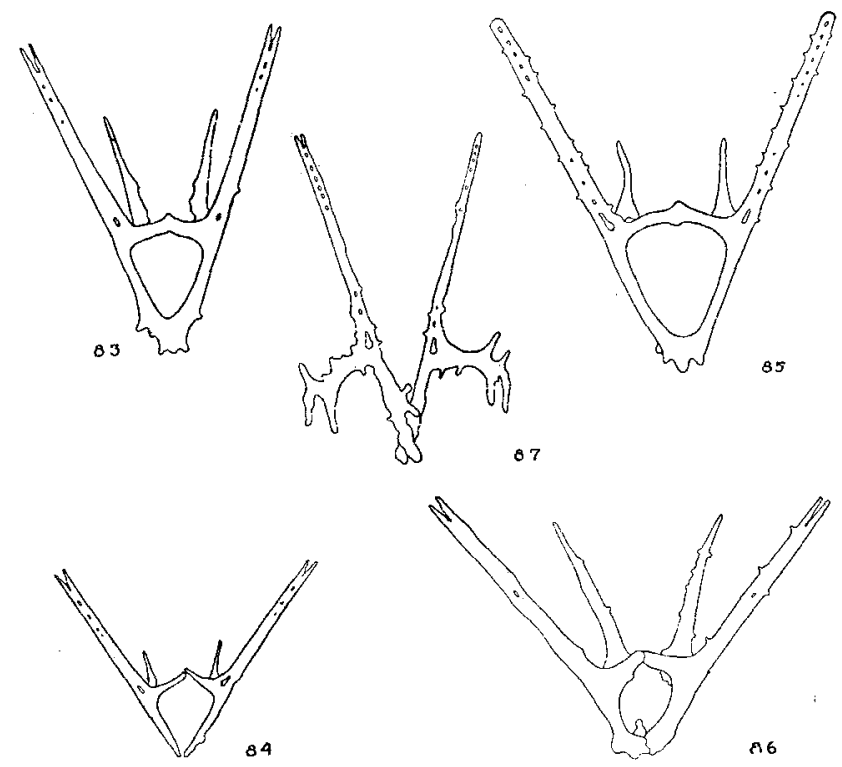

Fig. $839 f, 48 \mathrm{hrs}$. All the principal parts heavier. Precocious fusion of the arms. Lack of processes. Reduction in size.

Fig. $849 g, 48$ hrs. Same chracaters except that here the lateral connectives and the body-rods have not fused. Specimen very symmetrieal.

Fig. $859 f, 72$ hrs. Usual type. Skeleton thickened, simplified in structure. Slight traces of lattice-formation. Reduction in the number of spines and processes. Highly symmetrical.

Fig. $869 f, 72$ hrs. Skeleton heavier than in figure 85, the two halves unfused.

Fig. $879 f, 72$ hrs. Two portions of the skeleton unfused. Dorso-ventral connectives (?) turned laterally, with oral arms (?) turned posteriorwards.

body-rods, yet it shows no indication of lack of symmetry. The tendency toward irregularity of structure under the various other experimental conditions described above is entirely lacking here, and a comparison of the measurements taken of the two sides of the body in these cultures shows quite as little 
tendency toward variations in this respect as is shown in the control.

In the specimen illustrated by figure 87, the main part of the additional calcareous deposit occurred on the dorso-ventral connectives which were turned laterally instead of dorsally. The oral arms may be said to be directed posteriorly, or to be lacking entirely, and the dorsal body-branches to be very highly developed. A few individuals of this type were found, not only in this experiment in the stronger solutions, but also in similar cultures with individuals from different parents.

Experiment 11 deals with the effects of $\mathrm{Na}_{2} \mathrm{CO}_{3}$, which was employed because upon hydrolysis it gives hydroxyl ion concentration greater than that given by $\mathrm{NaHCO}_{3}$. The following solutions were used:

Experiment 11. Plot 12. July 9, 1915

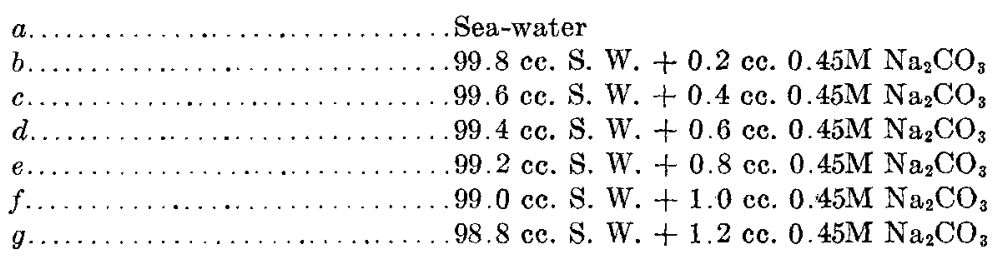

The following measurements were obtained:

\begin{tabular}{|c|c|c|c|c|c|c|}
\hline & 24 HO URS & 36 HotRs & 48 HOURS & 72 HOURS & 96 Hoणns & 120 HOCRS \\
\hline$a$. & 24.40 & 55.72 & 68.16 & 84.31 & 92.26 & 96.48 \\
\hline$b \ldots \ldots \ldots \ldots$ & 27.82 & 60.55 & 71.94 & 85.97 & 91.90 & 94.37 \\
\hline$c \ldots$ & 36.72 & 62.68 & 72.13 & 83.89 & 88.03 & 89.78 \\
\hline$d \ldots$ & 32.14 & 56.13 & 64.17 & 74.76 & 77.08 & 78.01 \\
\hline$e \ldots \ldots$ & 20.30 & 38.32 & 45.12 & 54.73 & 55.91 & 56.22 \\
\hline$f \ldots \ldots$ & 5.63 & 15.69 & 21.34 & 28.14 & & \\
\hline$g \ldots \ldots$ & & 0.06 & 2.85 & & & \\
\hline
\end{tabular}

The specimens of the control culture of this experiment greatly exceed in size those of the general average for the corresponding season. Here again, the effect of the increased alkalinity is shown in the growth-curves produced by the various solutions. The specimens in $b, c$ and $d$ are in advance of those in $a$ at the ages of 24 and 36 hours, but $b$ drops behind after 
48 hours and $c$ after 72 . By the 96 hour period, all are smaller than those in the control.

Frary and Nietz ('15) give a table of the hydrolysis of sodium carbonate in solutions at $25^{\circ} \mathrm{C}$, according to which $0.005 \mathrm{M} \mathrm{Na}_{2} \mathrm{CO}_{3}$ furnishes concentration of hydroxyl ions equivalent to a $0.00081 \mathrm{M} \mathrm{NaOH}$ solution. By interpolating in the table, the addition of 0.8 cc. $0.45 \mathrm{M} \mathrm{Na} \mathrm{NaO}_{3}$ (11e) to 100 cc. water would furnish approximately the same concentration of hydroxyl ions as addition of $0.66 \mathrm{cc} . \mathrm{M} / 10 \mathrm{NaOH}(6 b)$. These, being in distilled water, would not have the same values as when added to sea-water, but it seems significant that in the

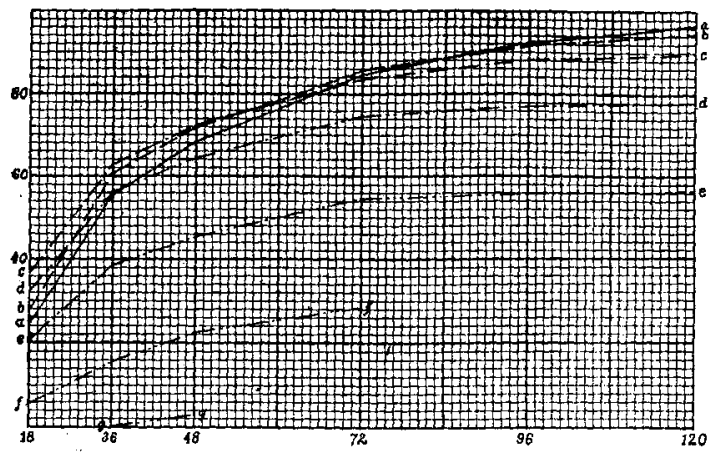

Plot 12

two experiments, these two solutions produce strikingly similar modifications of the growth-curves.

The modifications found in the $\mathrm{Na}_{2} \mathrm{CO}_{3}$ solutions were of very much the same type as in those of the $\mathrm{NaHCO}_{3}$, except that the changes were not apparent so early. In these solutions the lattice-formation was very evident, even more so than in the control cultures, and persisted until a later stage. Figures 88, 89 and 90 represent specimens from $a, c$ and $d$ at 48 hours; figures 91 and 92 , specimens from solution $e$; figures 93 and 94 , two from solutions $f$; figure 95 , one from $g$. In comparison with those of the same age in Experiment 9, it may be seen that the skeleton is heavier and the lattice-formation persists later. For instance, the specimens represented in figure 91 
(11e) and in figure $86(9 f)$ are of approximately the same size and both are 48 hours old. In figure 91, the arms are somewhat heavier, but the individual rods comprising them have not fused so greatly and the spines, though reduced in

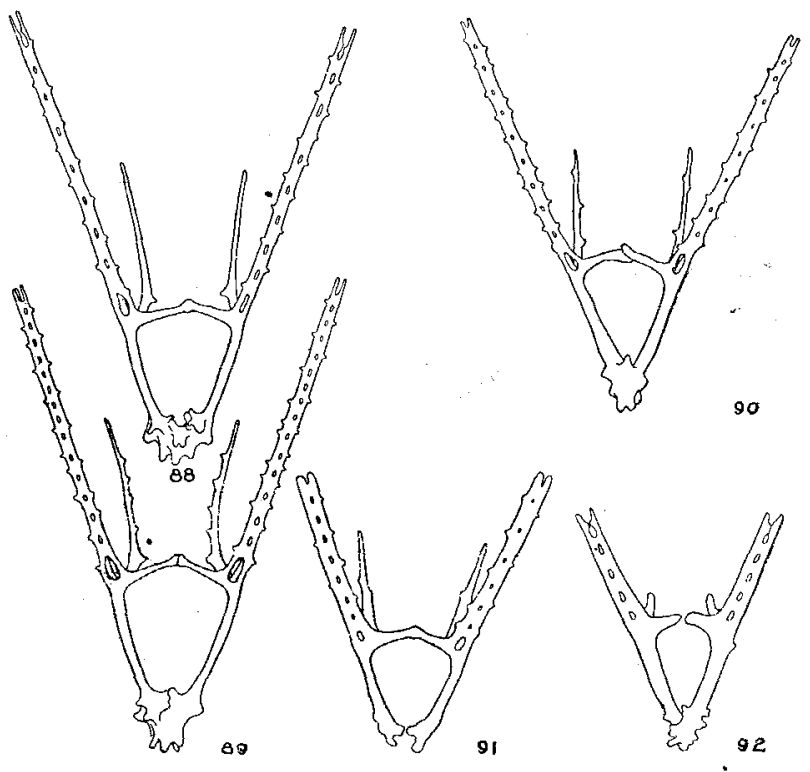

Figs. 88 and 89. Experiment 11. $\mathrm{Na}_{2} \mathrm{CO}_{3}$.

Fig. $8811 a, 48$ hrs. Control.

Fig. $8911 c$, 48 hrs. All the structures slightly heavier, but in a less advanced stage of fusion than the control, indicating influence of increased $\mathrm{Na}$ content.

Fig. $9011 d, 48 \mathrm{hrs}$. Same as above, but influence of Na less pronounced. Resembles more closely those in the $\mathrm{NaHCO}_{3}$ solutions. Symmetry.

Figs. 91 and $9211 e$, figures 93 and $9411 f$, figure $9511 g, 48 \mathrm{hrs}$. Increasing inhibition of growth. Gradual loss of evidence of Na influence and acquirement of $\mathrm{CO}_{3}$ characters; such as, heavy symmetrical skeletons, with highly fused arm-rods.

number, are still present. In other specimens of the same solution (fig. 92) spines are lacking. Figures 93 and 94 represent two of the extreme variants of solution $f$. In 92 , spines have disappeared, but the rods have not fused to a greater extent than in the control culture (fig. 88). Figures 96 and 97 are 
from solutions $e$ and $f$ at 72 hours and 98 from $e$ at 96 hours. The same features characterize these specimens except that here fusion of the individual rods in the arms has been almost complete.

All these figures are characterized by a high degree of symmetry. This quality is evident, even in those cultures where skeletons have been reduced to the extent indicated in figure 95. In the presence of an excess of carbonate, then, in contrast

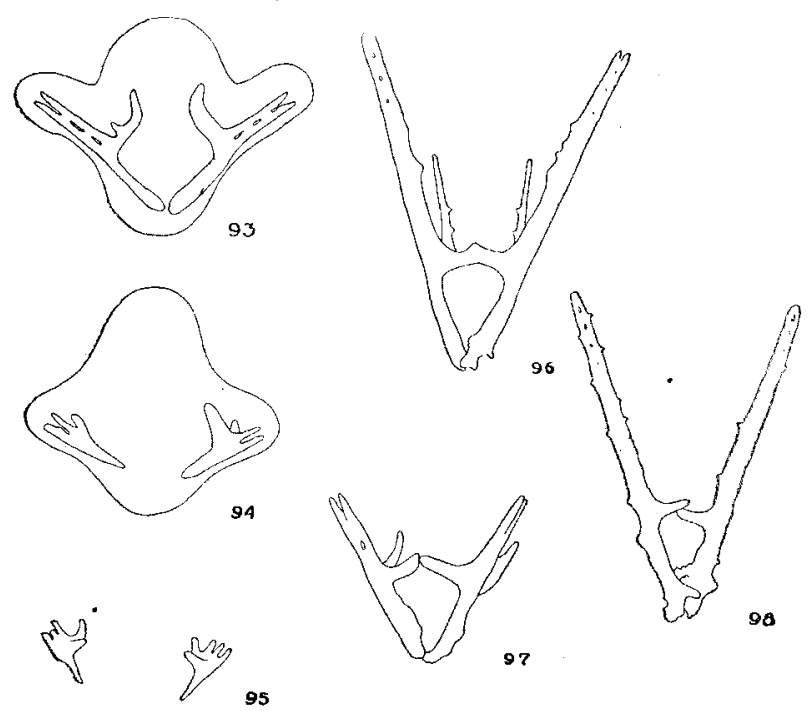

Fig. $9611 e$, figure $9711 f, 72 \mathrm{hrs}$; figure $9811 e, 96 \mathrm{hrs}$. Complete disappearance of $\mathrm{Na}$ characters and appearance of $\mathrm{CO}_{3}$.

to the other experimentally altered media, asymmetry is not correlated with inhibition of growth.

The most pronounced effect of addition of acids or alkalies to the medium in which the Arbacia eggs are developing is the decrease or increase in rate of growth. As shown in the accompanying experiments, acid invariably produces a retarding and inhibiting effect; alkalies, in small amounts, cause an acceleration of growth in early stages, resulting in increased size. In later stages, however, these same cultures show a retardation of the rate of development so that ultimately they lag 
behind the control. In solutions more highly alkaline, the excessively precocious development results in irregularity and asymmetry and finally in complete inhibition.

Loeb ('98) in an early paper called attention to this effect of acids and alkalies upon the rate of development. He stated, however, that alkalinity produced a scarcely noticeable effect in the first few hours, and a gradually increasing one on the second and third days. "So gewinnt man den Eindruck," he says, "als ob die Hydroxylionen des Alkali eine langsame aber stetige Zunahme in der Geschwindigkeit der Entwicklung bedingen." But after three or more days, disintegration of the larvae set in and he could no longer determine any difference between those in alkaline solutions and those in sea-water. He suggested that by this time the alkali was largely neutralized by the acids produced in the process of growth.

Later, in his "Artificial Parthenogenesis and Fertilization" he takes an entirely different position. He says that "he has since vainly attempted to show that the rate of development of the sea-urchin egg can be increased with the increase of the concentration of hydroxylions in the sea-water. This leads him to believe that these eggs develop best in a solution in which the concentration of hydroxylions equals that of the seawater; and that while it is possible to delay their development by a lowering of this concentration, no acceleration can be produced if the $\mathrm{C}_{\text {он }}$ in the sea-water is raised."

That some effect upon rate of development is produced in the earliest stages, was demonstrated by the following experiment in which solutions of the same constitution as in Experiment 11 were employed. Each culture was divided into two portions and at one hour after insemination one of each was killed.quickly by the introduction of a few drops of fixing fluid, and a count taken of the number in the one- and two-cell stages. After 18 hours, the percentage of those possessing skeletons was taken in the other portions. 
Experiment 12. July 9, 1915

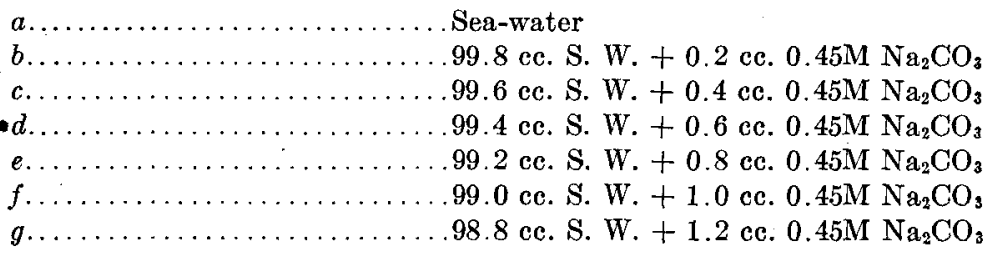

The following data were obtained:

Time after insemination

\begin{tabular}{|c|c|c|c|c|}
\hline & $\begin{array}{c}1 \text { HOVR } \\
\text { PER CENT IN I-CELL }\end{array}$ & $\begin{array}{c}1 \text { HOUR } \\
\text { PER CEN'T IN 2-GETL } \\
.\end{array}$ & $\begin{array}{c}18 \text { HOURS } \\
\text { PER CENT } \\
\text { WITH SKELETONS }\end{array}$ & $\begin{array}{l}18 \text { HóURs } \\
\text { SIZE OF } \\
\text { BKELETONS }\end{array}$ \\
\hline$\ldots \ldots \ldots \ldots$ & 14.0 & 86.0 & 53.2 & $0-2$ \\
\hline$b$. & 8.0 & 92.0 & 82.1 & $0-4$ \\
\hline$c \ldots \ldots$ & 4.7 & 95.3 & 100.0 & $2-4$ \\
\hline$d \ldots \ldots$ & 3.3 & 96.7 & 84.6 & $0-3$ \\
\hline e......... & 13.5 & 86.2 & 58.3 & $0-2$ \\
\hline$f \ldots \ldots \ldots$ & 18.8 & 81.2 & 0.0 & \\
\hline$g$. & 23.9 & 76.1 & 0.0 & \\
\hline
\end{tabular}

A somewhat similar experiment was performed with $\mathrm{NaOH}$ and the effects at a still earlier'stage noted.

Experiment 13. July 29, 1915

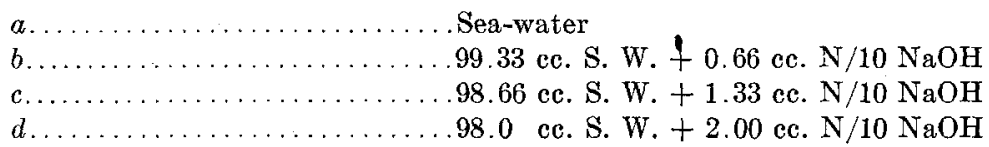

The following data were obtained:

Time after insemination

\begin{tabular}{|c|c|c|c|c|}
\hline & $\begin{array}{l}2.5 \text { MINUTES. } \\
\text { PER CENT WITH } \\
\text { FERT. MEMBR. }\end{array}$ & $\begin{array}{l}1 \text { HOUR, } 20 \text { MTNUTES. } \\
\text { PER CENT IN } 2 \text { CELL }\end{array}$ & $\begin{array}{l}1 \text { HOUR, } 20 \text { MINUTES. } \\
\text { PER CENT IN 4-CELL }\end{array}$ & $\begin{array}{l}1 \text { HOUR, } 20 \text { MIN UTES } \\
\text { PER CENT IN } 8 \text {-CELLL }\end{array}$ \\
\hline $\begin{array}{l}a \ldots \ldots \ldots \ldots \\
b \ldots \ldots \ldots \ldots \ldots \\
c \ldots \ldots \ldots \ldots \\
d \ldots \ldots \ldots \ldots\end{array}$ & $\begin{array}{l}42.6 \\
63.7 \\
81.5 \\
27.1\end{array}$ & $\begin{array}{r}4.1 \\
0.8 \\
98.8\end{array}$ & $\begin{array}{r}95.9 \\
99.2 \\
97.4 \\
1.2\end{array}$ & 2.6 \\
\hline
\end{tabular}


These experiments indicate that the effect of alkalinity upon rate of development is immediate, and decreases in intensity during later stages. This later retardation of growth may be a secondary effect produced as a result of the embryo's having exceeded its optimum rate. In other words, there may be a point beyond which rapid development ceases to be beneficial to the organism and hence precocious growth may be conducive to later inhibition. This fact is shown more clearly in the case of the very alkaline solutions where overrapid development leads at once to irregularity of structure and inhibition of growth.

The specific effect of the hydroxyl may be said, then, to be an acceleration of the rate of growth in the early stages, succeeded by inhibition. In very weak solutions both these effects are slight, but the greater the alkalinity, the more rapid the acceleration and the more marked the succeeding asymmetry and inhibition. The effect, of course, is not exactly proportional to the amount of alkali added; since, in the higher concentrations, some magnesium and calcium hydroxides must precipitate out.

In the experiments given above (Experiment 6), the limit of endurance was reached when 2 cc. $\mathrm{N} / 10 \mathrm{NaOH}$ were added to 98 cc. sea-water, but in an experiment of the following year, the limit was found to be $3 \mathrm{cc} . \mathrm{N} / 10 \mathrm{NaOH}$ to $97 \mathrm{cc}$. sea-water. The concentration productive of maximum rate of growth at each stage was found to be about the same, the only material difference in the reaction of the embryos to the changed environment being a greater degree of resistance, characterized by a more retarded setting in of the typical abnormalities.

In the carbonate solutions we also have acceleration of development by the alkalinity produced as a result of the hydrolysis of $\mathrm{NaHCO}_{3}$ and $\mathrm{Na}_{2} \mathrm{CO}_{3}$, both salts of a strong base with a weak acid. In the bicarbonate solutions, as we should expect, acceleration is slighter and in stronger solutions is overshadowed by the specific effect of the carbonate. In the sodium carbonate, especially in the weaker solutions, a third element enters, the specific effect of the sodium, a fact which may be 
explained by the presence of a greater proportion of the sodium in the molecule added.

The specific effect of the carbonate must be considered to increase the bulk of the skeleton, combined with a strong tendency toward regularity and symmetry. This latter quality is so pronounced that it inhibits completely the opposite tendency produced by alkalinity, that is, irregularity and asymmetry. In the stronger carbonate solutions, even in the earliest stages, the retarding and inhibiting effect of the carbonates suppresses completely any tendency for increased rate of development that would otherwise occur.

In the preceding set of experiments, the one in which $\mathrm{Na}_{2} \mathrm{CO}_{3}$ was employed gave some indication of the specific effect of the sodium; but since this is an alkaline salt, the modifications produced by its cation were complicated or completely masked by the greater effects of the anion and of the increasing alkalinity.

In the following series, neutral salts were employed, $\mathrm{NaCl}$, in a series of iso- and hyper-tonic solutions.

Experiment 14. Plot 13. July 16, 1915

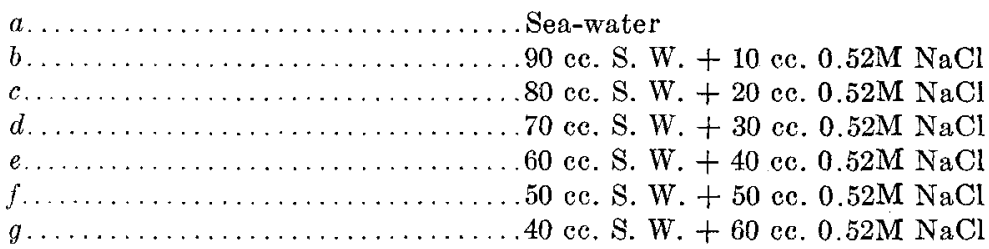

The corresponding measurements were:

\begin{tabular}{|c|c|c|c|c|c|}
\hline & 24 Ho URs & 48 HOURs & 72 HOURS & 96 Hours & 120 ночนร \\
\hline$a$. & 22.83 & 69.91 & 84,10 & 88.10 & 89.13 \\
\hline$b=$ & 25.74 & 72.94 & 88.17 & 92.01 & 93.31 \\
\hline$c \ldots \ldots$ & 20.91 & 68.24 & 85.23 & 89.90 & 91.65 \\
\hline$d \ldots$ & 16.27 & 61.70 & 81.82 & 87.61 & 89.94 \\
\hline$e \ldots \ldots$ & 9.90 & 54.19 & 78.43 & 84.73 & \\
\hline$f \ldots \ldots \ldots$ & 3.21 & 41.97 & 68,34 & & \\
\hline$g \ldots \ldots \ldots \ldots \ldots$ & & 26.62 & 28.73 & & \\
\hline
\end{tabular}


The individuals in this experiment were considerably larger than those of the general average for the corresponding period of that summer. The specimens in solution $b$ exceeded in size those in $a$ during the entire period; those in $c$ and $d$, although smaller at the age of 24 hours, grew more rapidly and when 120 hours old, were larger than those of the control. Those in $e$ underwent an initial inhibition, but at the age of 96 hours they attained almost as great a size as those in $a$; but failed to live through the following day.

If the production of the specific effects of the carbonate is due to the fact that molecular $\mathrm{MgCO}_{3}$ and $\mathrm{CaCO}_{3}$ are pushed

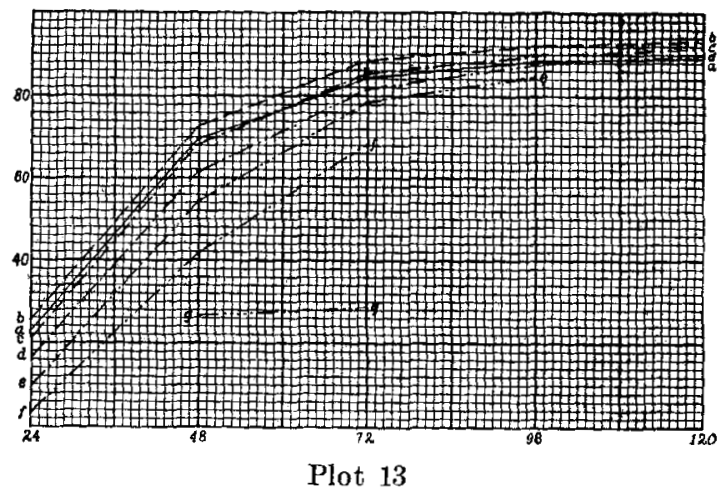

nearer to the point of saturation and rendered more available for the use of the embryo, then dilution of sea-water with $\mathrm{NaCl}$ should produce modifications consistent with a less saturated condition; and this is what actually occurs. The skeletons are more slender than in the normal individual, and are characterized by conspicuous perforations in the lattice-work of the arms, and thorn-like spines and processes of the body-rods.

Since the alkalinity of the sea-water is reduced by dilution with neutral $\mathrm{NaCl}$ solution, we might expect a reduction in size; but, on the contrary, an increase above the normal occursin Experiment 14 even at 30 per cent dilution. But it is significant that in solutions $c$ and $d$, in which the specimens ultimately attained a greater maximum growth than did those in $a$, an inhibition was produced during the first day, the time 
when alkalinity is most essential for growth. The increased growth might be accounted for by the fact that in the solutions in which sea-water is diluted with iso-tonic $\mathrm{NaCl}$, a reduction of the salts of $\mathrm{Mg}$ and $\mathrm{Ca}$, two elements antagonistic to $\mathrm{Na}$, occurs, and the stimulating effect of the $\mathrm{Na}$ might be expressed in the increased size. This is the most striking modification produced by the $\mathrm{NaCl}$ solutions.
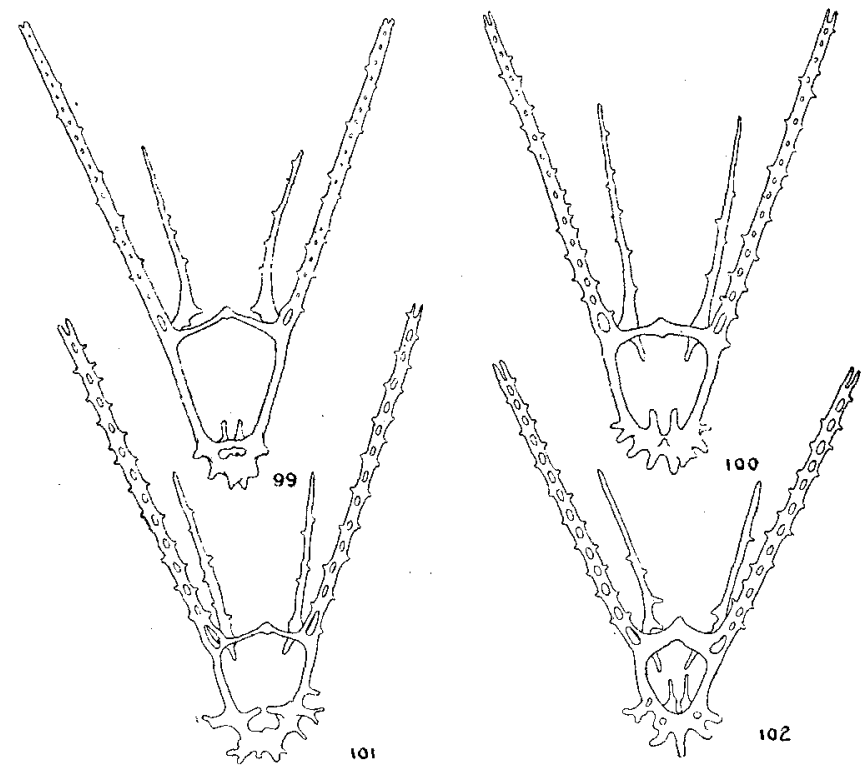

Figs. 99 to 102 Experiment 14. $\mathrm{NaCl}, 0.52 \mathrm{M}$.

Fig. 99 14a, 72 hrs. Control.

Fig. $10014 c$, figure $10114 e$, figure $10214 f, 72$ hrs. Characterized by reduced body-size and proportionately longer arms. The processes while not reduced in number are longer and more thorn-like. The lattice-work in the arms is more open, although the connecting branches are about as numerous as in the normal.

Another effect of increased $\mathrm{NaCl}$ content is the decreased length of the body-rods. Figures 99 to 102 illustrate all these modifications. Figure 99 represents the control at 72 hours; figure 100, one from culture $c$; figure 101, from $e$ and 102 from $f$. In the solutions of gradually increased $\mathrm{NaCl}$ content, we may observe the longer and more spiked character of the typical proc- 
esses, the greater prominence of the ventral and dorsal branches, the less highly fused condition of the arm-rods, and the reduced size of the body-rods. Were this last named characteristic not correlated with a proportionate increase of arm-length, we might ascribe it merely to the dilution of some necessary constituents of the sea-water, but since total size is not reduced, we must conclude that it is a specific effect of the Na.

In these solutions, then we have four specific effects:

a) A condition as to thickness of skeleton, diametrically opposed to that which occurs in the carbonate solutions, and expressed in slender, perforated skeletons with conspicuous processes.

b) A growth exceeding that of the normal in the solutions of slighter dilution, caused possibly by decrease in the proportion of $\mathrm{Mg}$ and $\mathrm{Ca}$. This excessive growth occurs during the later periods.

c) A tendency toward inhibition of growth during the first day of the experiment, the time when decrease of alkalinity produces its most marked effect.

d) Decreased length of body-rods.

Experiment 15 was made with solutions of $0.56 \mathrm{M} \mathrm{NaCl}$. Three solutions were employed, a control, $a$; $b$, of 10 cc. $0.56 \mathrm{M}$ $\mathrm{NaCl}$ to 90 cc. sea-water; and $c$, of 20 cc. $0.56 \mathrm{M} \mathrm{NaCl}$ to 80 cc. sea-water.

The corresponding measurements were:

Experiment 15. Plot 14. July 21, 1915

\begin{tabular}{|c|c|c|c|c|c|}
\hline & 24 нобRS & 48 HOURS & 72 HOURS & 96 ноURs & 120 HOURS \\
\hline$a$ & 4.27 & 56.82 & 73.13 & 83.12 & 86.01 \\
\hline$b$. & 7.53 & 55.76 & 72.19 & 82.09 & 86.96 \\
\hline$c \ldots \ldots$ & 3.25 & 52.84 & 71.37 & 81.80 & 83.77 \\
\hline
\end{tabular}


In Experiment 16, $\mathrm{NaCl}$ was used in solutions of still higher concentrations:-

Experiment 16. Plot 15. July 21, 1915
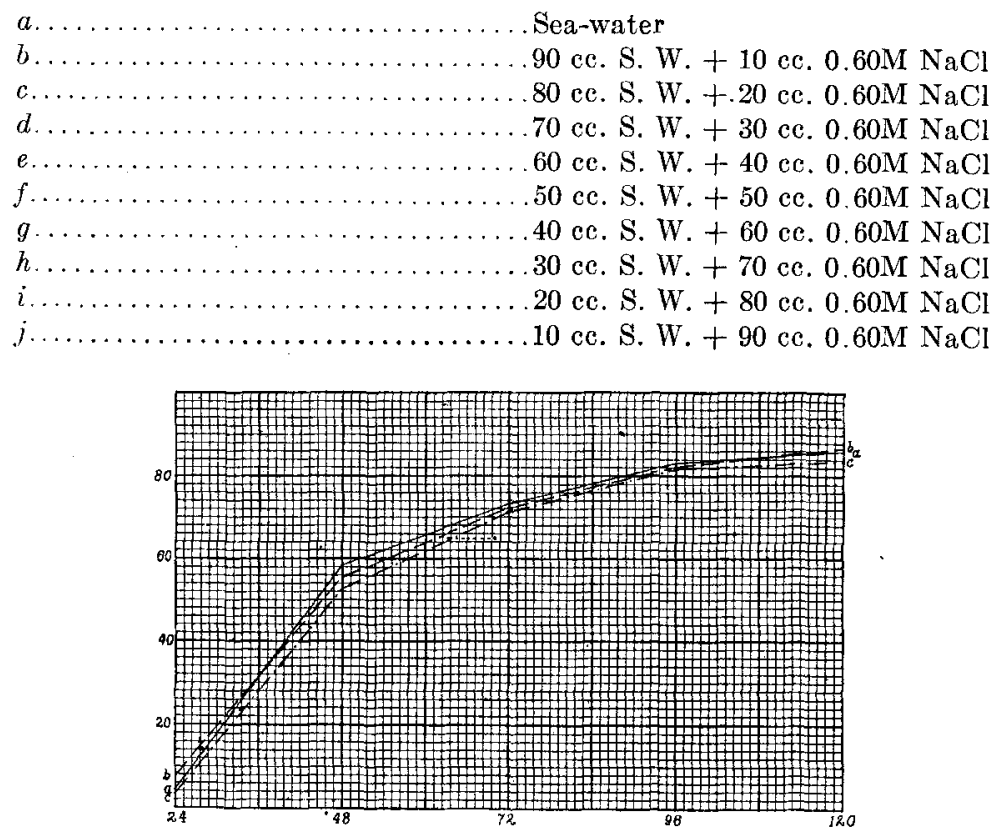

Plot 14

The corresponding measurements were:

\begin{tabular}{|c|c|c|c|c|c|}
\hline & 24 HOURs & 48 HO URs & 72 HOURS & 96 Hours & 120 Hо URs \\
\hline $\begin{array}{l}a \ldots \ldots \ldots \ldots \\
b \ldots \ldots \ldots \ldots \\
c \ldots \ldots \ldots \\
d \ldots \ldots \ldots \ldots \\
e \ldots \ldots \ldots \ldots \\
f \ldots \ldots \ldots \ldots \\
g \ldots \ldots \ldots \ldots \\
h \ldots \ldots \ldots \ldots \ldots \\
i \ldots \ldots \ldots \ldots \ldots \\
j \ldots \ldots \ldots \ldots \ldots\end{array}$ & $\begin{array}{l}2.93 \\
2.12 \\
1.39 \\
0.74 \\
0.30 \\
0.03\end{array}$ & $\begin{array}{l}67.01 \\
63.92 \\
59.83 \\
53.77 \\
46.62 \\
38.86 \\
30.24 \\
19.94\end{array}$ & $\begin{array}{l}79.23 \\
75.75 \\
71.46 \\
64.28 \\
53.93 \\
43.76 \\
31.42 \\
20.02\end{array}$ & $\begin{array}{l}54.67 \\
46.13 \\
37.81 \\
36.23 \\
35.19 \\
39.78\end{array}$ & $\begin{array}{l}48.72 \\
41.34 \\
36.18 \\
34.21 \\
33.88\end{array}$ \\
\hline
\end{tabular}

The growth-curve for the control of Experiment 15 agrees very closely during the first three days with that of the gen- 
eral average for the second period of the summer of 1915 (Plot $1 \mathrm{C}$ ) but during the following two days it increased more rapidly and exceeded the total average for the first part of the summer (Plot 1 B). In Experiment 16, the control showed the retarded growth characteristic of most of the experiments made later in the season. At the age of 24 hours, it was only 2.93 or 19.1 per cent of that of the total average of all the experiments (Plot $1 \mathrm{D}$ ) and 33.3 per cent of that of the general average for the later period of that season (Plot $1 \mathrm{C}$ ). Growth was very rapid the following two days, and at the age of 72 hours it reached the highest point in its curve. This maximum is considerably lower than that in any of the other experiments

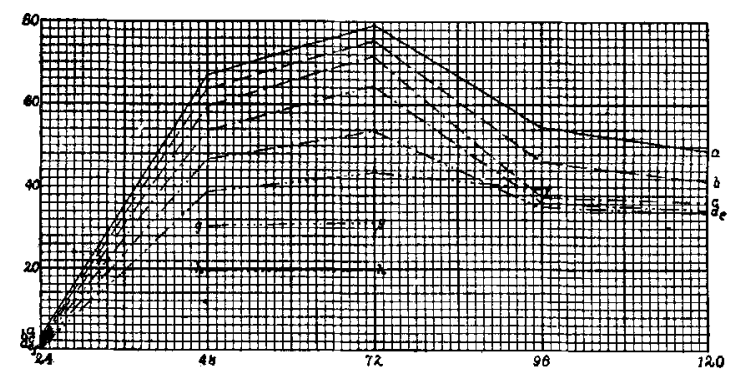

Plot 15

in which it has been attained precociously, and again demonstrates that rate of development is not necessarily correlated with size.

Figures 103 and 104 represent cultures $g$ and $h$ at 72 hours and show, together with the reduction in size obtained in hypertonic solutions, the typical abnormalities characteristic of $\mathrm{NaCl}$ solutions: comparatively long and slender oral arms, and short body-rods which at the posterior region are perforated by many openings. In cultures $i$ and $j$, the eggs underwent cleavage but the larvae did not form skeletons.

The following measurements were taken from a similar set of cultures in which development was more gradual; the maximum was not reached until the 120 th hour. 
Experiment 1\%. Plot 16. July 24,1915

\begin{tabular}{|c|c|c|c|c|c|}
\hline & 24 HOURs & 48 Hoणkf & 72 Hо URS & 96 HoURS & 120 HO URS \\
\hline$a \ldots \ldots \ldots \ldots$ & 6.23 & 58.31 & 73.17 & 79.17 & 82.14 \\
\hline$b \ldots \ldots \ldots \ldots$ & 4.39 & 55.44 & 70.14 & 76.11 & 78.76 \\
\hline$c \ldots \ldots \ldots \ldots$ & 2.67 & 52.92 & 67.27 & 72.75 & 75.33 \\
\hline$d \ldots \ldots \ldots \ldots$ & 1.34 & 50.13 & 63.78 & 69.19 & 71.42 \\
\hline$e \ldots \ldots \ldots$ & 0.28 & 47.28 & 60.59 & 65.80 & 66.23 \\
\hline$f \ldots \ldots \ldots$ & & 43.96 & 48.83 & 50.20 & \\
\hline & & 33.08 & & & \\
\hline$h \ldots \ldots \ldots \ldots$ & & 12.82 & & & \\
\hline
\end{tabular}

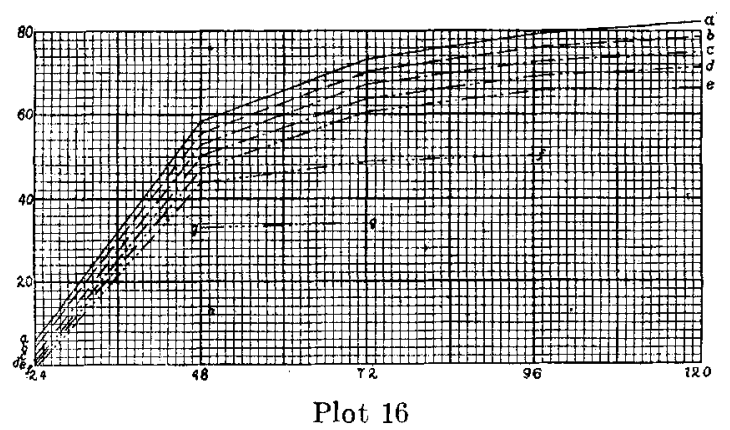

The control developed rather slowly at first, but ultimately reached a size slightly greater than that of the general average. In the experimental solutions, decrease of size was very slight and the various cultures maintained very nearly the same proportions throughout. "In $e, 40$ cc. $0.60 \mathrm{M} \mathrm{NaCl}$ to 60 cc. seawater, the solution of greatest $\mathrm{NaCl}$ percentage in which the specimens survived 120 hours, the average size was 80.6 per cent of that of the control. Except $h$, all the cultures in which the specimens formed skeletons lived the same length of time as did those in the previous experiment.

In the experiments in which the solutions of $\mathrm{NaCl}$ employed were of higher concentrations, an important variation in the medium was produced,-an increase of osmotic pressure. In solution $15 b$, the physical effect of the hypertonic solution was about sufficient to neutralize the physiological effect of the sodium, but in solutions of increased density, such as, $15 c$, $16 b, 17 b$, etcetera, the inhibiting effect of the hypertonic solution outweighed the stimulating effect of the sodium. 
Fischel ('09) used solutions of $\mathrm{N} / 2 \mathrm{NaCl}$ with sea-water in various proportions in his experiments with Echinus microtuberculatus, Strongylocentrotus lividus and Arbacia pustulosa. Only in the case of the first named did he obtain an acceleration in the rate of development; in the other two the opposite effect was produced. When he subjected the eggs of Arbacia, one half hour after fertilization, for the brief period of 30 minutes to a mixture of 87.5 parts sea-water to 12.25 parts $0.50 \mathrm{M} \mathrm{NaCl}$, they developed much more slowly than did the control. The inhibition was not especially apparent during cleavage, but appeared after blastula formation. He figures two which had been treated in this manner and at 3 days 20 hours and 4 days 18 hours respectively, they had not passed beyond a late gastrula stage. If this reaction of Arbacia pustulosa is typical, either some fundamental difference must exist between punctulata and the species employed by Fischel, or profound disturbances were set up when the embryos were transferred from the experimental solution back to sea-water. The slight change of osmotic pressure involved seems hardly adequate to account for the extensive injury incurred. Rather it seems necessary to conclude that the two species respond in a fundamentally different way to similar experimental conditions.

In order to ascertain the effects of $\mathrm{NaCl}$ in hypertonic solution without dilution of the other constituents of sea-water, the salt was added directly to the sea-water in the following amounts:-

Experiments 18 and 19

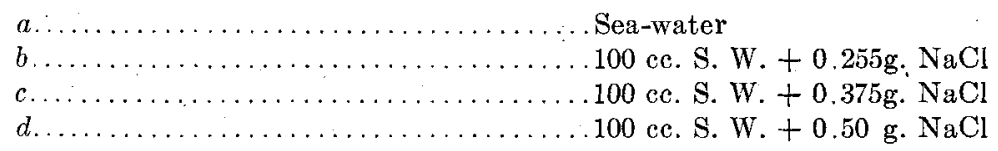

From these two experiments with similar solutions, the following results were obtained:

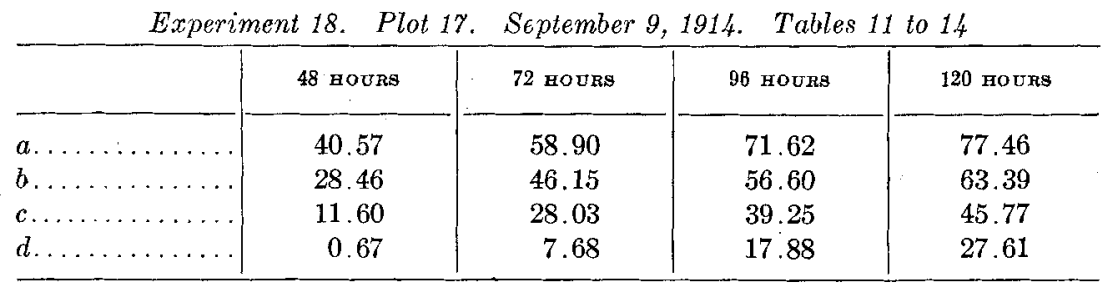


Experiment 19. Plot 18. September 9, 1914

\begin{tabular}{|c|c|c|c|c|}
\hline & 48 но URS & 72 но URs & 96 HOURS & 120 HоURЯ \\
\hline $\begin{array}{l}a \ldots \ldots \ldots \ldots \ldots \ldots \\
b \ldots \ldots \ldots \ldots \ldots \ldots \\
{ }_{1} \ldots \ldots \ldots \ldots \ldots \ldots \\
a \ldots \ldots \ldots \ldots \ldots \ldots\end{array}$ & $\begin{array}{r}30.22 \\
2.70\end{array}$ & $\begin{array}{l}45.46 \\
27.42 \\
11.80\end{array}$ & $\begin{array}{r}59.43 \\
40.26 \\
27.77 \\
7.91\end{array}$ & $\begin{array}{l}67.55 \\
45.85 \\
31.45\end{array}$ \\
\hline
\end{tabular}

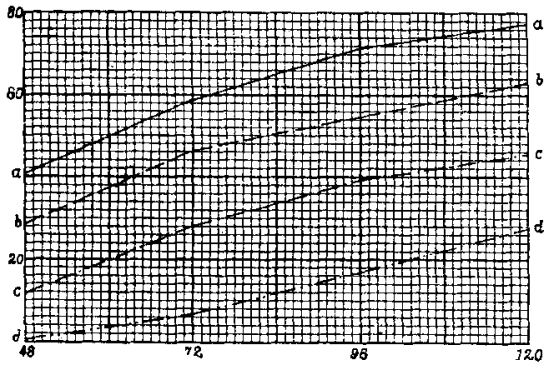

Plot.17

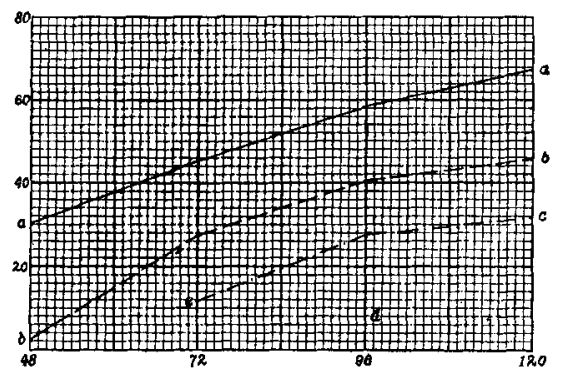

Plot 18

'These two experiments were performed very late in the summer of 1914, and, as may be seen, even the controls developed so slowly that they did not possess skeletons at the age of 24 hours. In Experiment 18, however, rate of growth was fairly rapid the following day and at the age of 48 hours the specimens were 10.5 per cent smaller than the average for that period.

In these cultures we find some of the modifications typical of hypertonic solutions and some of those specific to $\mathrm{NaCl}$. Figures 105 to 116 constitute a series of drawings from the various cultures of Experiment 18. In solutions of pure sea-water 
concentrated by evaporation there is, as we have seen, a tendency toward increase in the number of spines and other accessory processes. This also is typical for $\mathrm{NaCl}$ solutions, in which these processes assume slender, spike-like forms. Under both variations of the medium, asymmetry, appears in the stronger solutions. The main point of difference between the effects of these two changes of the medium is that in the pure, concentrated sea-water, fusion of the arm-rods occurs rather

TABLE 11

Constants, Experiment 18. Solution a (control)

\begin{tabular}{|c|c|c|c|c|}
\hline & & MEAN & $\begin{array}{l}\text { STANDARD } \\
\text { DEVIATION }\end{array}$ & $\begin{array}{l}\text { COEFFICIENT OF } \\
\text { VARIATION }\end{array}$ \\
\hline \multirow{4}{*}{48 hours } & Right anal. & $40.57 \pm 0.20$ & $2.96 \pm 0.14$ & $7.31 \pm 0.35$ \\
\hline & Left anal..... & $40.51 \pm 0.19$ & $2.93 \pm 0.13$ & $7.24 \pm 0.34$ \\
\hline & Right oral... & $30.71 \pm 0.09$ & $1.40 \pm 0.06$ & $4.56 \pm 0.21$ \\
\hline & Left oral........... & $30.74 \pm 0.09$ & $1.40=0.06$ & $4.56 \pm 0.21$ \\
\hline \multirow{4}{*}{72 hours } & Right anal. & $58.90 \pm 0.20$ & $3.09 \pm 0.14$ & $5.25 \pm 0.25$ \\
\hline & Left anal... & $58.90 \pm 0.20$ & $3.08 \pm 0.14$ & $5.23 \pm 0.25$ \\
\hline & Right oral. & $41.89 \pm 0.18$ & $2.71 \pm 0.12$ & $6.49 \pm 0.30$ \\
\hline & Left oral. . & $41.90 \pm 0.18$ & $2.70 \pm 0.12$ & $6.46 \pm 0.30$ \\
\hline \multirow{4}{*}{96 hours } & Right anal. & $71.62 \pm 0.25$ & $3.76 \pm 0.17$ & $5.25 \pm 0.25$ \\
\hline & Left anal ..... & $71.45 \pm 0.26$ & $3.86 \pm 0.18$ & $5.40 \pm 0.25$ \\
\hline & Right oral.... & $47.10 \pm 0.18$ & $2.75 \pm 0.13$ & $5.84 \pm 0.27$ \\
\hline & Left oral....... & $47.15 \pm 0.18$ & $2.77 \pm 0.13$ & $5.88 \pm 0.28$ \\
\hline \multirow{4}{*}{120 hours } & Right anal. & $77.46 \pm 0.29$ & $4.36 \pm 0.20$ & $5.64 \pm 0.26$ \\
\hline & Left anal... & $77.40 \pm 0.28$ & $4.16 \pm 0.19$ & $5.38 \pm 0.25$ \\
\hline & Right oral... & $51.67 \pm 0.20$ & $3.06 \pm 0.14$ & $5.93 \pm 0.28$ \\
\hline & Left oral... & $51.63 \pm 0.21$ & $3.12=0.14$ & $6.05 \pm 0.29$ \\
\hline
\end{tabular}

early, whereas in the $\mathrm{NaCl}$ solutions, a retardation of the process is evident.

The specimens in the cultures made hypertonic by the addition of $\mathrm{NaCl}$ show the modifications common to the two methods discussed above,- that is, prominent processes and slight irregularities of structure. In respect to fusion of the arm-rods, they agree more closely with the specimens in the solutions in which sea-water was diluted with iso-tonic $\mathrm{NaCl}$, in that a retardation of this process takes place. It is evident, then, that 
TABLE 12 Constants, Experiment 18 . Solution b

\begin{tabular}{|c|c|c|c|c|}
\hline & & MEAN & $\begin{array}{l}\text { STANDARD } \\
\text { DEVIATION }\end{array}$ & $\begin{array}{l}\text { COEFFTCIENT OF } \\
\text { CO RRELATION }\end{array}$ \\
\hline \multirow{4}{*}{48 hours } & Right anal. & $28.46 \pm 0.23$ & $3.46 \pm 0.16$ & $12.15 \pm 0.58$ \\
\hline & Left anal. . & $28.46 \pm 0.23$ & $3.46 \pm 0.16$ & $12.15 \pm 0.58$ \\
\hline & Right oral. & $28.58 \pm 0.23$ & $3.52 \pm 0.16$ & $12.34 \pm 0.59$ \\
\hline & Left oral. . & $28.58 \pm 0.23$ & $3.52 \pm 0.16$ & $12.34 \pm 0.59$ \\
\hline \multirow{4}{*}{72 hours } & Right anal. & $46.15 \pm 0.25$ & $3.80 \pm 0.18$ & $8.25 \pm 0.39$ \\
\hline & Left anal... & $46.03 \pm 0.25$ & $3.74 \pm 0.17$ & $8.13 \pm 0.38$ \\
\hline & Right oral. & $35.47 \pm 0.17$ & $2.55 \pm 0.12$ & $7.20 \pm 0.34$ \\
\hline & Left oral... & $35.08 \pm 0.16$ & $2.51 \pm 0.12$ & $7.17 \pm 0.34$ \\
\hline \multirow{4}{*}{96 hours } & Right anal. & $56.60 \pm 0.29$ & $4.34 \pm 0.20$ & $7.68 \pm 0.36$ \\
\hline & Left anal.. & $56.64=0.29$ & $4.37=0.20$ & $7.71 \pm 0.37$ \\
\hline & Right oral. . & $38.23 \pm 0.20$ & $2.97 \pm 0.14$ & $7.79 \pm 0.37$ \\
\hline & Left oral. . . & $38.21 \pm 0.20$ & $2.97 \pm 0.14$ & $7.79 \pm 0.37$ \\
\hline \multirow{4}{*}{120 hours } & Right anal. . & $63.39 \pm 0.35$ & $5.30 \pm 0.25$ & $8.37 \pm 0.40$ \\
\hline & Left anal. . & $63.42 \pm 0.35$ & $5.29 \pm 0.25$ & $8.35 \pm 0.40$ \\
\hline & Right oral. & $39.34 \pm 0.21$ & $3.26 \pm 0.15$ & $8.28 \pm 0.39$ \\
\hline & Left oral... & $39.34 \pm 0.23$ & $3.45 \pm 0.16$ & $8.78 \pm 0.42$ \\
\hline
\end{tabular}

TABLE 13.

Constants, Experiment 18. Solution c

\begin{tabular}{|c|c|c|c|c|}
\hline & & MEAN & $\begin{array}{l}\text { ETANDARD } \\
\text { DEVIATION }\end{array}$ & $\begin{array}{c}\text { COEFFICIENT OF } \\
\text { VARIATION }\end{array}$ \\
\hline \multirow{4}{*}{48 hours } & (Right anal. & $11.60 \pm 0.24$ & $3.66 \pm 0.17$ & $31.55 \neq 1.64$ \\
\hline & Left anal.. & $11.60 \neq 0.24$ & $3.66 \pm 0.17$ & $31.55=1.64$ \\
\hline & Right oral. & $11.96 \pm 0.23$ & $3.45 \pm 0.16$ & $28.86 \pm 1.48$ \\
\hline & Left oral. . & $11.96 \pm 0.23$ & $3.45 \pm 0.16$ & $28.86=1.48$ \\
\hline \multirow{4}{*}{72 hours } & Right anal. & $28.03 \pm 0.28$ & $4.17 \pm 0.19$ & $14.90 \pm 0.72$ \\
\hline & Left anal... & $27.89 \pm 0.26$ & $3.97 \neq 0.18$ & $14.25 \pm 0.69$ \\
\hline & Right oral. & $20.23 \pm 0.14$ & $2.13 \pm 0.10$ & $7.05 \pm 0.33$ \\
\hline & Left oral. & $20.32 \pm 0.15$ & $2.24=0.10$ & $7.40 \pm 0.35$ \\
\hline \multirow{4}{*}{96 hours } & Right anal... & $39.25 \pm 0.36$ & $5.37 \pm 0.25$ & $13.69 \pm 0.66$ \\
\hline & Left anal... & $39.37 \pm 0.36$ & $5.40 \pm 0.25$ & $13.72 \pm 0.66$ \\
\hline & Right oral... & $29.44 \pm 0.23$ & $3.47 \pm 0.16$ & $11.79 \pm 0.57$ \\
\hline & Left oral... & $31.50 \pm 0.18$ & $2.78 \pm 0.13$ & $8.83 \pm 0.42$ \\
\hline \multirow{4}{*}{120 hours } & Right anal. . & $45.77 \pm 0.42$ & $6.34 \pm 0.30$ & $13.86 \pm 0.66$ \\
\hline & Left anal... & $45.83 \pm 0.42$ & $6.23 \pm 0.29$ & $13.60 \pm 0.66$ \\
\hline & Right oral. & $33.10 \pm 0.22$ & $3.30 \pm 0.15$ & $9.99 \pm 0.53$ \\
\hline & Left oral... & $33.02 \pm 0.30$ & $4.50 \pm 0.21$ & $13.63 \pm 0.66$ \\
\hline
\end{tabular}


TABI E 14

Constants, Experiment 18. Solution d

\begin{tabular}{|c|c|c|c|c|}
\hline & & MEAN & $\begin{array}{l}\text { STAFDARD } \\
\text { DEVIATION }\end{array}$ & $\begin{array}{l}\text { COEFFICIENT } \\
\text { OF CORRELATION }\end{array}$ \\
\hline \multirow{4}{*}{48 hours } & Right anal. & $0.67 \pm 0.08$ & $1.20 \pm 0.06$ & $193.45 \pm 26.78$ \\
\hline & Left anal. & $0.76 \pm 0.09$ & $1.42 \pm 0.06$ & $187.11 \pm 25.24$ \\
\hline & Right oral. & $0.67 \pm 0.08$ & $1.29 \pm 0.06$ & $193.45=26.78$ \\
\hline & Left oral........... & $6.76 \pm 0.09$ & $1.42 \pm 0.06$ & $187.11=25.24$ \\
\hline \multirow{4}{*}{72 hours } & Right anal. & $7.68 \pm 0.35$ & $5.24 \pm 0.25$ & $68.33 \pm$ \\
\hline & Left anal. . & $7.74 \pm 0.33$ & $3.91 \pm 0.23$ & $63.51 \pm 4.02$ \\
\hline & Right oral. & $7.68 \pm 0.35$ & $5.24 \pm 0.25$ & $68.33 \pm$ \\
\hline & Left oral... & $7.74 \pm 0.33$ & $3.91 \pm 0.23$ & $63.51 \pm$ \\
\hline \multirow{4}{*}{96 hours } & Right anal. & $17.88 \pm 0.45$ & $6.80 \pm 0.32$ & $38.05=t$ \\
\hline & Left anal. & $17.88 \pm 0.45$ & $6.80 \pm 0.32$ & $38.05 \pm$ \\
\hline & Right oral. & $17.88 \pm 0.44$ & $6.66 \pm 0.31$ & $37.28 \pm$ \\
\hline & Left oral... & $17.88 \pm 0.44$ & $6.68 \pm 0.31$ & $37.28 \pm$ \\
\hline \multirow{4}{*}{120 hours } & Right anal. & $27.61 \pm 0.42$ & $6.33 \pm 0.30$ & $22.94 \pm$ \\
\hline & Left anal. & $27.85 \pm 0.45$ & $6.74 \pm 0.32$ & $24.20 \pm 1.22$ \\
\hline & Right oral. & $18.38 \pm 0.35$ & $5.25 \pm 0.25$ & $28.56 \pm 1.44$ \\
\hline & Left oral... & $18.28 \pm 0.38$ & $5.67 \pm 0.27$ & $31.05 \pm 1.11$ \\
\hline \multicolumn{5}{|c|}{ TABLE 15} \\
\hline & & $M F A N$ & $\begin{array}{l}\text { GTANDARD } \\
\text { DEYIATION }\end{array}$ & $\begin{array}{l}\text { CORPFICIENT } \\
\text { OF VARIATION }\end{array}$ \\
\hline \multirow{4}{*}{48 hours } & Right anal. & $30.22 \pm 0.15$ & $2.35 \neq 0.11$ & $7.78 \pm 0.37$ \\
\hline & Left anal. : & $30.22 \pm 0.15$ & $2.35 \pm 0.11$ & $7.78 \pm 0.37$ \\
\hline & Right oral. & $30.20 \pm 0.15$ & $2.33 \pm 0.11$ & $7.72 \pm 0.37$ \\
\hline & Left oral... & $30.20 \pm 0.15$ & $2.33 \pm 0.11$ & $7.72 \pm 0.37$ \\
\hline & Right anal. & $45.46 \pm 0.17$ & $2.53 \pm 0.12$ & $5.56 \pm 0.26$ \\
\hline & Left anal. & $45.43 \pm 0.16$ & $2.50 \pm 0.11$ & $5.51 \pm 0.26$ \\
\hline & Right oral. & $32.03 \pm 0.10$ & $1.60 \pm 0.07$ & $5.00 \pm 0.23$ \\
\hline & Left oral. . & $32.03 \pm 0.10$ & $1.59 \pm 0.07$ & $4.97 \pm 0.23$ \\
\hline \multirow{4}{*}{96 hours } & Right anal. & $59.43 \pm 0.20$ & $3.04 \pm 0.14$ & $5.11 \pm 0.24$ \\
\hline & Left anal... & $59.47 \pm 0.21$ & $3.11 \pm 0.14$ & $5.23 \pm 0.24$ \\
\hline & Right oral. & $41.35 \pm 0.19$ & $2.93 \pm 0.13$ & $7.09 \pm 0.34$ \\
\hline & Left oral... & $41.41 \pm 0.19$ & $2.95 \pm 0.14$ & $7.13 \pm 0.34$ \\
\hline \multirow{4}{*}{120 hours } & (Right anal. & $67.55 \pm 0.21$ & $3.16 \pm 0.15$ & $4.69 \pm 0.22$ \\
\hline & Left anal. & $67.45 \pm 0.21$ & $3.16 \pm 0.15$ & $4.68 \pm 0.22$ \\
\hline & Right oral. & $45.38 \pm 0.19$ & $2.89 \pm 0.13$ & $6.38 \pm 0.30$ \\
\hline & Left oral... & $45.41 \pm 0.19$ & $2.81 \pm 0.13$ & $6.20 \pm 0.29$ \\
\hline
\end{tabular}


TARLE 16

Constants, Experiment 19. Solution b

\begin{tabular}{|c|c|c|c|c|}
\hline & & MEAN & $\begin{array}{l}\text { STANDARD } \\
\text { DEVIATION }\end{array}$ & $\begin{array}{l}\text { COEFFICIENT } \\
\text { OF VARIATION }\end{array}$ \\
\hline \multirow{4}{*}{48 hours } & Right anal. & $2.70 \pm 0.11$ & $1.70 \pm 0.08$ & $62.96 \pm 4.02$ \\
\hline & Left anal. & $2.70 \pm 0.11$ & $1.70 \pm 0.08$ & $62.96 \pm 4.02$ \\
\hline & Right oral. & $2.83 \pm 0.11$ & $1.69 \pm 0.08$ & $59.76 \pm 3.73$ \\
\hline & Left oral. & $2.83 \pm 0.11$ & $1.69 \pm 0.08$ & $59.76 \pm 3.73$ \\
\hline \multirow{4}{*}{72 hours } & Right anal. & $27.42 \pm 0.24$ & $3.68 \pm 0.17$ & $13.42 \pm 0.65$ \\
\hline & Left anal. . & $27.42 \pm 0.24$ & $3.68 \pm 0.17$ & $13.42 \pm 0.65$ \\
\hline & Right oral. & $23.26 \pm 0.08$ & $1.27 \pm 0.06$ & $5.49 \pm 0.26$ \\
\hline & Left oral.. & $23.21 \pm 0.09$ & $1.33 \pm 0.06$ & $5.75 \pm 0.27$ \\
\hline \multirow{4}{*}{96 hours } & Right anal. & $40.26 \pm 0.27$ & $4.02 \pm 0.19$ & $10.00 \pm 0.48$ \\
\hline & Left anal. . & $40.32 \pm \cdot 0.26$ & $3.92 \pm 0.18$ & $9.74 \pm 0.46$ \\
\hline & Right oral. & $35.00 \pm 0.16$ & $2.51 \pm 0.12$ & $7.19 \pm 0.33$ \\
\hline & Left oral... & $35.06 \pm 0.17$ & $2.56 \pm 0.12$ & $7.32 \pm 0.34$ \\
\hline \multirow{4}{*}{120 hours } & Right anal. . & $45.85 \pm 0.25$ & $3.74 \pm 0.17$ & $8.17 \pm 0.38$ \\
\hline & Left anal.... & $45.78 \pm 0.25$ & $3.75 \pm 0.17$ & $8.19 \pm 0.39$ \\
\hline & Right oral... & $38.53 \pm 0.23$ & $3.43 \pm 0.16$ & $8.91 \pm 0.42$ \\
\hline & Left oral... & $38.61 \pm 0.23$ & $3.41 \pm 0.16$ & $8.84 \pm 0.42$ \\
\hline
\end{tabular}

TABLE 17

Constants, Experiment 19. Solution c

\begin{tabular}{|c|c|c|c|c|}
\hline & & MEAN & $\begin{array}{l}\text { STANDARD } \\
\text { DEVIATION }\end{array}$ & $\begin{array}{l}\text { COEFFICIENT } \\
\text { OF VARIATION }\end{array}$ \\
\hline \multirow{4}{*}{72 hours } & SRight anal. & $11.80 \pm 0.51$ & $7.62 \pm 0.36$ & $64.64 \pm 4.17$ \\
\hline & Left anal.. & $11.80 \pm 0.5 \mathrm{i}$ & $7.62 \pm 0.36$ & $64.64 \pm 4.17$ \\
\hline & Right oral. & $11.84 \pm 0.50$ & $7.46 \pm 0.35$ & $63.07 \pm 4.03$ \\
\hline & Left oral. & $11.84 \pm 0.50$ & $7.46 \pm 0.35$ & $63.07 \pm 4.03$ \\
\hline \multirow{4}{*}{96 hours } & Right anal. & $27.77 \pm 0.29$ & $4.30 \pm 0.20$ & $15.49 \pm 0.75$ \\
\hline & Left anal... & $27.77 \pm 0.29^{\circ}$ & $4.30 \pm 0.20$ & $15.49 \pm 0.75$ \\
\hline & Right oral. & $27.89 \pm 0.29$ & $4.37 \pm 0.20$ & $15.67 \pm 0.76$ \\
\hline & Left oral... & $27.89 \pm 0.29$ & $4.37 \pm 0.20$ & $15.67 \pm 0.76$ \\
\hline \multirow{4}{*}{120 hours } & Right anal. & $31.45 \pm 0.27$ & $4.08 \pm 0.19$ & $12.97 \pm 0.62$ \\
\hline & Left anal.. & $31.42 \pm 0.27$ & $4.15=0.19$ & $13.20=0.63$ \\
\hline & Right oral. & $28.21 \pm 0.17$ & $2.58=0.12$ & $9.16 \pm 0.44$ \\
\hline & Left oral.. & $28.22 \pm 0.16$ & $2.48 \pm 0.11$ & $\cdot 8.81 \pm 0.42$ \\
\hline
\end{tabular}


TABLE 18

Constants, Experiment 19. Solution d

\begin{tabular}{|c|c|c|c|c|}
\hline & & MEAN & $\begin{array}{l}\text { STANDARD } \\
\text { DEVIATION }\end{array}$ & $\begin{array}{c}\text { COEFFICIENT } \\
\text { OF CORRELATION }\end{array}$ \\
\hline \multirow{4}{*}{96 hours } & Right anal. & $7.91 \pm 0.54$ & $8.10 \pm 0.38$ & $102.50 \pm 8.60$ \\
\hline & Left anal.. & $7.91 \pm 0.54$ & $8.10 \pm 0.38$ & $102.50 \pm 8.60$ \\
\hline & Right oral. & $9.19 \pm 0.57$ & $8.57 \pm 0.40$ & $93.24 \pm 7.35$ \\
\hline & Left oral. . & $9.19 \pm 0.57$ & $8.57 \pm 0.40$ & $93.24 \pm 7.35$ \\
\hline
\end{tabular}

although $\mathrm{NaCl}$ is present in highest quantities in sea-water, the effects of concentration by evaporation are not merely specific for $\mathrm{NaCl}$ but are complicated by the presence of the other constituents, which are increased in the same proportion.

Figure 105 is a drawing of a specimen from the control at 48 hours and figure 106, of a specimen from solution $b$. In the latter there occurs a fusion of the posterior body-rods with developing processes, in contrast to the simple unfused condition of the corresponding elements in $a$. The arm-rods, on the contrary, are still separate, and fusion is only slightly more advanced in 108, which represents a specimen from the same culture 72 hours old. In figure 109, $c 72$ hours, the characteristics depicted are the same but are more pronounced. Figures 111 and 112 are taken from $b$ and $c$ at the age of 96 hours. In the latter, normal fusion of the arm-rods has taken place but the long spine-like processes are conspicuous. Figures 114 and 115 represent the same cultures at the age of 120 hours and in most respects are characteristic. In solution $d$ (fig. 116), inhibition has been so great that a true pluteus form is not attained by the embryo and only the rudiments of armprocesses are acquired. This is in marked contrast to the results of experiments in which isotonic $\mathrm{NaCl}$ solutions are substituted for portions of the sea-water, as in the latter case, bodysize is greatly decreased in proportion to arm-length.

The hydroxyl ion, the carbonates and the sodium, are all studied in detail by Herbst ('03), together with the other constituents of sea-water, in an effort to determine the exact rôle of each in development. In investigating this problem, he employed artificial sea-water from which the element under con- 
sideration was omitted and noted the resulting abnormalities. Whatever processes were modified or inhibited he assumed to be directly affected by the lack of that substance.

Sodium and hydroxyl he looked upon as general conditions of development, since their omission from the medium resulted in complete inhibition of all the life processes. By general condition he does not mean that the substance is necessarily indispensible for every separate process, but for some one or more fundamental process operating at each period of development. He contrasts the rôle of calcium to that of sodium in its effect on the cohesion of the cells and ascribes the injurious action of the Ca-free medium to the "Auflockerung des Zellenverbandes," which he assumes to be caused directly by the sodium. It may be that this lack of cohesion of the cells is concerned with the increased size of the larvae in the $\mathrm{NaCl}$ solutions.

Herbst assigns an important rôle to the carbonates in skeleton-formation, since in the alkaline $\mathrm{CO}_{2}$-free medium only small, rudimentary tri-radiate spicules are laid down. Later on, however, the same larvae may begin to form arms and become fairly normal. He suggests that the secondary regulation may
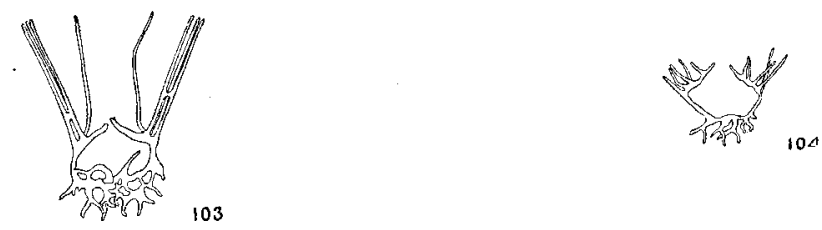

Figs. 103 and 104 Experiment 16. $\mathrm{NaCl}, 0.60 \mathrm{M}$

Fig. $10316 g, 72$ hrs. Greatly reduced in size, but proportions maintained about as in the normal. Many perforations in the posterior fused portion of the body-rods. Anal arms unfused except for one cross-branch. Processes all very long and prominent. Oral arms elongated.

Fig. $10416 h, 72 \mathrm{hrs}$. Still further reduction in size, about $1 / 5$ the size of the control. All the typical modifieations for $\mathrm{NaCl}$ solutions accentuated.

Figs. 105 and 106 Experiment 19. Sea-water $+\mathrm{NaCl}$.

Fig. 105 19a, 48 hrs. Control.

Fig. $10619 b$, figure $10719 c, 48 \mathrm{hrs}$; figure $10819 b$, figure $10919 c$, figure 110 $19 d, 72 \mathrm{hrs}$; ; figure $11119 b$, figure $11219 c$, figure $11319 d$, $96 \mathrm{hrs}$.; figure $11419 b$ figure $11519 c$, figure $11619 d .120 \mathrm{hrs}$. In the stronger solutions increasingly great reduction in size, and early fusion of the body-rods, followed by develop- 

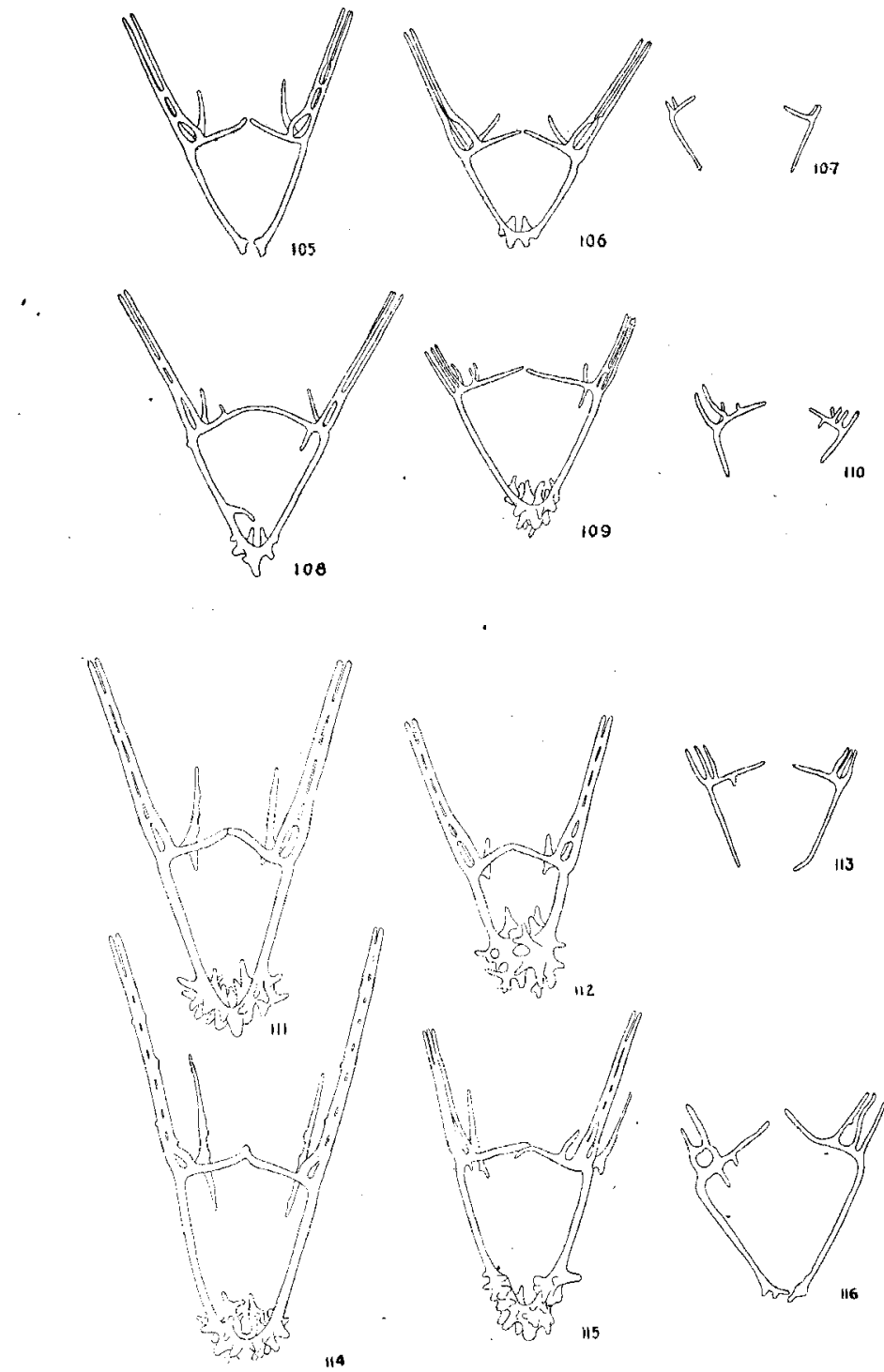

ment of numerous heavy processes in the posterior region. Fusion of the armrods inhibited. Irregularity of structure. In $d$, figures 113 and 116, a typical pluteus-like form is not attained. This is in marked contrast to the solutions in which isotonic $\mathrm{NaCl}$ is substituted for portions of the sea-water. In the latter, arm-length is increased in proportion to body-length. 
be due to the formation of $\mathrm{H}_{2} \mathrm{CO}_{3}$ from the $\mathrm{CO}_{2}$ of the air, since $\mathrm{H}_{2} \mathrm{CO}_{3}+2 \mathrm{KOH} \rightleftarrows \mathrm{K}_{2} \mathrm{CO}_{3}+2 \mathrm{H}_{2} \mathrm{O}$.

Herbst considers hydroxyl also an indispensable constituent of the medium for sea-urchin development and it is significant that the processes which he finds especially affected are those occurring early in development,--for example, fertilization and the formation of the fertilization membrane. In his artificial medium the optimum concentration varied in the different forms employed. For Echinus it lay deeper than for Spaerechinus and the spermatozoa could endure a lower percentage than the ova. Cleavage was accelerated up to a certain degree of alkalinity; size and symmetry of the larva were also affected, and were decreased both above and below a certain degree of the hydroxyl.

Herbst undertook to determine whether acids were evolved by the embryos in the process of development and found by the employment of various indicators that no strong acid was given off. He performed a series of experiments in aerating his $\mathrm{OH}$-free water with
a), air containing $\mathrm{CO}_{2}$,
b), $\mathrm{CO}_{2}$ free air,
c), $\mathrm{CO}_{2}$ and $\mathrm{NH}_{3}$ free air,

and concluded that the beneficial effect of the hydroxyl ions is to neutralize the carbonic acid which is present in the water in greater or less amounts, and which may be increased through the metabolism of the animals.

In the experiments recorded in this paper, however, the solutions in which the eggs were developing were changed so often during the first few hours after fertilization, that no opportunity was given for a decided accumulation of the products of. metabolism. Hence the neutralization of acids could not be urged as an explanation of the fact that addition of $\mathrm{NaOH}$ caused increase of rate of development. Even did this occur, still higher concentration of hydroxyl would not produce increasingly greater acceleration.

The experiments of this series indicate, then, that:-

a) Addition of acids produces an inhibitory effect upon growth. 
b) Increase of alkalinity above the normal causes acceleration, accompanied by irregularity of form, and finally, inhibition. When this increase of alkalinity is slight, the resulting injury is small, but with greater concentrations of the $\mathrm{OH}$ ion the effect is correspondingly more pronounced. In very strong solutions, varying from two to three cc. of $\mathrm{N} / 10 \mathrm{NaOH}$ per 100 cc. of sea-water, eleavage is irregular, and abnormal blastulae are formed which fail to undergo gastrulation.

c) Addition of carbonates produces a double effect:-

1) Increase of $\mathrm{OH}$ concentration, by which the typical effect of increased alkalinity upon rate of growth is brought about.

2) Increased bulk of skeleton, due possibly to the fact that - the $\mathrm{Mg}$ and Ca carbonates are nearer to the point of saturation in the modified medium.

The following experiment was made for the purpose of determining the effects upon development of carbon dioxide, the product of metabolism present in greatest proportions in the sea-water. To what extent it could exert any influence upon the young sea-urchins in their natural environment must be largely a matter of conjecture, but some effect is to be inferred from the fact that very minute amounts of acid produce marked inhibition in development and decrease of size.

A saturated solution of $\mathrm{CO}_{2}$ in sea-water was prepared and, for the various cultures, portions of this were diluted with sea-water as tabulated below. The solutions were changed the usual number of times until the blastulae began to swim, at about six hours after fertilization, then three times daily. Each time, they were prepared immediately before using, so as to maintain as nearly as possible a constant amount of $\mathrm{CO}_{2}$ in the medium. The following concentrations were employed:

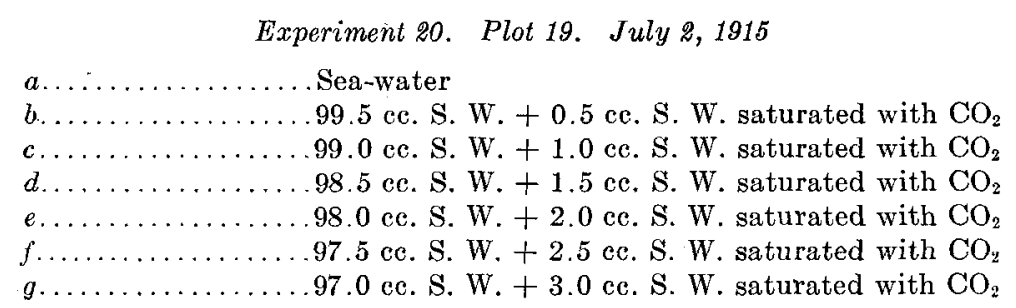


The corresponding measurements were:

\begin{tabular}{|c|c|c|c|c|c|}
\hline & 24 HoURs & 48 HO URS & 72 HoURs & 96 घо URs & 120 Hо Uns \\
\hline a. . & 6.01 & $64.23^{\circ}$ & 77.47 & 81.04 & 83.14 \\
\hline$b \ldots$ & 5.24 & 61.13 & 73.20 & 76.15 & 77.47 \\
\hline$c \ldots$ & 4.52 & 57.85 & 68.77 & 72.21 & 73.19 \\
\hline$d \ldots$. & 4.09 & 54.88 & 65.86 & 67.89 & 68.97 \\
\hline$e \ldots . .$. & 3.71 & 54.91 & 62.69 & 64.91 & 65.37 \\
\hline$f \ldots \ldots \ldots$ & 3.41 & 49.72 & 59.90 & 61.88 & 62.03 \\
\hline$g \ldots \ldots \ldots \ldots$ & 3.20 & 47.80 & 57.13 & 58.79 & \\
\hline
\end{tabular}

The specimens in the control culture for the above experiment developed slowly at first, being much smaller than the general average, but on the following day they increased more rapidly and at the close of the experiment very slightly surpassed the general average in size.

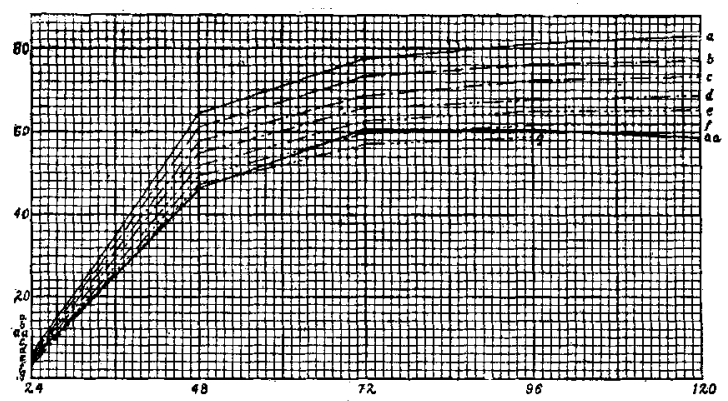

Plot 19

The curves constructed from the averages of the specimens in the experimental solutions are remarkable for their regularity, each indicating a slightly greater inhibition of growth than does that of the preceding one. Even the specimens in culture $g$, which lived only 96 hours, possessed a fairly high and regular growth curve, which was not at any time outside of the range of the control cultures, Plot 1, F.

Figures 117 to 142 are drawn from the various cultures on succeeding days. Figures 117 to 121 are from specimens 24 hours old and illustrate the most marked characteristics produced by subjection to $\mathrm{CO}_{2}$,- the appearance of radial symmetry. 
Figure 117 is from the control, 118 from solution $d, 119$ from $e$, 120 and 121 from $f$. In the control (fig. 117) all the specimens examined were strictly bilateral and the same was true in $b$. In $c$ a very few, not more than one or two in each hundred measured had three spicules present at the age of 24 hours, but in solution $d$ (fig. 118) this phenomenon was rather more common and appeared in about ten per cent of the specimens. In solution $e$ (fig. 119), four spicules were developed in a still larger percentage, while some possessed three and the remainder, two. In solution $f$, four seemed to be the predominating number among those in which radial symmetry was produced (fig. 120), while many possessed three and a few, five (fig. 121). In solutions of increasing $\mathrm{CO}_{2}$ content, there was very little inhibition of growth, as may be seen from the figures, and in each specimen all the spicules were apparently equal and normally shaped.

Figures 122, 123 and 124 are from solutions $a, b$ and $c$ respectively at the age of 48 hours. The skeletons are approximately of the same size, but those in the $\mathrm{CO}_{2}$ cultures are heavier and slightly less regular. This change is still more marked in solution $d$ (fig. 125) and in addition a small accessory spicule is present in the right side. These accessory spicules were much less frequent in the specimens 48 hours old than in those 24 , and in many cases were still smaller than at the early period, indicating that resorption was taking place. Figure 126 illustrates another specimen from the same culture. Its skeleton is somewhat more regular and is not so heavy as that represented in figure 125 , but the accessory spicule which lies at the left side has enlarged and possesses the main parts characteristic of normal skeletons: body-rod, dorso-ventral connective, anal and oral arm-rods. In the right side, compensatory structures have developed in the form of accessory rods on the lateral connectives. In the side in which the accessory skeleton is present, the armrod is more slender, and instead of the usual three, is composed of two single rods in a less advanced stage of fusion.

Figures 127 and 128 are from solution $e$. The specimen represented in 127 was smaller but the skeleton was heavier and more irregular. In 128, four spicules are present but although irregu- 
lar and abnormal, they are of approximately equal size. Figures 129, 130 and 131 are from culture $f$. Figure 129 represents a specimen below the average size, but it is regular and about like that of a normal individual 36 hours old. In figure 130 the actual length of the skeleton is very little greater but the form more nearly approaches that of a true pluteus. It is still more irregular than any of the preceding and has a small accessory spicule in the right side. In figure 131, skeletal structures are present but while they are large and massive, they have not passed be-

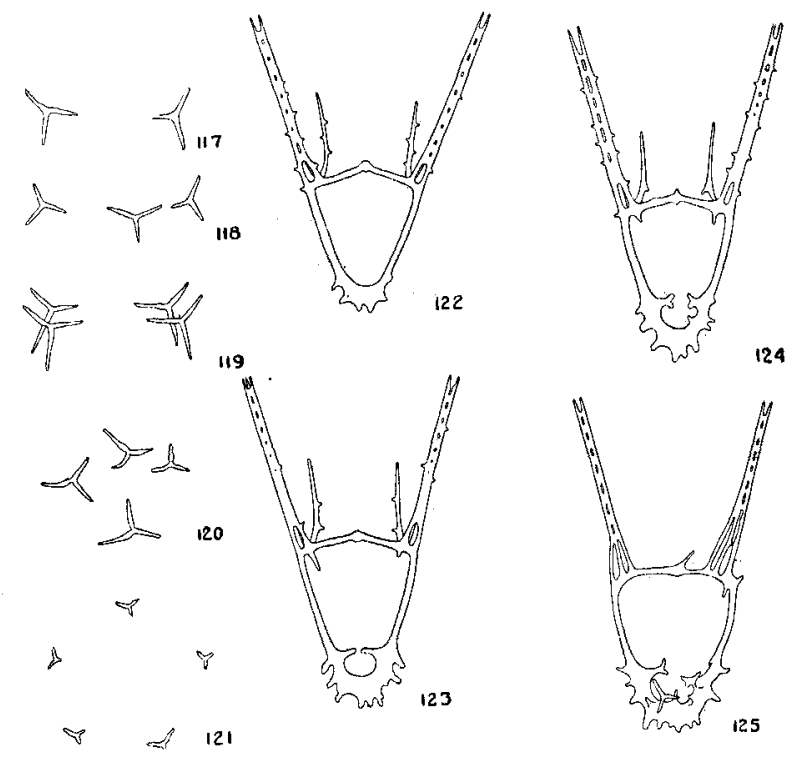

Figs. 117 to 142. Experiment 20, $\mathrm{CO}_{2}$.

Fig. $11720 a, 24$ hrs. Control.

Fig. $11820 d, 24 \mathrm{hrs}$. Three skeletal centers of about normal size.

Fig. 11920 , $24 \mathrm{hrs}$. Four centers. Size approximately normal.

Fig. $12020 f, 24$ hrs. Four centers.

Fig. $12120 f, 24$ hrs. Five conters. Reduction in size.

Fig, 122 20a. $48 \mathrm{hrs}$. Control.

Fig. $12320 b, 48$ hrs. Skeleton somewhat heavier and less regular. About the same size as control.

Fig. $12420 c, 48 \mathrm{hrs}$. Same eharacters more pronounced.

Fig. $12520 d, 48 \mathrm{hrs}$. Specimen less symmetrical. Accessory spicule present on the right side. 
yond the tri-radiate stage. Figures 132,133 and 134 are from culture $g$. They are still smaller than those of solution $f$, but in the main show the same characteristics. Figure 132 is com-
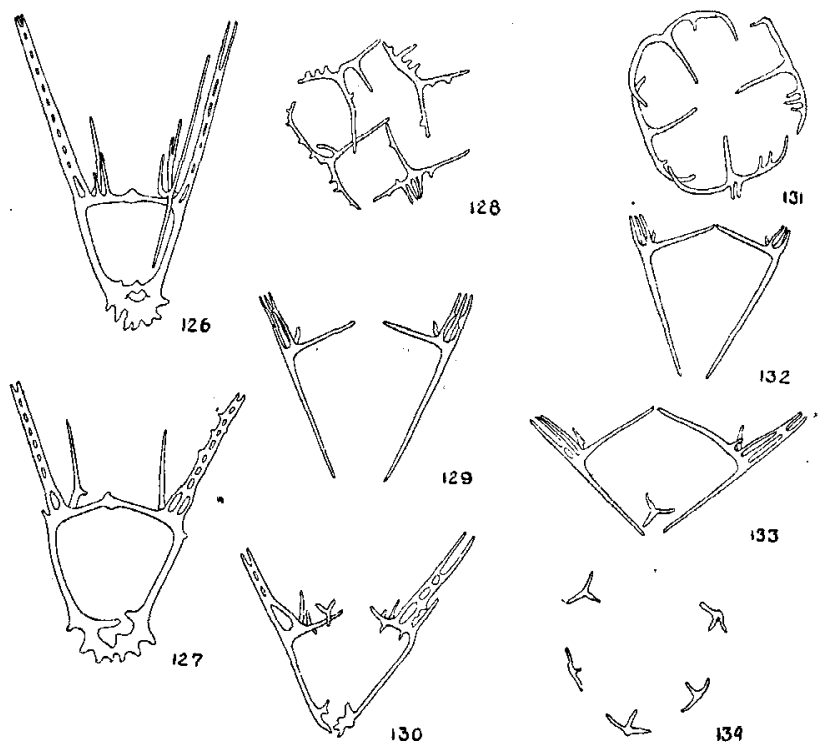

Fig. $12620 d, 48 \mathrm{hrs}$. Skeleton somewhat more regular and less heavy than the preceding, but an accessory skeleton on the left side has enlarged and developed most of the parts typical of a normal skeleton.

Fig. $12720 e, 48 \mathrm{hrs}$. Skeleton heavier, reduced in size; irregular. No accessory spicule.

Fig. $12820 e, 48$ hrs. Four centers present, all of about equal size and highly abnormal.

Fig. $12920 \mathrm{f}, 48 \mathrm{hrs}$. Inhibition of growth very evident. Skeleton about like that of a normal individual of $36 \mathrm{hrs}$. age.

Fig. $13020 f, 48 \mathrm{hrs}$. Skeleton of about the same size as that of figure 129 but more nearly of a true pluteus form. Irregular, and possessing accessory rods. Accessory spicule present on the right side.

Fig. $13120 f, 48 \mathrm{hrs}$. Four abnormal skeletal centers.

Fig. $13220 \mathrm{~g}, 48 \mathrm{hrs}$. Inhibition of growth still more pronounced than in figure 129. About like a normal individual of $18 \mathrm{hrs}$.

Fig. $13320 g, 48 \mathrm{hrs}$. Specimen about the same size as in figure 132 , but with true pluteus form. Slightly irregular and with arm-rods unfused. Accessory spicule present.

Fig. $13420 \mathrm{~g}, 48 \mathrm{hrs}$. Five spicules present, which are irregular and still in the tri-radiate stage. 
parable to 129 , but indicates a slightly less advanced condition. Figure 133, like 130, is more irregular and possesses an accessory spicule. In 134, five spicules are present, but are small and even at this stage show decided irregularity of form.

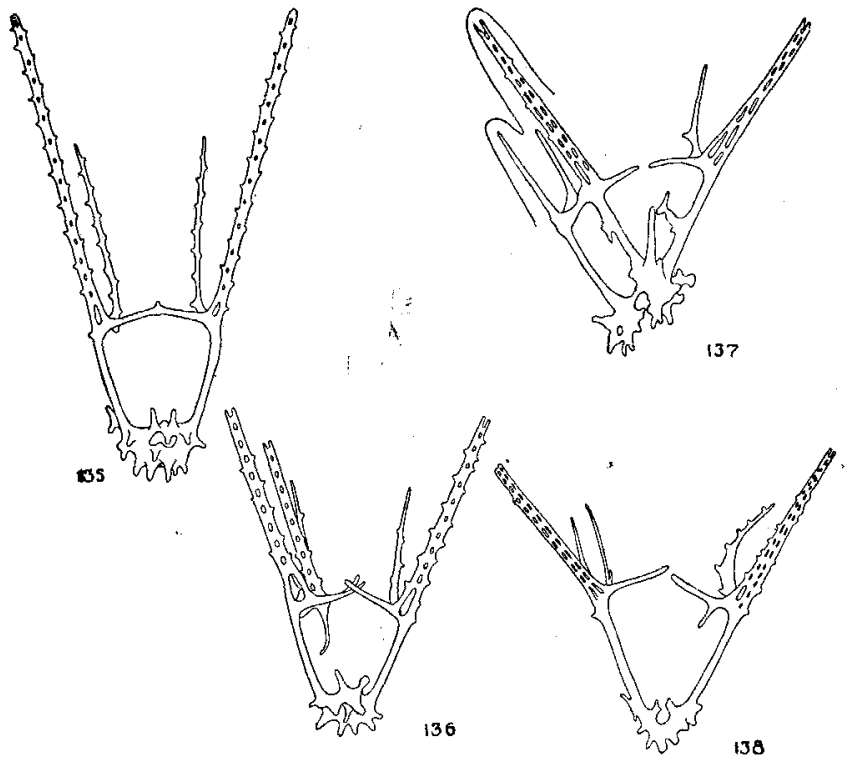

Fig. $13520 a, 72$ hrs. Control.

Fig. $13620 e, 72$ hrs. Skeleton smaller than control, but fairly normal. Large accessory skeleton on the right, fused to the primary at the base of the arm-rods.

Fig. $13720 f, 72$ hrs. Asymmetrical. Several rods in each arm, with spines missing from the right. Accessory skeleton on the right side, with all the typical parts. The anal rod of the secondary skeleton forms an accessory arm; and the oral rod of the secondary functions instead of the oral rod of the primary, which is missing on this side.

Fig. $13820 f, 72$ hrs. Slight irregularities. Spines missing from the right side. Left oral arm is exceedingly heavy, while that on the right is of very light structure and possesses an accessory rod.

Figure 135 represents a larva from the control 72 hours old. In figure 136; solution $e$, the primary skeleton is smaller than the normal, but otherwise is fairly regular. In the right side there is a large secondary skeletal structure, consisting of armrods fused to about the same extent as those in the primary, short 
body rod, and transverse rod. It is connected with and apparently fused to the primary skeleton at the base of the arm-rods. Figures 137 and 138 are from $f$. Although the latter at first glance would seem to be rather symmetrical, eloser inspection reveals that in many details the two sides are unlike. In the right,
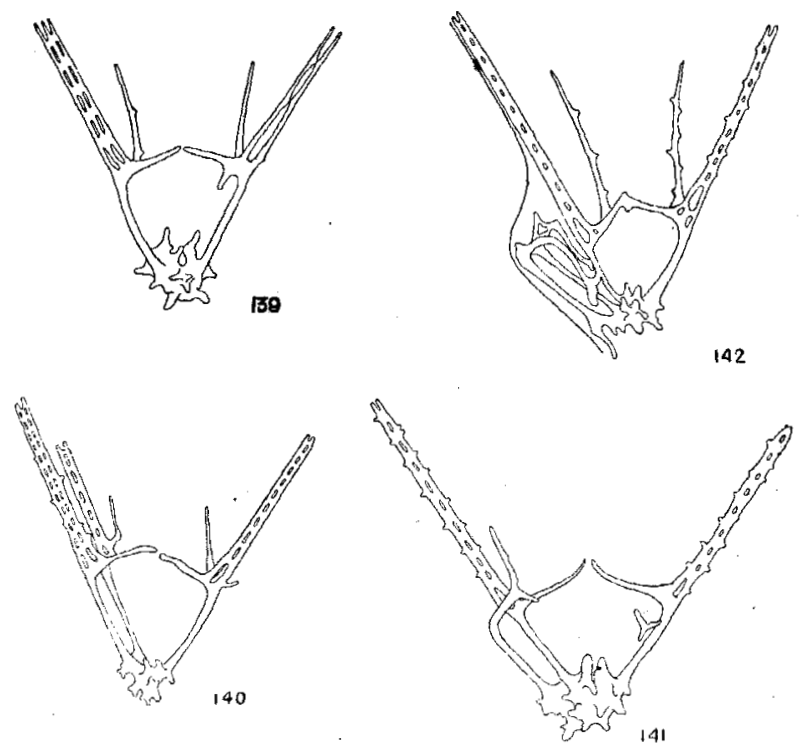

Fig. $13920 \mathrm{~g}, 72$ hrs. General form of the pluteus highly symmetrical, but right side heavier than the left and four well fused rods present in the corresponding anal arm. Left anal arm possesses only two rods which are just beginning to unite in two places.

Fig. $14020 \mathrm{~g}, 72 \mathrm{hrs}$. In this also, the right side of the skeleton is much heavier than the left, and possesses an accessory skeleton. Right oral arm is lacking in the primary structure, and its place is supplied by that of the secondary. This oral arm is small and gives the pluteus an abnormal form.

Fig. 141 20f, 96 hrs. Primary skeleton highly symmetrical. Accessory spicule on the left side and secondary skeleton on the right, having a well developed body-rod with ventral branches. The other portions cannot be positively identified.

Fig. $14220 \mathrm{~g}, 96 \mathrm{hrs}$. Primary skeleton less regular. Secondary skeleton on right side, consisting of two body-rods with ventral branches, and dorsoventral connectives (?) with dorsal body-branches. The secondary skeleton probably originated from two centers both of which subsequently shifted to the right side. 
spines are missing from the arm-rods, while in the left they are abundant and are heavy and irregular. In this side the oral arm is abnormally massive, whereas the corresponding structure in the opposite side is slender and has an accessory rod. In figure 137 a secondary skeleton is present in the right side.

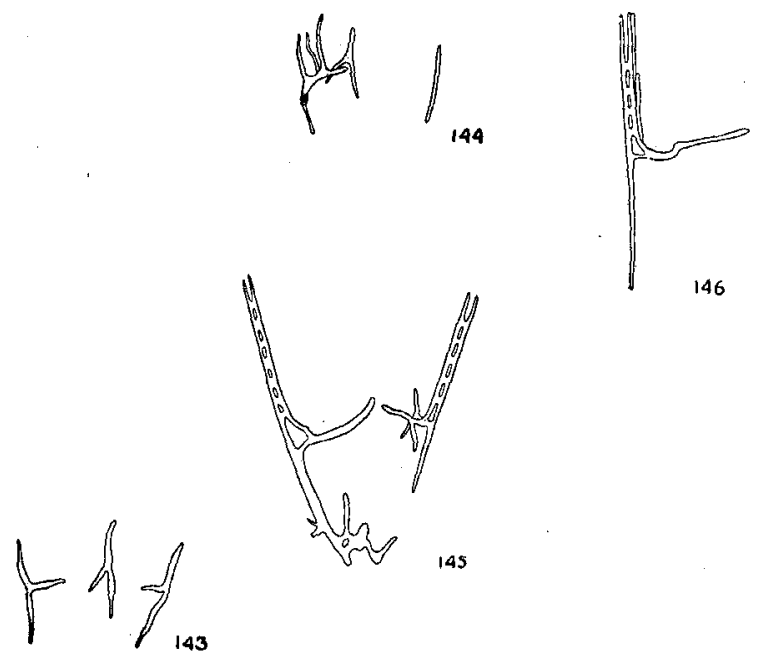

Figs. 143 to 146 Experiment 20. Stale sea-water.

Fig. $14320 a a, 24 \mathrm{hrs}$. Three spicules present, radially arranged, but irregular in form.

Fig. $14420 a \mathrm{a}, 24 \mathrm{hrs}$. Three centers again present, but extremely irregular. One spicule is small and abnormal, but has some of the typical parts,-body-rod, arm-rods and lateral connective. One is still tri-radiate, while the third is in the form of a straight rod.

Fig. $14520 a a, 48$ hrs. Skeleton on right side somewhat irregular, but possessing all the normal parts excepting dorso-ventral connective and oral armrod. On the left side these are present but the body-rod is incomplete. That of the right side has bent forward and is developing a compensatory structure.

Fig. $14620 \mathrm{aa}, 48 \mathrm{hrs}$. Only one skeletal structure present which lacks dorsoventral connective and anal arm.

It possesses arm-rods, dorso-ventral connective and body-rod with ventral branches by which it is fused to the primary skeleton. It is also joined by what apparently corresponds to the lateral connective. Its anal rod is not so closely applied to that of the primary skeleton, as are those in the specimens previously considered, and here the pluteus has developed an ac- 
cessory arm, as indicated by the outline in the drawing. The oral arm-rod is lacking from the primary skeleton, and the corresponding structure of the secondary functions in its stead; but since the point of origin of this secondary oral arm-rod is lower in the body of the pluteus than that of the primary of the opposite side, the animal, in spite of a rather high degree of symmetry characterizing the primary skeleton, is irregular and abnormal looking.

Figures 139 and 140 are from specimens of solution $g$, and are also 72 hours old. In the latter the accessory skeleton is present, and though smaller than the primary has nearly all the characteristic parts, - - body-rod, anal arm-rod composed of two fused single rods, greatly reduced oral arm-rod and dorso-ventral connective. The primary and secondary skeletons are joined by the ventral branches of their body-rods. In this animal, the oral arm-rod, though much smaller than normal and united with the anal arm-rods by an exceedingly short dorsoventral connective, likewise functions instead of the corresponding structure of the primary. Contrary to the usual compensatory regulation, the skeleton in the side possessing the accessory structure, is more massive than in the side where these parts are missing. In 139 also, one side of the skeleton is much heavier than the other, and the anal arms possess three well fused rods in contrast to two unfused ones in the opposite side.

Figure 142 is from the same culture after 96 hours of development. Here the accessory parts are more complicated and harder to identify. Two body-rods with corresponding ventral branches are evidently present, and the parts which are bent over and fused to the right body-rod of the primary skeleton are possibly dorso-ventral connectives with dorsal bodybranches. Rudiments of anal arm-rods are present. This secondary skeleton may have originated from a single center, as in some cases it is known that one side of a skeleton may cross over and supply the missing parts on the opposite side; but this generally extends only to some one definite element and does not involve a duplication of all the structures. Hence it seems probable that this skeleton must have arisen from 
two centers, which have grown very symmetrically as regards each other.

Figure 141 represents a specimen from culture $f$ at an age of 96 hours. Here two secondary skeletons are present, that in the right having developed most of the characteristic parts while that in the left side has not grown beyond the tri-radiate stage.

This production of radial symmetry is the most characteristic change caused by the employment of carbon dioxide. Herbst obtained it in Spaerechinus and Echinus by reducing the amount of potassium or sulphate in the medium. In the latter case, the number of skeletal centers sometimes reached seven. With the addition of lithium halides he obtained a similar effect, which resulted in the appearance of three, four or five centers.

Fischel obtained radial symmetry by the employment of hypertonic $\mathrm{KCl}$ solutions, by which also the number might be increased to five. It seems difficult to reconcile the fact that absence of potassium and hypertonic solutions with an excess of potassium could produce the same result. Herbst suggests that the reduced larval size in K-free sea-water may be due to a failure on the part of the tissues to imbibe water in sufficient quantities. If this in any way affects the symmetry, we should expect the same results to be obtained with hypertonic solutions. This, however, does not occur in Fischel's other experiments nor is any evidence of it to be observed in the experiments with hypertonic solutions described above.

The appearance of an uneven number of skeletal centers cannot be due to mere doubling of that of one side. Herbst says, "Ist nur ein Dreistrahler vorhanden, so kann man wegen der unregelmäsigen Lage nicht sagen, ob dies der rechte oder linke ist, und ebensowenig kann man bei Vorhandensein von dreien behaupten, dass der linke oder der rechte verdoppelt sei." $\mathrm{He}$ describes the gradual appearance of bilateral symmetry thus; "Man kann aber trotzdem als Regeln bezeichnen, dass zwei von den Dreistrahlern, deren Lage mehr an die Norm erinnert, die anderen in der Entwickelung überholen so dass schliesslich 
doch noch bilaterale Larven von annähernd Plutéusform aus den ursprünglich mehr radiär aussehenden Larven hervorgehen."

This is what occurs in Arbacia. During the first 24 hours, all the skeletal centers develqp equally (figs. 118 to 121) and in very strong solutions the radial symmetry is maintained until later periods (figs. 128, 131 and 134, $e, f$ and $g, 48$ hours). Either these larvae fail to develop further, or else, as Herbst describes, two spicules which most closely approximate the normal in position, elongate and give the animal a bilateral form. The other skeletal centers may remain without undergoing any change for some time, (fig. $133 \mathrm{~g}, 48$ hours), but subsequently a shifting occurs, so that the centers come to lie upon one side or other of the larva. This is especially true when the third spicule ultimately develops into a secondary skeleton (fig. $126 d$, 48 hours, etc.), and generally it is fused to one side of the primary skeleton (figs. $137 f, 72$ hours and $140 \mathrm{~g}, 72$ hours). In figure $141 f, 96$ hours, an accessory skeleton has remained at each side, but in $142 \mathrm{~g}, 96$ hours, both have shifted to one side and fused with the primary skeleton. In no instance did radial symmetry obtain in so late a stage as is shown by Herbst ('03), in his figure 13. When a third arm appears, as in figure 137,72 hours, it is more or less closely applied to one of the primary.

Addition of $\mathrm{CO}_{2}$ to the sea-water does not cause any tendency toward the appearance of those characteristics specific to the carbonate solutions. Since addition of $\mathrm{CO}_{2}$ produces increase of $\mathrm{CO}_{3}$ and $\mathrm{HCO}_{3}$ ions, the absence of any tendency toward the carbonate effect when $\mathrm{CO}_{2}$ is added, gives further evidence for the conclusion reached previously, that those modifications are caused by the molecular calcium and magnesium carbonates, rather than by the $\mathrm{CO}_{3}$ or $\mathrm{HCO}_{3}$ ions.

In another culture run parallel to this experiment, the fertilization was made in normal sea-water and the medium left unchanged for the following five days, in order to determine whether the modifications were similar to those of the carbon dioxide solutions. It was not to be expected that the growthcurve would be like those of the others since in this instance the carbon dioxide would appear in the medium as a gradual ac- 
cumulation. The growth-curves indicate a considerable inhibition during the first 24 hours, the period when the presence in the medium of such substances as inhibit or accelerate growth produces the greatest effect. The measurements for the succeeding days (aa) were 24 hours, 4.28 ; 48 hours, 56.18 ; 72 hours, 60.38; 96 hours, 60.47; and 120 hours, 58.47.

In this solution a tendency toward radial arrangement of the skeletal structures was evidenced in the early stages, followed by irregularity in the later. Figures 143 and 144 represent specimens at the 24 hour stage, and figure 145, at the end of 48 hours. Some, as in figure 146, have skeletons in one side only, while others appear normal except for decreased size. The animals had far from a healthy appearance, their movements were less regular, and many had sunk to the bottom of the dish. At the end of 120 hours a large number were dying.

These modifications were not typical altogether of carbon dioxide solutions, although the tendency toward radial symmetry is one of its characteristic effects. The abnormalities caused by a medium which remains unchanged for several days, is not then, due to the accumulating carbon dioxide alone, but probably to the presence of other products of metabolism as well. The dishes were shallow, and while they were closely covered to prevent evaporation, sufficient air-space was left above the surface of the water to allow plenty of oxygen for the developing embryos. Vernon, by a gas determination, estimated that the amount of oxygen in the water actually increased and the amount of carbon dioxide in his cultures during the eight days in which his experiments were run. Yet when such water was used as a medium for a second culture, a decrease in size of 7.9 per cent and 7.3 per cent resulted.

Another factor which might be exceedingly potent in determining the qualities and rate of development of the larvae would be the degree to which the characters of the parents are inheritable, and the extent to which these are modified in different fertilizations. Since it was impossible to keep the sea-urchins for two generations, an experiment was performed similar to that done by Tennent ('10). He selected five fe- 
males and divided the eggs of each into five portions. The sperm from five males was treated in the same way, and from each portion of sperm, one division of eggs from each female was fertilized. This resulted in 25 cultures which he observed for three days and noted the variations in the different cultures.

In the present experiment, since it was desired to take the usual number of measurements in each culture every day, only four males (I, II, III and IV), and four females (A, B, C and D) were selected. In this way 16 cultures were procured and observed for the usual five days.

The following measurements were obtained:

Experiment 21. June 27,1915

Plot 20

A

\begin{tabular}{|c|c|c|c|c|c|}
\hline & 24 ноткS & 48 ноURS & 72 ночRs & 96 ночия & 120 но URз \\
\hline I.. & 6.91 & 48.82 & 64.80 & 75.15 & 81.29 \\
\hline II. . & 4.10 & 41.93 & 60.77 & 73.88 & 79.09 \\
\hline III. & 2.14 & 37.78 & 55.68 & 68.78 & 77.90 \\
\hline$\ldots \ldots$ & 11.65 & 52.84 & 67.91 & 78.64 & 75.22 \\
\hline \multicolumn{6}{|c|}{$\begin{array}{c}\text { Plot } \mathscr{Q} 1 \\
\text { B }\end{array}$} \\
\hline$\ldots \ldots \ldots$ & 23.16 & 63.88 & 79.91 & 86.20 & 90.01 \\
\hline II. . & 18.64 & 56.92 & 76.15 & 82.73 & 89.17 \\
\hline III.. & 16.29 & 52.74 & 70.59 & 79.87 & 83.90 \\
\hline IV ... & 24.18 & 67.94 & 82.63 & 89.95 & 81.78 \\
\hline
\end{tabular}

Plot 2Q2

$\mathrm{C}$

\begin{tabular}{r|l|l|l|l|l}
\hline I $\ldots \ldots \ldots \ldots \ldots$ & 26.10 & 67.76 & 81.78 & 80.62 & $\mathbf{7 6 . 1 1}$ \\
II $\ldots \ldots \ldots \ldots \ldots$ & 19.97 & 61.83 & 77.10 & 78.13 & $\mathbf{7 3 . 2 6}$ \\
III $\ldots \ldots \ldots \ldots \ldots$ & 21.97 & 56.69 & 72.57 & 75.44 & 70.15 \\
IV $\ldots \ldots \ldots \ldots \ldots$ & 28.27 & 71.91 & 84.64 & 83.14 & 68.32 \\
\hline
\end{tabular}

Plot 23

D

\begin{tabular}{r|r|r|r|r|r}
\hline I $\ldots \ldots \ldots \ldots \ldots$ & 15.78 & 62.80 & 75.79 & 84.21 & 90.09 \\
II $\ldots \ldots \ldots \ldots \ldots$ & 12.82 & 55.74 & 71.63 & 80.57 & 86.85 \\
III $\ldots \ldots \ldots \ldots \ldots$ & 8.67 & 51.66 & 66.54 & 78.33 & 83.91 \\
IV $\ldots \ldots \ldots \ldots$ & 18.15 & 66.79 & 79.10 & 85.14 & 81.87 \\
\hline
\end{tabular}


Some conclusions of interest may be deduced from these figures. First, it may be noted that after 24 hours, the cultures from each separate female show a slight degree of variation as to size, and center about a mean which is characteristic for each. For instance, with $\mathrm{A}$, the mean is 6.2 : with $\mathrm{B}, 20.56$; C, 24.04 and D 13.85. Some influence of definite characters

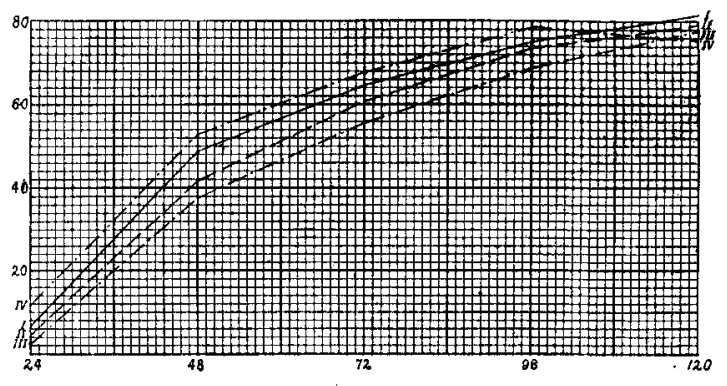

Plot 20
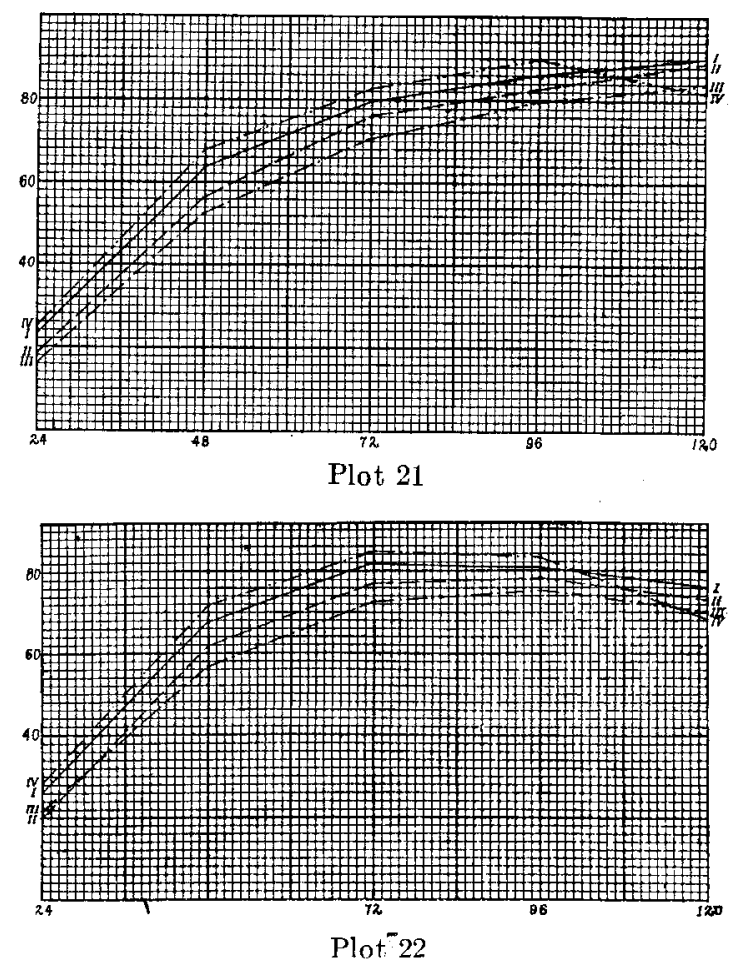


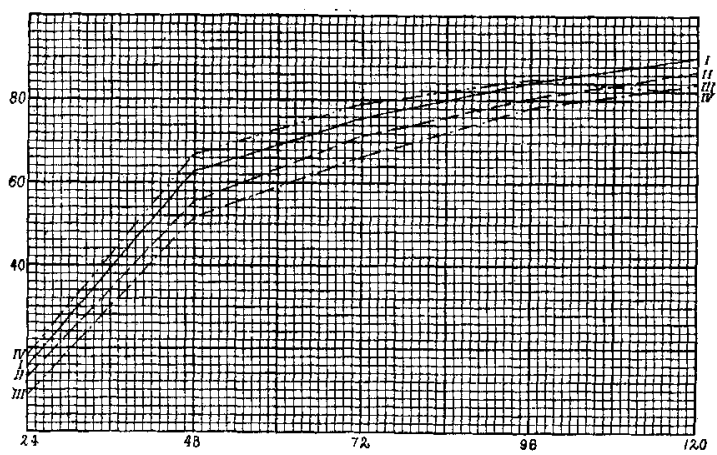

Plot 23

of the sperm is, however, also evident, since in all the sets, the order of the cultures as to size is identical, IV, I, II, III, except in $\mathrm{C}$ where III and II are reversed. This may be ascribed to experimental error in handling or measuring since no other explanation can be offered. At the close of the experiment, however, the order of all the sets is the same, being I, II, III, IV.

In all combinations except C (Plot 23), cultures I, II and III

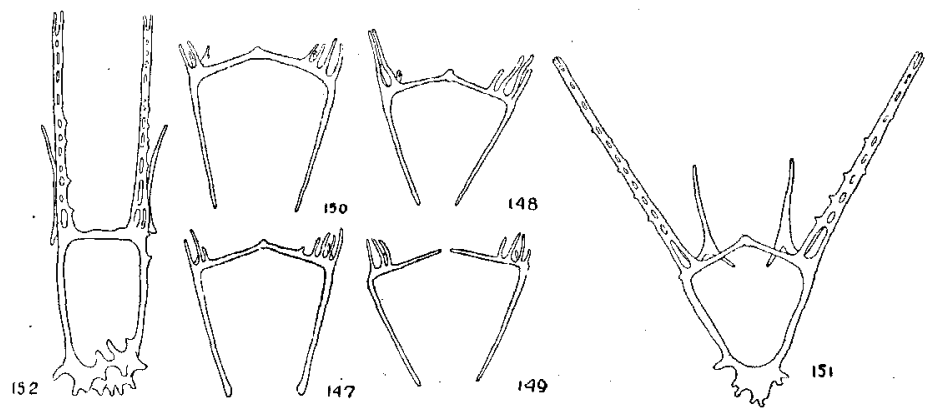

Figs. 146 to 152 Experiment 21. Eggs from different females fertilized with sperm from different males.

Fig. $14721 \mathrm{AI}$, figure $14821 \mathrm{AII}$, figure $14921 \mathrm{AIII}$, figure $15021 \mathrm{AIV}, 24$ hrs. Specimens showing the tendency for appearance of four rods in place of three on the left side of a large number of Iarvae of all the cultures from eggs of Female A.

Fig. 15121 BIII, 24 hrs. Specimen with unusually widely spread arms. Present in a large proportion of all the cultures fertilized with sperm from Male III.

Fig. 15221 BIII, $24 \mathrm{hrs}$. Specimen with anal arms and body-rods parallel. This type appeared in about 1 per cent of all cultures from Male III. 
grew slowly and continuously for the five days. On the other hand all of IV and all of $C$ reached a maximum either at the 72 or the 96 hour period, indicating that this quality of rapid development must be contributed by all of the eggs and all of the sperm of those two individuals. The combined effects of these two forces is greater than that of either one alone, since C IV reaches a lower point on the curve than any other culture 120 hours old.

Some characteristic modifications in the skeletons were also observable. For instance, all the cultures of A contained a few individuals having four rods in one of the anal arms. This is not an unusual variation in Arbacia plutei and is found in many of the cultures. In this set, however, it occurred in greater proportions than ordinarily happens, and usually on the left side. Figures 147 to 150 are from AI, AII, AIII and AIV respectively. In each one four rods are present in this position and in AI there is the rudiment of a fifth which might ultimately have fused with the rest.

In all the solutions of III, a large number of plutei had the arms spread much more widely than is usual (fig. 151, BIII, 48 hours). In a count of 100 specimens from each solution taken after 48 hours, AIII possessed 79; BIII, 24; CIII, 81 and DIII, 97 with widely spread arms. In each of these solutions there were also a few of the type represented in figure 152 (BIII, 48 hours). The arms and body-rods were about the same length as in the normal but were almost parallel and formed right angles with the narrow transverse connectives and the broad plate-like posterior portion of the body-rods. The oral arms were spread much as in the normal specimens and hence projected at the sides beyond the anal. Individuals of this type averaged about one per cent of each of these cultures. There were none like them to be found in any others of the series, but in an entirely different solution fertilized with sperm from the same male, a still greater percentage of skeletons of this type was present. 
In all the previous experiments, care was taken to use the germinal products as quickly as possible after extrusion, as it was thought that staleness might have some effect upon size or vigor of the larvae. To ascertain in how far this might be true, the eggs and sperm from two individuals were kept in separate vessels and from portions of these, fertilizations were made at the following times:

Experiment 22. July 22, 1915

\begin{tabular}{|c|c|c|c|c|}
\hline & & 24 HOURS & 48 HOURS & 72 HOURs \\
\hline$a$ & 8.45 a.m. (Immediately after extrusion)...... & 27.4 & 68.7 & 84.3 \\
\hline$b$ & 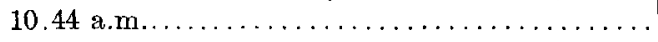 & 27.1 & 67.4 & 85.1 \\
\hline$c$ & 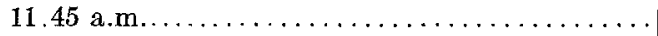 & 27.8 & 69.1 & 83.9 \\
\hline$d$ & 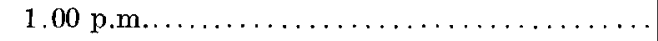 & 27.0 & 68.5 & 83.8 \\
\hline$e$ & 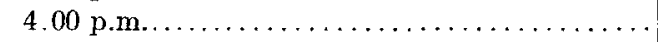 & 26.9 & 68.2 & 84.2 \\
\hline f & 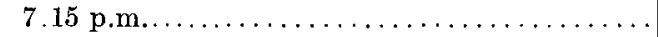 & 26.7 & 67.9 & 84.7 \\
\hline
\end{tabular}

It may be seen from these figures that keeping the germinal products for 10 hours and 30 minutes effected no reduction of size. Moreover, these larvae seemed quite as vigorous as those fertilized immediately after extrusion.

In the experiment above, the eggs and sperm were kept in Syracuse watch glasses and covered with very little sea-water. Since the fact that they were thus in a highly concentrated condition might explain the lack of effect of long standing upon the vigor of the resulting individuals, another experiment was performed, and some of the eggs and sperm placed in separate vessels and covered with a considerable volume of water. Other portions were kept in a concentrated condition as in the previous experiment. All the eggs were mature and the sperm was very active. The following fertilizations were made: $(\mathrm{C}$ \% indicates eggs from the concentrated stock; $\mathrm{D}$ \%, eggs from the dilute. $\mathrm{C}_{0^{x}}$ designates concentrated and $\mathrm{D} 0^{x 1}$ dilute spermsuspension.) 


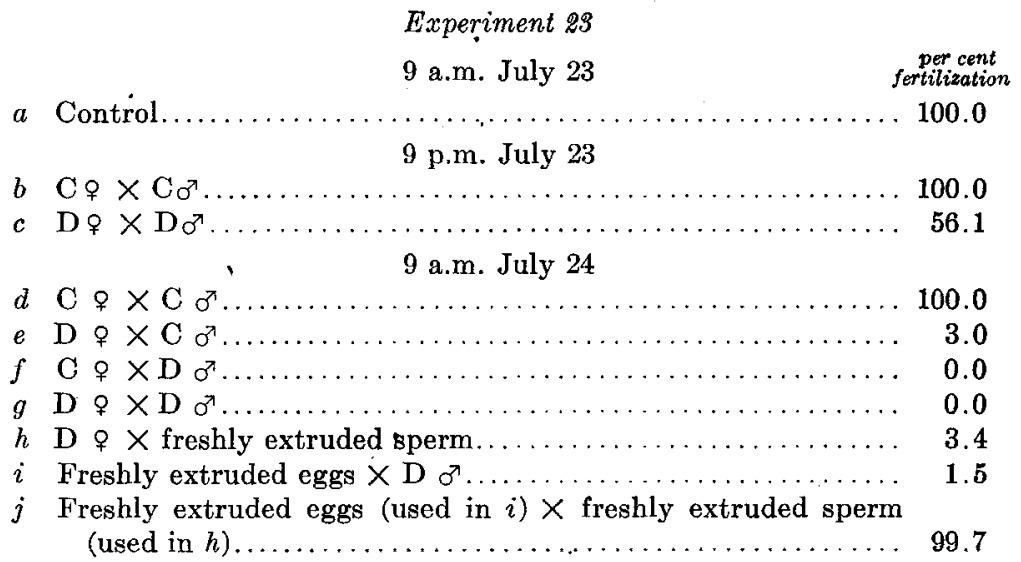

The measurements from the various cultures were:

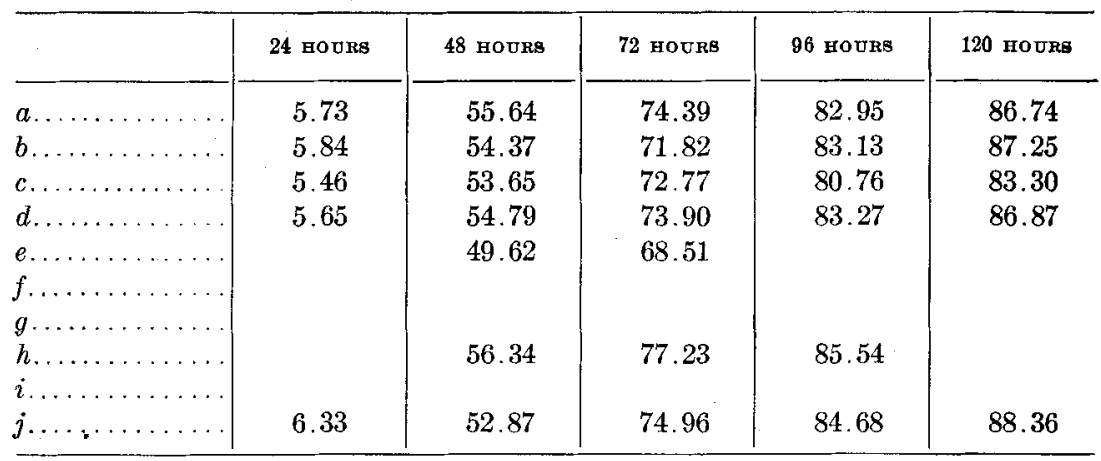

Both controls, $a$ and $\jmath$, gave regular growth-curves which agreed very closely with the average for the period in which the experiments were made. As may be seen from the above measurements, when the egg supply and the sperm-suspensions were kept concentrated so that the action of the sea-water was reduced to a minimum, no abnormal effect was produced by delaying fertilization twelve or even twenty-four hours ( $b$ and d). But when the sperm was diluted so that all were in contact with the sea-water, a reduction in size of 3.9 per cent was produced (c).

. After standing 24 hours in the dilute condition, the sperm was more injured than the eggs; for the latter when inseminated with concentrated sperm resulted in a 3 per cent mem- 
brane-formation (e), while the eggs from the concentrated supply, fertilized with diluted sperm-suspension gave entirely negative results $(f)$. The sperms, although slightly activated, were unable to penetrate even into freshly extruded eggs (i). In solution $e$, the small percentage that developed were of low vigor, were smaller than the control, and lived only three days. The eggs from the diluted stock fertilized with fresh sperm (h) also showed lowered vitality, so that before 120 hours all were dead.

In another series of experiments done in the same way, the sperm was so active at the end of 24 hours and the percentage of fertilizations was so high, that the germinal products were kept for several days and the experiments repeated. The following results were obtained:

Experiment 24. July 26, 1915. Percentage forming membranes

\begin{tabular}{|c|c|c|c|c|}
\hline & 24 HOURS & 48 HOURS & 72 ношиs & 96 HOURS \\
\hline $\mathrm{C}+9 \times \mathrm{C} 0^{7}$. & 100.0 & 100.0 & 100.0 & 97.0 \\
\hline $\mathrm{D} \& \times \mathrm{C} \sigma^{x}$. & 100.0 & 97.3 & 87.5 & 47.3 \\
\hline $\mathrm{C} q \times \mathrm{D} \sigma^{7}$. & .98 .6 & 94.2 & 80.6 & 25.7 \\
\hline $\mathrm{D} q \times \mathrm{D} \sigma^{7}$. & 99.7 & 91.7 & 74.4 & 10.0 \\
\hline
\end{tabular}

Owing to the lack of time, the measurements of these larvae were not taken, but the cultures were kept for several days and the vigor of the resulting individuals observed. No reduction in size in the later fertilization was observable, but as in the previous experiment, this decrease would probably be so small that it could be determined only by actual measurement.

All from the 24 and 48 hour fertilizations were apparently as vigorous as the control which was started immediately after extrusion. After 72 hours, however, a lessened vitality was observable, but only when the sperm had been diluted. In these cultures the death-rate was so much highęr that comparatively few attained the pluteus stage. After 96 hours, a lessened vigor was apparent in all the solutions. Normal plutei were formed in $a$ and $b$, but in $c$ the cleavage was irregular, and few normal individuals resulted. 
Fisher ('03), also working on Arbacia at Woods Hole, performed somewhat similar experiments using diluted sperm-suspensions at various intervals to fertilize freshly extruded eggs. In some instances the last successful fertilization he was able to obtain was 24 hours after the sperm was removed from the male. In one case, the sperm was still able to fertilize the eggs after 133 hours, 30 minutes, and Fisher thought possibly it might have been active longer had he been able to continue the experiment. He found that "whenever fertilization occurs the fertilized egg develops to the adult stage . . . . never was a segmented egg found that did not develop into a pluteus." In this respect, his results disagree with those obtained above, where a slight effect on the size and a still greater effect upon the vigor of the resulting individuals were obtained.

Goldfarb ('15), made a similar study with Toxopneustes variegatus, and in most respects the results of this investigation agree with his. He found that "increasingly stale eggs of a given female, though fertilized by freshly prepared sperm suspensions, at each trial gave a decreasing number of fertilizations, and that this decrease was approximately the same for all females. . . . . The rate of cleavage is progressively retarded. The number that cleave irregularly is increased The number of atypic larvae is correspondingly increased." But his results disagree with those in this study, in the experiment; with fresh eggs $\times$ stale sperm and stale eggs $\times$ fresh sperm. In both cases development was normal. Possibly the germinal products employed by Goldfarb had not been kept so long as those in the experiment above, or else Toxopneustes sperm and eggs may differ in viability from those of Arbacia.

\section{DISCUSSION}

We have seen that the control cultures in the previous experiments exhibited wide variation. As the plot containing the curves of the general averages shows, the condition of the larvae 24 hours old varies from no skeleton to one of 44.83 , which is slightly larger than that of the control of Experiment 18 (seawater $+\mathrm{NaCl}$ ), 72 hours old. The widest variation is found in 
larvae aged 120 hours, due to the fact that some have reached their maximum and resorption of skeleton has commenced: The lowest point attained at this time by any control still undergoing increase of sze is 67.55, Experiment 19, Plot 1, FF. The wide variation exhibited by the control cultures may be ascribed partly to the fact that although they were raised under conditions as nearly standard as possible, some fluctuations in the environment could not be avoided.

No attempt was made during the course of the experiments to regulate the density of the sea-water,-a factor which the experiments on dilution and concentration show has a profound influence upon growth and development, and, under the conditions usually existing in the Woods Hole region, may produce a variation of about five per cent.

Fluctuations in the temperature were reduced to a minimum by keeping the finger-bowls in which the sea-urchins were raised surrounded by running sea-water. But this did not eliminate all variations in temperature since a gradual rise occurred during the course of the summer. On June 12, the date of the first determination for 1915 , the sea-water registered $16.5^{\circ} \mathrm{C}$. On June 20 it was $17.5^{\circ} \mathrm{C}$., on June $27,18.5^{\circ}$, on July $5,19.5^{\circ}$, on July $16,20.5^{\circ}$ and on July $22,21.5^{\circ}$. The highest point, $21.6^{\circ}$, was recorded on July 23 . During the following week the temperature fell somewhat; and on July 28, the date of the last observation, was $20.8^{\circ}$.

Unfortunately, owing to lack of time, no experiments dealing with temperature as a separate factor could be carried out; hence no estimation can be made of the range of variation produced by these changes; but it was observed that the individuals in the cultures kept surrounded by running sea-water were more vigorous than were those exposed to the fluctuations ordinarily occurring in the laboratory.

Moreover, during the summers of 1914 and 1915, there was a wide difference in the size and vigor of the larvae raised at different seasons, confirming the conclusions of previous investigators that there is a seasonal variation. During the early period they grew rapidly and reached a high maximum 
which might be attained at the 120 hour period or later, or might be passed as early as the 72. During the latter portion of the summer, growth was much slower, especially the first day, and continued steadily for the 120 hours that the larvae were under observation. The ultimate size, however, was not so great as during the early period. The averages of the maximum sizes during the two seasons were 86.23 and 82.25 respectively. But these distinctive characteristics were not absolute with the various periods,--for instance, in the second part of the summer (Period C), one of the seven averages reached its maximum at the 72 hour stage, and in all the periods there was considerable variation as to size of skeleton at the 24 .

Usually those that underwent the most rapid growth during the first day were the ones that reached an early maximum. We have a typical instance of such an early maximum with high initial rate of growth in Experiment 21, CVIV, one of the cultures in which the eggs from different females were fertilized with sperm from different males. But this again does not hold absolutely, as in BVI, another culture of the same experiment, the measurements on the first day were exceptionally high, yet growth was continuous for the entire time.

Since, then, modifications due to environmental factors which could not be controlled under the conditions of these experiments, and modifications referable to different seasons, were insufficient to explain the wide variation that occurred in the larvae of the control cultures, other causes must be sought. Among the factors involved, as the above experiments show, are: variations in the degree of alkalinity; variations in the proportions of the different constituents of sea-water, which may be associated with changes in density; and the presence of the products of metabolism.

No definite data for the comparison of the alkalinity of the sea-water seem available. Determinations have been made in various regions, but owing to a difference in terminology and in the indicators employed, definite comparisons cannot be drawn. Loeb states that the concentration of the free $\mathrm{OH}$ ions in the sea-water at Pacific Grove "seems to lie between 10"-6 
and $10^{-5} \mathrm{~N}$, while that of Woods Hole is somewhat higher and may reach $10^{-5} \mathrm{~N}$." Moore, Roaf and Whitely give that of Port Erin Bay, using the same indicator, phenol-phthalein, as $0.00023 \mathrm{~N}$, or $2.3 \times 10^{-4} \mathrm{~N}$.

The degree of alkalinity necessary for development, moreover, depends upon the character of the salts present. Herbst found that the most favorable alkalinity of his artificial sea-water was greater than that of the natural sea-water, yet addition of hydroxyl to the latter caused no acceleration of growth. $\mathrm{He}$ offered as a suggestion that possibly the concentration of hydroxyl could be less in the presence of such salts as the phosphates and carbonates of the sea-water, or else the phenolphthalein is altered in its reaction in the presence of some salts found in the sea-water but not in his artificial solution. These facts indicate that the alkalinity of the sea-water is not a constant factor, and that, even under the same degree of hydroxyl concentration, the effects vary with varying concentrations of salts. That the latter are not always present in different waters in constant amounts has been adequately determined. Mayer ('14) states that a $0.60 \mathrm{M} \mathrm{NaCl}$ solution is isotonic with the sea-water at Tortugas. Garrey ('04) gives $0.52 \mathrm{M}$ as equivalent to that at Woods Hole, 0.54M for Pacific Grove and $0.58 \mathrm{M}$ for Beaufort.

In the above experiments I have attempted to show some of the modifications produced by these factors operating separately. To determine the effects of all possible combinations and of gradual subjection would require much additional investigation. But since it is impossible to alter one constituent of the sea-water without involving other changes, some evidence of the combined effects of several independent factors has been produced; for instance, in the employment of $0.60 \mathrm{M} \mathrm{NaCl}$ solutions dilution of the other constituents occurs coincident with increase of osmotic pressure; in the carbonate solutions decrease in the $\mathrm{CaCO}_{3}$ - and $\mathrm{MgCO}_{3}$ - content occurs at the same time as increase of alkalinity, and, in the gradual concentration of the sea-water, a condition of increased density replaces one of highly decreased concentration. 
In how far may these combined factors modify normal development? In many of the experimental solutions in which conditions are so adverse that life is barely maintained, the measurements come well within the range of size of the controls. In the first experiment with concentrated medium (2), the measurements of the specimens subjected to 40 per cent concentration $(e+)$, which lived only 96 hours, are greater than those indicated by $1 \mathrm{~F}$ (Plot 1) for the corresponding days, and drops beneath those of $1 \mathrm{FF}$ only at the 96 hour stage. The same is true of the specimens in the solution of 30 per cent dilution, which lived only 96 hours, except that at the age of 72 hours they measured slightly more than those in $1 \mathrm{~F}$.

These two solutions represent the limits to which concentration and dilution could be pushed, and yet the size of the larva was not reduced below that of the extreme variants of the control cultures. In the second experiment with $\mathrm{NaHCO}_{3}$ (9), the same conditions may be observed. In the culture with 91 cc. sea-water +9 cc. $0.45 \mathrm{NaHCO}_{3}$, the larvae were in a dying condition at the close of the fourth day. At the ages of 24,48 . and 72 hours they were well within the range of the controls, and at the age of 96 hours were within $1 \mathrm{~F}$ but below $1 \mathrm{FF}$. Likewise in the experiment with carbon dioxide $(20 \mathrm{~g})$, the same conditions occur. Not until 96 hours, after 24 hours of almost complete inhibition of growth, does the average measurement drop below that of $1 \mathrm{FF}$.

It is significant that these three experiments were performed during the early period (B),--a fact which may account for the high resistance of the individuals to the foreign solutions. But in other experiments made during the same period, in which the controls seemed equally vigorous, life was maintained at a much lower level. For instance, in the experiment with gradual concentration of the sea-water (3), the specimens in the solution of $120 \mathrm{cc}$. sea-water concentrated to $100(e+)$, the larvae lived 120 hours and seemed fairly vigorous at the close; but except at the 24 hour period, when skeletons were present merely as spicules scarcely tri-radiate, the measurements were never within the range of the controls. This leads to our 
first general conclusion, that equally adverse conditions do not produce equally great reduction in size, and agrees with the results of the experiments with increased hydroxyl concentration, where the injury inflicted may be ascribed to over-rapid growth.

In Experiment 2, we have two experiments made with the same control, one of dilution and one of concentration of the seawater. The specimens in the solution of 30 per cent dilution $(g)$ and those in the solution of 120 cc. sea-water concentrated to $100(e+)$, lived only 96 hours, and hence we may look upon them as having undergone practically the same extent of injury, yet a comparison of their growth-curves reveals the widely different effects of the two modes of treatment. We may conclude, therefore, that each modification of the medium produces its specific effect upon growth.

In those instances in which two constituents of the medium are changed, the effects of one may completely mask the effects of the other. Thus increased alkalinity tends to produce irregularity of structure and inhibition of growth, while the carbonates, although alkaline in reaction, are associated with a high degree of symmetry. Moreover, in cultures in which seawater was diluted with isotonic $\mathrm{NaCl}$ solution, dilution of the other constituents with increase of $\mathrm{Na}$, produced a size above the normal. But when the $\mathrm{NaCl}$ solutions were hypertonic, the physical effects of increased osmotic pressure neutralized the physiological effects of the $\mathrm{Na}$, and a growth-curve scarcely different from the normal was produced. As the solutions became still more hypertonic, all stimulating effect of the $\mathrm{Na}$ was lost, and a decreased size resulted.

In other instances, when both factors tend to produce the same result, the combined effect may be greater than either one alone. In the solutions of high degree of dilution, those in the first experiment, such as $f$ (30 per cent dilution) possessed a much lower vitality than did those in the solution of the same dilution in the second $(g)$.

This leads to our next general conclusion, that where the control is below the average size, the experimental solutions exert a more unfavorable influence. In the two experiments in 
which $\mathrm{NaCl}$ was added to the sea-water (18 and 19) the control of the first was one characteristic of that period, and the measurements on the various days are not unlike those of the general average for $\mathrm{A}$. In the second, all the values for the control are lower and correspond to Curve FF (Plot 1). A comparison of the figures obtained for the experimental solutions shows that each measurement in the second experiment is less than the corresponding one in the first, and the specimens were less vigorous.

Even when the experimental solution tends to produce increase of size, the injury is more intense when the control possesses a low average. For example, in the $\mathrm{NaOH}$ solutions, (6d) 2 cc. $\mathrm{N} / 10 \mathrm{NaOH}$ to $98 \mathrm{ec}$. sea-water represented the highest concentration of $\mathrm{OH}$ that could be endured by the larvae, but the following summer, when the animals were very vigorous, in one instance (0a) 3 cc. $\mathrm{N} / 10 \mathrm{NaOH}$ to 97 cc. sea-water was employed. It follows, then, that although abnormal conditions are not always productive of reduced size, a size below the normal is usually indicative of reduced vigor.

What, then, is normal development? We cannot say that the specimens of greatest size are necessarily normal, since some changes of the medium, such as dilution of the sea-water or concentration of the hydroxyl, produce increased growth but lead to secondary inhibition. Nor can we say that those are normal which have developed under standard conditions of the medium, since sea-water is exceedingly complex and variable. Moreover, we have seen that other factors, such as the season at which the eggs are produced and the staleness of the sexual products modify development, and that the eggs of different parents do not respond in the same way to similar treatment, nor do all the eggs of the same parent react identically.

Normal development we ean regard only as the modal development, and the mode must vary according to the place and the time; that is to say, the environment. If some sudden change in the composition of the medium were to occur, the largest class to respond in a specific way would be regarded as normal; but a few extreme variants might perhaps be best fitted to the new 
conditions. A fluctuating variation might therefore be beneficial to the individual and a mutation to the species also, even though it might be termed an abnormality.

What, then, may the range of variation in the Arbacia larvae be? No attempt could be made to answer this for mutations; but for such variations as are inherited and for such as are produced by modification of the medium, some idea may be drawn

\begin{tabular}{|c|c|c|c|c|c|c|c|}
\hline \multirow{2}{*}{$\begin{array}{l}\text { EXPERT- } \\
\text { MENT }\end{array}$} & \multirow{2}{*}{ COMPOSITION OF MEDIOMM } & \multirow{2}{*}{$\begin{array}{l}\text { SOLU- } \\
\text { TION }\end{array}$} & \multicolumn{5}{|c|}{ PERCENTAGE OF INCREAFE ABOVE CONTROD } \\
\hline & & & $\begin{array}{c}24 \\
\text { hours }\end{array}$ & $\begin{array}{c}48 \\
\text { hours }\end{array}$ & $\begin{array}{c}72 \\
\text { hours }\end{array}$ & $\begin{array}{c}96 \\
\text { hours }\end{array}$ & $\begin{array}{l}120 \\
\text { hours }\end{array}$ \\
\hline 1 & Dilution of the sea-water & 6 & 6.5 & 14.3 & 16.3 & 7.8 & 3.0 \\
\hline 2 & $\begin{array}{l}\text { Dilution and concentration of } \\
\text { sea-water }\end{array}$ & $\begin{array}{l}b \\
c \\
d\end{array}$ & & $\begin{array}{l}4.2 \\
5.7 \\
2.4\end{array}$ & $\begin{array}{l}3.8 \\
6.4 \\
1.3\end{array}$ & $\begin{array}{l}3.5 \\
5.1 \\
0.2\end{array}$ & \\
\hline 3 & $\begin{array}{l}\text { Gradual concentration of sea- } \\
\text { water }\end{array}$ & $\begin{array}{l}c \\
d \\
e \\
f\end{array}$ & & $\begin{array}{l}2.3 \\
0.7\end{array}$ & $\begin{array}{l}3.2 \\
4.7\end{array}$ & $\begin{array}{l}1.6 \\
3.8\end{array}$ & $\begin{array}{l}2.7 \\
2.0 \\
1.1\end{array}$ \\
\hline 6 & Increased alkalinity & $\begin{array}{l}b \\
c \\
d\end{array}$ & $\left|\begin{array}{l}0.48 / 0 \\
3.21 / 0 \\
6.20 / 0\end{array}\right|$ & $\begin{array}{l}1.0 \\
1.4 \\
1.6\end{array}$ & & & \\
\hline 8 & Addition of $\mathrm{NaHCO}_{3}$ & $\begin{array}{l}b \\
c \\
d \\
e \\
f\end{array}$ & $\begin{array}{r}4.4 \\
7.5 \\
13.5 \\
9.8 \\
5.2\end{array}$ & $\begin{array}{l}1.0 \\
2.0 \\
1.8\end{array}$ & & & \\
\hline 9 & Addition of $\mathrm{NaHCO}_{3}$ & $\begin{array}{l}b \\
c\end{array}$ & $\begin{array}{l}1.8 \\
4.7\end{array}$ & 2.7 & 0.2 & & \\
\hline 11 & Addition of $\mathrm{Na}_{2} \mathrm{CO}_{3}$ & $\begin{array}{l}b \\
c \\
d\end{array}$ & $\begin{array}{l}10.4 \\
50.4 \\
31.7\end{array}$ & $\begin{array}{l}5.5 \\
8.7\end{array}$ & 1.9 & & \\
\hline 14 & Addition of $0.52 \mathrm{M} \mathrm{NaCl}$ & $\begin{array}{l}b \\
c \\
d\end{array}$ & 12.7 & 4.3 & $\begin{array}{l}4.8 \\
1.3\end{array}$ & $\begin{array}{l}4.4 \\
2.0\end{array}$ & $\begin{array}{l}4.6 \\
2.8 \\
0.9\end{array}$ \\
\hline 15 & Addition of $0.56 \mathrm{M} \mathrm{NaCl}$ & $b$ & & & & & 0.9 \\
\hline
\end{tabular}


from the above data. The following table gives the increase in size in percentages above the average of the control in each of the foregoing experiments. (Values are not given where decreased size has been produced nor after the control has passed the highest point on its growth-curve.)

This table gives some idea of the degree to which size may be increased in Arbacia larvae under experimental conditions. The percentage may be comparatively large when the embryos are 24 hours old, but becomes gradually less until finally when the larva are 120 hours old, it is limited to 4.6 (Experiment 14). This represents approximately the maximum increase in size, since if the factors which produce this excessive growth are applied in greater concentrations, an inhibition rather than a further increase occurs. But these figures do not stand for absolute values, since the controls, themselves, represent varying quantities. Would the effect be greater if the values of the control were low? The first experiment with dilutions (1) seems to indicate that it would, in the early stages; but at the close of the experiment increase of size is not relatively greater than in the other experiments.

Decrease in size may be so great under experimental conditions, that some cultures never approach the range of the control,- -for example, the specimens in the second experiment in which $\mathrm{NaCl}$ is added to the sea-water, do not acquire skeletons until 96 hours old. These forms resemble the 'Dauerblastulae' of Driesch, but have archenterons fully developed or short and bent over so that the mouth opens close to the blastopore. Strictly speaking, however, they are not Dauer-blastulae for if subjected to a more favorable medium they may resume development, but may not, as we have seen, "attain the maximum size to which they can develop." On the otherr hand, the larvae may endure adverse conditions of greater intensity if subjected gradually to the medium than if subjected suddenly, as shown by the experiment with gradually concentrated sea-water (3).

The excessively low values which may be produced in the eariy stages, indicate so great an injury that life cannot long 
be maintained. The following percentages represent the maximum inhibition in each experiment when the control has reached its greatest size.

\begin{tabular}{|c|c|c|c|c|}
\hline $\begin{array}{l}\text { EXPERI- } \\
\text { MENT }\end{array}$ & COMPOSITION & $\begin{array}{l}\text { SOLU- } \\
\text { TION }\end{array}$ & PERIOD & $\begin{array}{l}\mathrm{PER} \\
\mathrm{CENT}\end{array}$ \\
\hline & & & hours & \\
\hline 2 & Concontration and dilution & $g$ & 96 & 44.1 \\
\hline 2 & Goncentration and cinution.... & $e+$ & 96 & 34.2 \\
\hline 3 & Gradual concentration. . & $g$ & 96 & 1.8 \\
\hline $\mathbf{0}$ & Graduat conceniration.. & $e+$ & 96 & 63.3 \\
\hline 4 & $\mathrm{CH}_{3} \mathrm{COOH}$ & $b$ & 120 & 21.0 \\
\hline $\mathbf{5}$ & $\mathrm{CH}_{3} \mathrm{COOH}$. & $d$ & 120 & 25.8 \\
\hline 8 & $\mathrm{NaHCO}_{3} \ldots$. & $g$ & 72 & 11.7 \\
\hline 9 & $\mathrm{NaHCO}_{3} \ldots .$. & $f$ & 120 & 38.8 \\
\hline 11 & $\mathrm{Na}_{2} \mathrm{CO}_{3} \ldots \ldots$ & $e$ & 120 & 41.7 \\
\hline 16 & $\mathrm{NaCl} 0.60 \mathrm{M} \ldots$. & $h$ & 72 & 74.7 \\
\hline 17 & $\mathrm{NaCl} 0.60 \mathrm{M}$. & $e$ & 120 & 19.2 \\
\hline 18 & $\mathrm{NaCl}$ (hypertonic) $\ldots \ldots \ldots \ldots \ldots \ldots \ldots$ & $d$ & 120 & 64.3 \\
\hline 19 & $\mathrm{NaCl}$ (hypertonic) $\ldots \ldots \ldots \ldots \ldots \ldots \ldots \ldots$ & $c$ & 120 & 53.4 \\
\hline 20 & 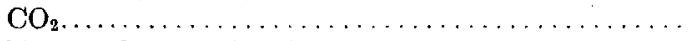 & $a a$ & 120 & 29.6 \\
\hline 21 & Eggs $\times$ Sperm of different parentage $\ldots \ldots \ldots \ldots$ & $c$ & 120 & 3.9 \\
\hline
\end{tabular}

These tables show the greater plasticity of Arbacia larvae in respect to decrease in size than in respect to increase. In practically all of these solutions, while the larvae had departed widely from the normal in the characters distinctive for the various substances employed, they seemed vigorous and capable of continued development. To what extent they could resist new adverse conditions that might be superimposed, or to what extent they could survive these same conditions at a later period has not been determined in these experiments; but these figures indicate to some extent the range of variation which may possibly occur in Arbacia larvae during early stages in their natural environment. 


\section{SUMMARY}

In conclusion, the experiments recorded above tend to show that:

1. The factors producing variations in the growth and development of the larvae of Arbacia punctulata are of two types,non-environmental or intrinsic and environmental or extrinsic.

2. Among the factors of a non-environmental nature are,-

a. Different reaction of the offspring of the same parents to similar environmental conditions.

b. Different reaction of the offspring of different parents to identical environmental conditions.

c. Different reaction of eggs produced at different seasons to similar environmental conditions.

d. Staleness of the sexual products.

3. Among the factors of an environmental nature are,--

a. Modifications in the concentration of the sea-water.

b. Modifications in the alkalinity of the sea-water.

c. Modifications in the salt-content of the sea-water.

d. Accumulations of the products of metabolism in the surrounding medium.

4. Each modification of an environmental nature produces its specific effect upon growth.

If two or more factors in the medium are varied, in case the modifications are of an antagonistic nature, the effects of one may completely mask the effects of the other; in case both factors tend to produce the same result, the combined effect may be greater than that of either one alone.

5. Sudden change of medium produces an inhibition of growth. If the change be gradual, and from one of less to one of more favorable medium, a complete compensation for early inhibition may occur, but the ultimate growth is not equal to that which would have occurred had the larvae been subjected during the entire period to the more favorable environment.

If the transfer be gradual and to a less favorable medium, the injury would not be so great as if the larvae had been subjected continuously to the adverse conditions.

6. Size and degree of development are not correlated.

Increased size is not correlated with increased vigor. 
Decreased size is correlated with reduced vigor.

Individuals subnormal as to size, when subjected to an unfavorable environment, undergo more extreme modifications than do normal specimens when subjected to similar conditions.

7. The larvae of Arbacia punctulata show greater plasticity in respect to decrease in size than in respect to increase. In such modifications of the medium as occurred in the foregoing experiments, the range of variation extended, at the time of maximum size, from a 5.1 per cent increase above the size of the control, to a 63.3 per cent decrease.

This range of variation probably corresponds approximately to that of the larvae of Arbacia in their natural environment.

The subject of this paper was suggested by Dr. D. H. Tennent and the work has been carried out under his direction. The experimental part was done at the Marine Biological Laboratory at Woods Hole, Massachusetts, during the summers of 1914 and 1915. I am very glad to express my gratitude to Dr. Tennent for his constant help and guidance in this research during the two years of its progress.

\section{BIBLIOGRAPHY}

DrIESCH, H. 1893 Entwicklungsmechanische Studien. IV. Experimentelle Veränderung des Typus der Furchung und ihre Folgen. Zs. wiss. Zool., Bd. 55, S. 10.

Fischel, Alfred 1909 Uther die Entwicklung des Echinodermeneies unter dem Einflusse chemischer Ageńtien. Arch. Entwmech., Bd. 27, S. 465.

Frsher, M. H. 1903 How long does (Arbacia) sperm live in sea-water? Amer. J. Physiol., vol. 8, p. 430.

Frary, F. C. and Nietz, A. H. 1915 The hydrolysis of sodium carbonate in solution. J. Am. Chem. Soc., vol. 37, p. 2268.

GARREY, W. E. 1904 The osmotic pressure of sea water and of the blood of marine animals. Biol. Bull., vol. 8 , p. 257.

1915 Some cryoscopic and osmotic data. Biol. Bull., vol. 28, p. 77.

Godlewski, E. 1908 Plasma und Kernsubstanz in der normalen und der durch äussere 'Faktoren veränderten Entwicklung der Echiniden. Arch. EntwMech., Bd. 26, S. 278.

GoldfanB, A. J. 1914 Experimental studies upon stale germinal products. Year Book, No. 14. Carnegie Inst. Wash., p. 205.

Herbst, Curt. 1893 Experimentelle Untersuchungen über den Einfluss der veränderten chemischen Zusammensetzung des umgebenden Mediums auf die Entwicklung der Tiere. I Theil. Versuche an Seeigeleiern. Zs. wisss. Zool., Bd. 55, S. 446. 
Herbst, Curt. 1895 II Theil. Weiteres über die morpholigische Wirkung der Lithiumsalze und ihre theoretische Bedeutung. Mitt. Zool. Stat. Neapel., Bd. 11, s. 136.

1895 VI Theil. Utber den Einfluss einiger anderer organischer Salze. Arch. EntwMech., Bd. 2, s. 497.

1897 Über die zur Entwickelung der Seeigellarven nothwendigen anorganischen Stoffe, ihre Rolle und ihre Vertretbarkeit. I Theil. Die zur Entwickelung nothwendigen anorganischen Stoffe. Arch. EntwMech., Bd. 5, s. 649.

1901 II Theil. Die Vertretbarkeit der nothwendigen Stoffe durch andere ähnlicher chemischer Natur. Arch. EntwMech., Bd. 11, s. 617.

1903 III Theil. Die Rolle der nothwendigen anorganischen Stoffe. Arch. EntwMech., Bd. 17, s. 306.

1906 Vererbungsstudien II. Uther den Einfluss der Temperatur auf die Ausbildung der Seeigelbastarde. Arch. EntwMech., Bd. 21, s. 177.

LOEB, J. 1898 Ueber den Einfluss von Alkalien und Säuren auf die embryonale Entwickelung und das Wachsthum. Arch. EntwMech., Bd. 7, s. 631. 1908 Ueber den Temperaturkoeffizienten für die Lebensdauer kaltblütiger Thiere und über die Ursache des natürlichen Todes. Arch. für die Gesam. Physiol., Bd. 124, s. 411.

1913 Artificial Parthenogenesis and Fertilization. U. of Chicago Press. Chicago, Ill.

Marcos, H. 1906 Utber die Wirkung der Temperatur auf die Furchung bei Seeigeleiern. Arch. EntwMech., Bd. 22, s. 445.

MaYer, A. G. 1914 Relationship between the degree of concentration of electrolytes of the sea-water and the rate of nerve-conduction in Cassiopea. Pub. No. 183 Carnegie Inst. Wash., p. 25.

Moore, B., RoAf, H. E., and Whitely, E. 1905 On the effects of alkalies and acids, and of alkaline and acid salts, upon growth and cell division in the fertilized eggs of Echinus esculentus, - a study in the relationship to the causation of malignant disease. Proc. R. Soc. Lond., vol. 127, Ser. B, p. 102.

Peter, KarL 1905 Der Grad der Beschleunigung tierischer Entwicklung durch erhöhte Temperatur. Arch. Entwmech., Bd. 20, s. 130.

1908 Experimentelle Untersuchungen über individuelle Variation in der tierischen Entwicklung. Arch. EntwMech., Bd. 27, s. 153.

Pouchet, G. ex Chabry, L. 1889 Sur le développement des larves d'Oursin dans l'eau de mer privée de chaux. C. R. Soc. biol., Paris. (9) Sér. 1, p. 17.

Tennent, D. H. 1910 Variation in Echinoid plutei. A study of variation under laboratory conditions. Jour. Exper. Zool., vol. 9, p. 657.

VERnon, V. 1895 The effects of environment on the development of Echinoderm larvae; an experimental inquiry into the causes of variation. Phil. Trans. R. Soc. Lon. 186, Pt. II, p. 557.

1900 Certain laws of variation. I. The reaction of developing organisms to envirọnment. Proc. R. Soc. Lon., vol. 67, p. 85. 